\title{
Empacotamento de árvores em grafos completos
}

\author{
Renzo Gonzalo Gómez Diaz
}

\author{
DisSERTAÇÃO APRESENTADA \\ $\mathrm{AO}$ \\ Instituto de Matemática e Estatística \\ DA \\ Universidade DE SÃo PAUlo \\ PARA \\ OBTENÇÃO DO TÍTULO \\ $\mathrm{DE}$ \\ Mestre em CiÊnCIAS
}

Programa: Mestrado em Ciência da Computação

Orientadora: Profa. Dra. Yoshiko Wakabayashi

Durante o desenvolvimento deste trabalho o autor recebeu auxílio financeiro da CAPES

São Paulo, janeiro de 2015 


\title{
Empacotamento de árvores em grafos completos
}

\begin{abstract}
Esta versão da dissertação/tese contém as correções e alterações sugeridas pela Comissão Julgadora durante a defesa da versão original do trabalho, realizada em 28/08/2014. Uma cópia da versão original está disponível no Instituto de Matemática e Estatística da Universidade de São Paulo.
\end{abstract}

Comissão Julgadora:

- Profa. Dra. Yoshiko Wakabayashi (orientadora) - IME-USP

- Prof. Dr. Orlando Lee - UNICAMP

- Prof. Dr. César Israel Hernández Vélez - IME-USP 


\section{Agradecimentos}

Em primeiro lugar, agradeço a Deus, por estar comigo a cada instante, me mostrar luz nos momentos de escuridão e me dar forças para continuar a longa caminhada que é a vida.

Aos meus pais, José e Natalia, por todo o esforço e sacrifício que fizeram para dar-me uma boa educação. Pelo apoio em cada etapa da minha vida e, especialmente, na decisão de eu deixar meu país na busca dos meus sonhos. Não existem palavras para descrever o amor que sinto por vocês.

Um agradecimento especial à minha orientadora, professora Yoshiko. Primeiramente, porque, sem me conhecer, acreditou em mim e na minha capacidade. Muito obrigado pelos conselhos, pela paciência e pelos ensinamentos durante todo o tempo de orientação. Minha admiração, respeito e gratidão por você só aumentam cada dia.

Aos professores Arnaldo Mandel e Cristina Fernandes pelos seus ensinamentos e paciência.

Ao meu amigo e irmão Juan, pelo apoio desde o começo da graduação, pelas muitas conversas e pelo interesse no meu bem-estar. Você é um amigo para toda a vida.

Aos meus amigos da Maratona, Stefano e Antonio, pelas horas de diversão resolvendo problemas e por me oferecer a sua amizade desde que cheguei aqui.

Aos amigos da pós-graduação, Genaro, Cerda, Harry, Raul, Jesús, Milson, Jorge, John, Edu, Leandro e Anuar, pelas conversas no salão de chá e os momentos de sossego.

Por último, porém não menos importante, à minha "família" da república Próspero: Luara, Alfonso, Talita, Nicolas, Alcira, Fredy, Edison e Dimitry, por todos os momentos felizes nesses últimos seis meses. Em especial, por me fornecer um lugar que posso chamar de lar. 


\section{Resumo}

GÓMEZ, R. G. Empacotamento de árvores em grafos completos. 2014. Dissertação (Mestrado) - Instituto de Matemática e Estatística, Universidade de São Paulo, São Paulo, 2014.

Nesta dissertação estudamos problemas de empacotamento de árvores em grafos, com ênfase no caso de grafos completos. Denotamos por $T_{i}$ uma árvore de ordem $i$. Dizemos que existe um empacotamento de árvores $T_{1}, \ldots, T_{n}$ num grafo $G$ se é possível encontrar em $G$ subgrafos $H_{1}, \ldots, H_{n}$, dois a dois disjuntos nas arestas, tais que $H_{i}$ é isomorfo a $T_{i}$. Em 1976, A. Gyárfás e J. Lehel levantaram a seguinte questão, que conjecturaram ter uma resposta positiva: é possivel empacotar qualquer sequência de árvores $T_{1}, \ldots, T_{n}$ no $K_{n}$ ? Esta dissertação tem como tema principal os estudos realizados por diversos pesquisadores na busca de uma resposta para esta pergunta, que permanece ainda em aberto. Tendo em vista a dificuldade para tratar esta questão, surge naturalmente a pergunta sobre a existência de classes de árvores para as quais a resposta é afirmativa. Nessa linha, existem diversos resultados positivos, como por exemplo quando queremos empacotar estrelas e caminhos, ou estrelas e biestrelas. Por outro lado, em vez de restringir a classe das árvores, faz sentido restringir o tamanho da sequência e reformular a pergunta. Por exemplo, dado $s<n$, é possível empacotar qualquer sequência de árvores $T_{1}, \ldots, T_{s}$ no $K_{n}$ ? Em 1983, Bollobás mostrou que a resposta é afirmativa se $s \leqslant\lfloor n / \sqrt{2}\rfloor$. Na primeira parte deste trabalho focamos nosso estudo em questões desse tipo. Na segunda parte desta dissertação investigamos algumas conjecturas que foram motivadas pela pergunta levantada por Gyárfás \& Lehel. Por exemplo, Hobbs, Bourgeois e Kasiraj formularam a seguinte questão: para $n$ par, é possivel empacotar qualquer sequência de árvores $T_{1}, \ldots, T_{n}$ no grafo bipartido $K_{n / 2, n-1}$ ? Para essa pergunta apresentamos alguns resultados conhecidos análogos aos obtidos para a conjectura de Gyárfás \& Lehel. Mais recentemente, Gerbner, Keszegh e Palmer estudaram a seguinte generalização da conjectura original: é possível empacotar qualquer sequência de árvores $T_{1}, \ldots, T_{k}$ num grafo $k$-cromático? Neste trabalho estudamos essas e outras questões relacionadas e apresentamos os principais resultados que encontramos na literatura.

Palavras-chave: Empacotamento de árvores, estrelas, biestrelas, grafo completo, decomposição em árvores, grafo $k$-cromático. 


\section{Abstract}

GÓMEZ, R. G. Packing trees into complete graphs. 2014. Dissertation (Master) - Instituto de Matemática e Estatística, Universidade de São Paulo, São Paulo, 2014.

In this dissertation we address the problem of packing trees into graphs, with focus on complete graphs. We denote by $T_{i}$ a tree of order $i$. We say that there exists a packing of trees $T_{1}, \ldots, T_{n}$ in a graph $G$ if its possible to find in $G$ pairwise edge-disjoint subgraphs $H_{1}, \ldots, H_{n}$ such that $H_{i}$ is isomorphic to $T_{i}$. In 1976, A. Gyárfás and J. Lehel raised the following question, that they conjectured to have an affirmative answer: is it possible to pack any sequence of trees $T_{1}, \ldots, T_{n}$ into the complete graph $K_{n}$ ? In this dissertation, we study a number of contributions made by various researchers in the search for an answer to this question, that is still open. In view of the difficulty of this question, it is natural to look for the existence of classes of trees for which the answer is affirmative. In this direction, some positive results have been found, as for example, when the sequences of trees are restricted to stars and paths, or stars and bistars. On the other hand, instead of restricting the classes of trees, it makes sense to restrict the length of the sequence and reformulate the question. For example, given $s<n$, is it possible to pack any sequence of trees $T_{1}, \ldots, T_{s}$ into $K_{n}$ ? In 1983 , Bollobás showed that the answer is affirmative if $s \leqslant\lfloor n / \sqrt{2}\rfloor$. In the first part of this work, we focus on such kind of questions. In the second part of this dissertation we investigate some other conjectures that were motivated by the conjecture of Gyárfás \& Lehel. For example, Hobbs, Bourgeois and Kasiraj formulated the following question: For $n$ even, is it possible to pack any sequence of trees $T_{1}, \ldots, T_{n}$ into the complete bipartite graph $K_{n / 2, n-1}$ ? For this question, we present some known results analogous to those obtained for the conjecture of Gyárfás \& Lehel. More recently, Gerbner, Keszegh and Palmer studied the following generalization of the of former conjecture: is it possible to pack any sequence of trees $T_{1}, \ldots, T_{k}$ in a $k$-chromatic graph? In this dissertation, we study this and other related questions and present the main results we found in the literature.

Keywords: Packing of trees, stars, bistars, complete graph, decomposition into trees, $k$-chromatic graph. 


\section{Sumário}

$\begin{array}{ll}\text { Lista de Figuras } & \text { ix }\end{array}$

1 Introdução 1

2 Preliminares $\quad 3$

2.1 Conceitos básicos sobre grafos . . . . . . . . . . . . . . . . . . . . . 3

2.2 Grafos orientados . . . . . . . . . . . . . . . . . 6

$\begin{array}{lll}3 & \text { Empacotamento em grafos completos } & \mathbf{7}\end{array}$

3.1 Árvores de diâmetro limitado . . . . . . . . . . . . . . . . . . . . 8

3.1 .1 Estrelas . . . . . . . . . . . . . . . . . . . . . 8

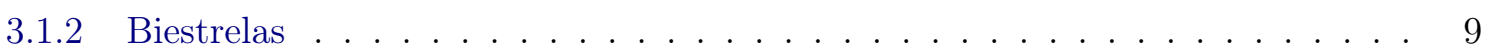

3.2 Estrelas ou caminhos . . . . . . . . . . . . . . . . . . . . . . 11

3.2.1 Prova de Gyárfás \& Lehel . . . . . . . . . . . . . . . . . . . . . . . . . . . 12

3.2.2 Prova de Zaks \& Liu . . . . . . . . . . . . . . . . . . . . . . . . . 15

3.3 Lagartas e aranhas . . . . . . . . . . . . . . . . . . . . . . . 17

3.4 Limitando o tamanho da sequência . . . . . . . . . . . . . . . . . 23

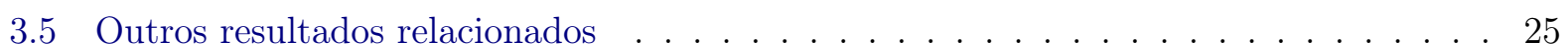

3.5.1 Quase-estrelas . . . . . . . . . . . . . . . . . 26

3.5.2 Empacotamento de matrizes . . . . . . . . . . . . . . . . . . . . . 29

4 Variantes da conjectura $\quad 31$

4.1 Empacotamento em grafos bipartidos completos . . . . . . . . . . . . . . . 31

4.1 .1 Estrelas e caminhos . . . . . . . . . . . . . . . . . . 31

4.1 .2 Limitando o tamanho da sequência . . . . . . . . . . . . . . . . . . . . 33

4.2 Empacotamento de árvores balanceadas . . . . . . . . . . . . . . . . . 36

4.3 Empacotamento em grafos $k$-cromáticos . . . . . . . . . . . . . . . . . 39

$\begin{array}{lll}5 & \text { Considerações finais } & 47\end{array}$

$\begin{array}{ll}\text { Referências Bibliográficas } & 49\end{array}$ 


\section{Lista de Figuras}

1.1 Empacotamento de estrelas no $K_{5} \ldots \ldots \ldots \ldots \ldots \ldots \ldots$

2.1 Alguns grafos completos . . . . . . . . . . . . . . . . . . . . 4

2.2 Algumas classes especiais de árvores . . . . . . . . . . . . . . . . . 5

3.1 Estendendo o empacotamento de $T_{n-2}^{\prime}$ e $T_{n-3}^{\prime} \ldots \ldots \ldots \ldots \ldots \ldots \ldots$

3.2 Empacotamento de biestrelas no $K_{5} \ldots \ldots \ldots \ldots \ldots \ldots \ldots$

3.3 Adicionando arestas aos vértices de um caminho (a) do Tipo I e (b) do Tipo II. . . . 14

3.4 Decomposição do $K_{6} \ldots \ldots \ldots \ldots \ldots \ldots \ldots$

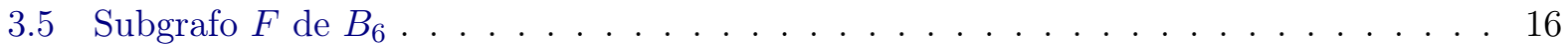

3.6 Grafos $H_{2 k}$ e $H_{2 k+1}$ para $k=3 \ldots \ldots \ldots \ldots \ldots \ldots \ldots \ldots$

3.7 Exemplos de lagartas e escorpião . . . . . . . . . . . . . . . . . . . . . . . 19

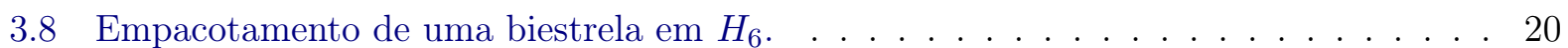

3.9 Empacotamento de uma triestrela em $H_{8} \ldots \ldots \ldots \ldots \ldots \ldots \ldots$

3.10 Empacotando uma lagarta 3 -interior em $H_{10} \ldots \ldots \ldots \ldots \ldots \ldots \ldots \ldots$

3.11 Empacotando um escorpião em $H_{10} \ldots \ldots \ldots \ldots \ldots \ldots \ldots \ldots$

3.12 Grafo que não contém um subgrafo $H$ tal que $\delta(H) \geqslant 3 \ldots \ldots \ldots$. . . . . . . . . 24

3.13 Matriz $M$ induzida pelo empacotamento de estrelas. . . . . . . . . . . . . . . . . . 29

4.1 Decomposição de $K_{3,5} \quad \ldots \ldots \ldots \ldots \ldots$

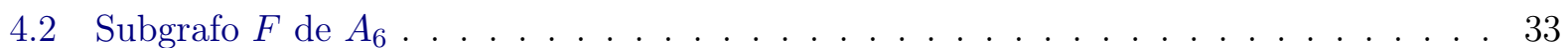

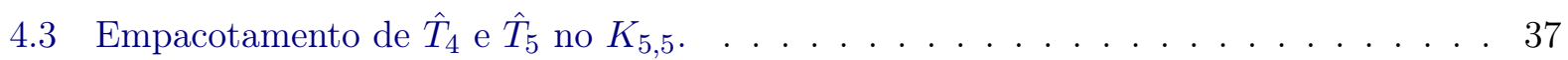

4.4 Matriz de biadjacência de $T$, caso $T$ fosse desconexo. . . . . . . . . . . . . . 38 


\section{Capítulo 1}

\section{Introdução}

Seja $G$ um grafo simples não-orientado de ordem $n$. Dizemos que uma sequência de árvores $T_{1}, T_{2}, \ldots, T_{n}$, onde $\left|V\left(T_{i}\right)\right|=i$ para $i=1,2, \ldots, n$, pode ser empacotada em $G$, se existem subgrafos $H_{1}, H_{2}, \ldots, H_{n}$, de $G$, dois a dois disjuntos nas arestas, tais que $T_{i} \cong H_{i}$ para $i=1,2, \ldots, n$ (veja na Figura 1.1 um exemplo de empacotamento). De agora em diante, vamos supor que $T_{i}$ sempre denota uma árvore de ordem $i$.

Em 1976, em um colóquio na área de combinatória, Gyárfás \& Lehel [13] levantaram a seguinte questão: é possivel empacotar qualquer sequência de árvores $T_{1}, T_{2}, \ldots, T_{n}$ no $K_{n}$ ? Até hoje não se conhece uma resposta para essa pergunta, que esses autores conjecturaram ser positiva. Tendo em vista este fato, é natural perguntar se existem classes especiais de árvores para as quais a resposta é afirmativa. Gyárfás \& Lehel [13] mostraram que existe tal empacotamento nos casos em que (a) cada uma das árvores $T_{i}$ é uma estrela ou um caminho, ou (b) quando no máximo duas das árvores não são estrelas. Recentemente, Gerbner, Keszegh e Palmer [12] generalizaram o resultado (b) mencionado acima, mostrando que se uma sequência de árvores $T_{1}, T_{2}, \ldots, T_{k}$ contém no máximo três árvores que não são estrelas, então tal sequência pode ser empacotada num grafo $k$-cromático. Além disso, Dobson [6] mostrou que tal empacotamento é possível se, em cada árvore $T_{i}$ existe um vértice adjacente a um número mínimo de folhas (que depende de $i$ ). Por outro lado, em vez de restringir a classe das árvores, faz sentido restringir o tamanho da sequência e reformular a pergunta. Por exemplo: dado $s<n$, é possível empacotar qualquer sequência de árvores $T_{1}, T_{2}, \ldots, T_{s}$ no $K_{n}$ ? Neste caso, a resposta é positiva se $s \leqslant\lfloor n / \sqrt{2}\rfloor$, como provou Bollobás [1] em 1983.

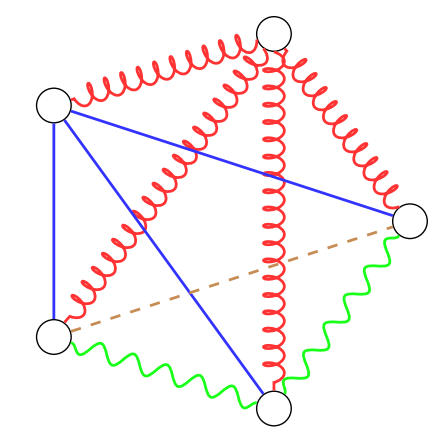

Figura 1.1: Empacotamento de estrelas no $K_{5}$

Um resultado relacionado à conjectura de Gyárfás \& Lehel, diz respeito ao maior inteiro $n$ para o qual foi provado que qualquer sequência de árvores $T_{1}, \ldots, T_{n}$ pode ser empacotada no $K_{n}$. Fishburn [11] mostrou que para $n \leqslant 9$ qualquer sequência de árvores $T_{1}, T_{2}, \ldots, T_{n}$ pode ser empacotada 
no $K_{n}$, melhorando o resultado de Straight [16], que provou essa afirmação para $n \leqslant 7$.

Vale notar que a conjectura de Gyárfás \& Lehel tem motivado outras questões relacionadas. Em 1981, Graham [11, 14] notou que se essa conjectura fosse verdadeira, ela teria a seguinte consequência.

Asserção 1. Para cada inteiro $i \geqslant 1$, seja $s_{i}$ uma sequência de $i+1$ números inteiros positivos cuja soma é $2 i$. Considere uma sequência $s_{1}, s_{2}, \ldots, s_{n-1}$. Então existe uma matriz $M$ de dimensão $n-1 \times n$ tal que cada linha $i$ de $M$ é uma permutação de $s_{i}$ (possivelmente aumentada por zeros) e cada coluna de $M$ tem soma $n-1$.

Em 1983, Fishburn [10] mostrou uma prova para a Asserção 1. Veremos neste trabalho como a veracidade da conjectura se relaciona a esta asserção.

Em 1987, Hobbs, Bourgeois e Kasiraj [14] formularam a seguinte questão, como variante à conjectura original: para $n$ par, é possivel empacotar qualquer sequência $T_{1}, T_{2}, \ldots, T_{n}$ no grafo completo $K_{n / 2, n-1}$ ? A respeito dessa pergunta, há alguns resultados análogos ao caso da conjectura inicial. Por exemplo, Zaks \& Liu [18] deram uma resposta positiva se cada $T_{i}$ é uma estrela ou um caminho. Além disso, Yuster [17] provou que é possível empacotar qualquer sequência $T_{1}, T_{2}, \ldots, T_{s}$ no $K_{n / 2, n-1}$ (respectivamente, $K_{(n-1) / 2, n}$ ) para $n$ par (respectivamente, ímpar), onde $s \leqslant\lfloor\sqrt{5} / 8 n\rfloor$, melhorando o resultado obtido por Caro \& Roditty [4] para a mesma afirmação quando $n$ é par e $s \leqslant\lfloor(\sqrt{13}-3) n / 2)\rfloor$.

Nesta dissertação, o tópico central de nosso interesse é o estudo de questões como as mencionadas anteriormente. Um aspecto recorrente nas provas dessas afirmações é o uso de indução no tamanho da sequência. Por exemplo, dado um empacotamento da sequência $T_{1}, T_{2}, \ldots, T_{n-1}$ no $K_{n-1}$, queremos encontrar uma maneira de empacotar $T_{n}$ no $K_{n}$. Ao adicionar um novo vértice no $K_{n-1}$, digamos $v$, e $n-1$ arestas ligando $v$ aos vértices do $K_{n-1}$, para empacotar $T_{n}$, se $T_{n}$ não é uma estrela, teremos que usar arestas já usadas no empacotamento feito no $K_{n-1}$, sendo necessário fazer algumas trocas. Nesses casos, uma forma de garantir o empacotamento de $T_{n}$ é encontrar uma condição suficiente sobre um subgrafo de $K_{n-1}$ para completar o empacotamento da sequência (veja a Seção 3.1). Outra das técnicas usadas é definir um grafo auxiliar no qual mostramos propriedades que garantem o empacotamento de $T_{n}$. Por outro lado, quando limitamos o tamanho da sequência, mostramos que, sem importar a forma como foram empacotados $T_{k+1}, \ldots, T_{r}$ no $K_{n}, 1<k<r<n$, o grafo resultante contém uma quantidade de arestas suficientes que garantem o empacotamento da árvore $T_{k}$, o que permite provar o passo da indução (por exemplo, veja a Seção 4.1).

O restante do texto está organizado da seguinte maneira. No Capítulo 2 introduzimos a notação e as definições básicas que serão usadas ao longo do texto. No Capítulo 3 apresentamos os resultados que existem na literatura sobre a conjectura original. Depois, no Capítulo 4 apresentamos algumas variantes da conjectura e os resultados a respeito. Na Seção 4.1 tratamos o caso de empacotamento em grafos bipartidos completos, e na Seção 4.3 apresentamos a generalização introduzida por Gerbner et al. [12] para o caso em que trocamos o grafo $K_{n}$ por um grafo $k$-cromático. 


\section{Capítulo 2}

\section{Preliminares}

Neste capítulo apresentamos algumas definições e a notação usada no texto, além de algumas convenções. A terminologia e a notação usadas seguem o padrão utilizado na maioria dos livros de teoria dos grafos. Omitimos a definição de alguns conceitos (como o de grafos de Turán), e sugerimos ao leitor não familiarizado com esses conceitos que consulte os livros de Bondy \& Murty [3] e Diestel [5].

\subsection{Conceitos básicos sobre grafos}

Um grafo é um par $G=(V, E)$, onde $V \cap E=\varnothing$, juntamente com uma função $\psi$ que associa a cada elemento de $E$ um subconjunto de $V$ de cardinalidade 2. Os elementos de $V$ são chamados de vértices, e os de $E$, de arestas. Muitas vezes, denotamos por $V(G)$ e $E(G)$ o conjunto dos vértices e o conjunto das arestas, respectivamente de um grafo $G$. A ordem de um grafo $G$ é a cardinalidade de $V(G)$. Se $e \in E$, e $\psi(e)=\{u, v\}$, onde possivelmente $u=v$, dizemos que $e$ liga os vértices $u$ e $v$, e que $u$ e $v$ são os extremos de $e$. Também dizemos que $e$ incide em $u$ ou $v$, e que $u$ e $v$ são vizinhos ou adjacentes. Quando $u=v$, dizemos que $e$ é um laço e se existem $a, e \in E$ tais que $\psi(a)=\psi(e)$, dizemos que $a$ e $e$ são paralelas. Dizemos que um grafo é simples se não possui laços nem arestas paralelas. Note que, se $G$ é um grafo simples, podemos definir o conjunto das arestas de $G$ especificando-se diretamente quais são os subconjuntos de vértices distintos que estão em $E(G)$, ficando a função $\psi$ implicitamente definida. Neste caso, se $\psi(e)=\{u, v\}$, abreviaremos esse fato escrevendo $e=u v$. Neste texto só trataremos de grafos simples; assim, omitiremos a menção à função $\psi$. Em particular, no restante desta seção $G=(V, E)$ denota um grafo simples.

Se $G^{\prime}=\left(V^{\prime}, E^{\prime}\right)$ é um grafo tal que $V^{\prime} \subseteq V$ e $E^{\prime} \subseteq E$, então, dizemos que $G^{\prime}$ é um subgrafo de $G$ e que $G$ é um supergrafo de $G^{\prime}$. Para $S \subseteq V$, o subgrafo de $G$ induzido por $S$ é o subgrafo $G[S]:=(S, A)$, onde $A \subseteq E$ é o subconjunto das arestas de $E$ com ambos os extremos em $S$. Além disso, denotamos por $G-S$ o subgrafo $G[V \backslash S]$, e se $F \subseteq E$, denotamos por $G-F$ o grafo $(V, E \backslash F)$. Se $\alpha$ é um vértice ou uma aresta de $G$, escrevemos simplesmente $G-\alpha$ em vez de $G-\{\alpha\}$. Seja $v \in V$. A vizinhança de um vértice $v$ em $G$ é $N(v):=\{u \in V: u$ é adjacente a $v\}$. O grau de $v$ em $G$, denotado por $g_{G}(v)$ ou simplesmente $g(v)$ é $|N(v)|$. Denotamos por $\delta(G)$ e $\Delta(G)$ o grau mínimo e o grau máximo de $G$, respectivamente; ou seja $\delta(G):=\min \{g(v): v \in V\}$ e $\Delta(G):=\max \{g(v): v \in V\}$. Um conceito relacionado aos graus dos vértices de $G$ é a sua sequência de graus. A sequência dos graus de $G$ é a sequência não-crescente dos graus dos vértices de $G$.

Um caminho $P$, em $G$, é uma sequência $P:=\left\langle v_{1}, e_{1}, v_{2}, \ldots, e_{k}, v_{k+1}\right\rangle$, onde $v_{1}, \ldots, v_{k+1}$ são 
vértices distintos de $G$ e $e_{i}$ é uma aresta que liga $v_{i}$ e $v_{i+1}$ para $i=1,2, \ldots, k$. Neste caso, dizemos que $P$ é um caminho entre $v_{1}$ e $v_{k+1}$, ou que $P$ liga $v_{1}$ e $v_{k+1}$, e tem comprimento $k$. Algumas vezes representamos um caminho $P$ apenas pela sequência de seus vértices, escrevendo abreviadamente $P=\left\langle v_{1}, \ldots, v_{k+1}\right\rangle$. Denotamos por $P_{n}$ um caminho com $n$ vértices. Dizemos que $G$ é conexo se para quaisquer pares de vértices $u, v \in V$ existe um caminho que liga $u$ e $v$ em $G$. A distância entre um par de vértices $u, v$ de um grafo conexo $G$ é o comprimento de um caminho mínimo entre $u$ e $v$ em $G$. O diâmetro de um grafo conexo $G$ é a maior distância entre quaisquer pares de vértices de $G$. Um circuito $C$, em $G$, é uma sequência $C:=\left\langle v_{1}, e_{1}, v_{2}, \ldots, v_{k}, e_{k}, v_{k+1}\right\rangle$, onde $v_{1}, v_{2}, \ldots, v_{k}$ são vértices distintos de $G, v_{1}=v_{k+1}$ e $e_{i}$ é uma aresta que liga $v_{i}$ e $v_{i+1}$, para $i=1,2, \ldots, k$. Se $G$ não tem circuitos, dizemos que $G$ é acíclico.

A união de dois grafos $G$ e $H$ é o grafo com conjunto de vértices $V(G) \cup V(H)$ e conjunto de arestas $E(G) \cup E(H)$. A operação de união é associativa e comutativa, desta forma, podemos estender a definição a um conjunto finito de grafos de maneira natural. O complemento $\bar{G}$ de um grafo $G$ é um grafo simples tal que $V(\bar{G})=V(G)$ e $E(\bar{G})=\{u v: u, v \in V(G)$, uv $\notin E(G)\}$.

Dizemos que dois grafos $G$ e $H$ são isomorfos se existem duas bijeções $\phi: V(G) \rightarrow V(H)$ e $\varphi: E(G) \rightarrow E(H)$ tais que $e=u v \in E(G)$ se só se $\varphi(e)=\phi(u) \phi(v) \in E(H)$. Se $G$ e $H$ são isomorfos escrevemos $G \cong H$. Se para cada par de vértices distintos $u$ e $v$ de $G$ existe uma aresta que os liga, dizemos que $G$ é completo. Note que existe um único grafo completo com $n$ vértices, a menos de isomorfismo. Tal grafo é denotado por $K_{n}$. Na Figura 2.1(a) exibimos o $K_{5}$.

Dizemos que $G$ é um grafo bipartido se existem subconjuntos não vazios $X$ e $Y$ de $V(G)$ tais que $X$ e $Y$ são disjuntos, $X \cup Y=V(G)$ e para cada aresta $e \in E(G)$ um dos seus extremos está em $X$ e o outro em $Y$. Neste caso, também dizemos que $G$ é $(X, Y)$-bipartido e chamamos os conjuntos $X$ e $Y$ de classes da bipartição de $G$. Se $G$ é um grafo $(X, Y)$-bipartido tal que para todo par de vértices $x \in X$ e $y \in Y$ tem-se que $x y \in E(G)$, dizemos que $G$ é bipartido completo. Denotamos por $K_{m, n}$ o grafo $(X, Y)$-bipartido completo, onde $|X|=m$ e $|Y|=n$. Note que existe um único grafo $K_{m, n}$ a menos de isomorfismo. Na Figura 2.1(b) exibimos o $K_{3,3}$.

A matriz de adjacência de um grafo $G$ é a matriz $M_{G}:=\left(m_{u v}\right)$ sobre $V(G) \times V(G)$ definida da seguinte maneira. Para cada par de vértices $u, v \in V(G)$,

$$
m_{u v}= \begin{cases}1, & \text { se } u \text { e } v \text { são adjacentes } \\ 0, & \text { caso contrário. }\end{cases}
$$

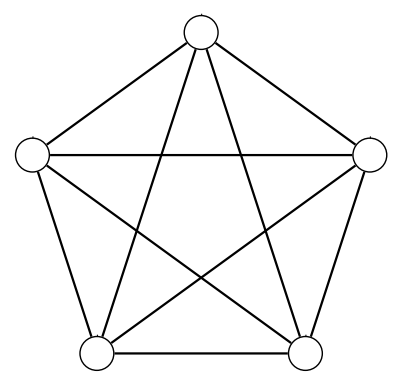

(a) $K_{5}$

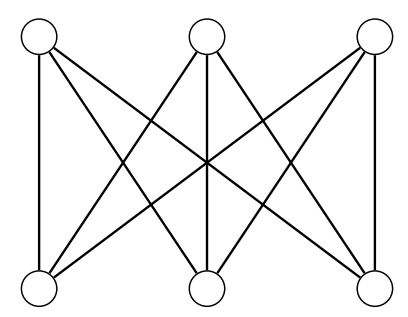

(b) $K_{3.3}$

Figura 2.1: Alguns grafos completos

Uma $k$-coloração de um grafo $G=(V, E)$ é uma função $c: V \rightarrow C$, onde $C$ é um conjunto 
de $k$ cores. Normalmente, consideramos $C=\{1,2, \ldots, k\}$. Uma coloração é chamada própria se para qualquer par de vértices adjacentes $u$ e $v$ temos $c(u) \neq c(v)$. Nesta dissertação só estamos interessados em colorações próprias, assim no restante do texto, ao referirmos a uma coloração de $G$, deve ficar subentendido que ela é própria. O número cromático de $G$ é o menor inteiro $k$ tal que $G$ admite uma $k$-coloração. Se o número cromático de um grafo $G$ é $k$ então também dizemos que $G$ é um grafo $k$-cromático.

Sejam $G$ e $H$ grafos quaisquer. Dizemos que podemos empacotar $H$ em $G$ se existem funções injetoras $\nu: V(H) \rightarrow V(G)$ e $\lambda: E(H) \rightarrow E(G)$ tais que se $e=u v \in E(H)$ então $\lambda(e)=\nu(u) \nu(v)$ pertence a $E(G)$. Sejam $H_{1}, \ldots, H_{k}$ uma sequência de grafos, $S=\bigcup_{i=1}^{k} V\left(H_{i}\right)$ e $F=\bigcup_{i=1}^{k} E\left(H_{i}\right)$. Dizemos que a sequência de grafos $H_{1}, \ldots, H_{k}$ pode ser empacotada num grafo $G$, se existem duas funções $\nu: S \rightarrow V(G)$ e $\lambda: F \rightarrow E(G)$ tais que $\lambda$ é injetora e se $e=u v \in F$ então a aresta $\lambda(e)=\nu(u) \nu(v) \in E(G)$ para $i=1,2, \ldots, k$. Por outro lado, dizemos que um grafo $G$ admite uma decomposição em grafos $H_{1}, \ldots, H_{k}$ se $E(G)=\bigcup_{i=1}^{k} E\left(H_{i}\right)$ e para $i=1, \ldots, k$, temos que $H_{i} \subseteq G$ e $E\left(H_{i}\right) \cap E\left(H_{j}\right)=\varnothing$ para $i \neq j$. Ou seja, a sequência $H_{1}, \ldots, H_{k}$ pode ser empacotada em $G$, e neste caso a função $\lambda$ é bijetora. Algumas vezes, especialmente no caso de empacotamentos, usamos o termo "mapeamento", no lugar de função, e dizemos que um certo elemento é "mapeado" a outro.

Uma floresta é um grafo acíclico. Uma árvore é uma floresta conexa. Os vértices de uma árvore que têm grau 1 são chamados folhas. Um tipo especial de árvore é o grafo $K_{1, n-1}$ que chamamos de estrela de $n$ vértices, e também denotamos por $S_{n}$ (veja a Figura 2.2(a)). Para $n \geqslant 3$, o único vértice de grau $n-1$ em $S_{n}$ é chamado centro de $S_{n}$. Os grafos $K_{1}$ e $K_{2}$ também são estrelas, e todos os seus vértices são centros. Uma classe especial de árvores é aquela formada por árvores que têm diâmetro três. Tais árvores são chamadas biestrelas (veja a Figura 2.2(b)). As biestrelas caracterizam-se por ter exatamente dois vértices com grau maior do que 1 (também chamados de centros).

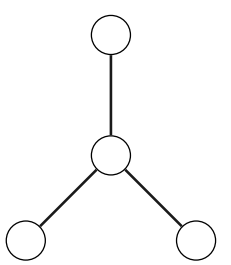

(a) $S_{4}$

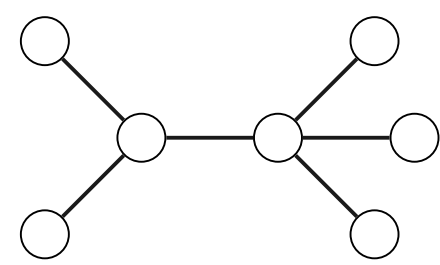

(b) Biestrela

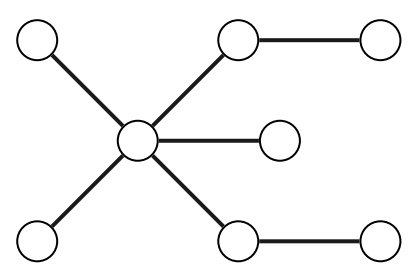

(c) Aranha

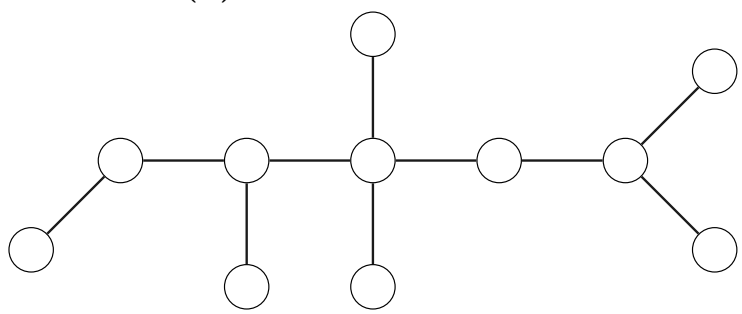

(d) Lagarta

Figura 2.2: Algumas classes especiais de árvores

Outras classes especiais de árvores às quais faremos referência são as aranhas e as lagartas. Uma aranha (spider) é uma árvore cujos vértices têm grau no máximo dois, com exceção de um único vértice, chamado junção, que tem grau pelo menos três (veja a Figura 2.2(c)). Um caminho entre a junção da aranha e uma folha é denominado perna. Uma lagarta (caterpillar) é uma árvore 
tal que a remoção de suas folhas dá origem a um caminho (veja a Figura 2.2(d)). Os vértices que são extremos desse caminho são chamados penúltimos e os outros vértices do caminho são chamados interiores. Notamos que estrelas, biestrelas e caminhos são tipos de lagartas. A seguir enunciamos alguns resultados básicos que usaremos no restante do texto.

Asserção 2. Para todo grafo $G=(V, E)$ tem-se que

$$
\sum_{v \in V} g(v)=2|E|
$$

Asserção 3. Toda árvore diferente de uma estrela possui pelo menos duas folhas que não são adjacentes a um mesmo vértice.

\subsection{Grafos orientados}

Um grafo orientado é um par $D=(V, A)$, onde $V \cap A=\varnothing$, juntamente com uma função $\psi$ que associa a cada elemento de $A$ um par ordenado de elementos (não necessariamente distintos) de $V$. Os elementos de $V$ são chamados de vértices, e os de $A$, de arcos. Muitas vezes, denotamos por $V(D)$ e $A(D)$ o conjunto dos vértices e o conjunto dos arcos, respectivamente de um grafo orientado $D$. Se $a \in A$, e $\psi(a)=(u, v)$, dizemos que $u$ é ponta inicial de $a$ e que $v$ é ponta final de $a$. Também dizemos que $a$ sai de $u$ e que $a$ entra em $v$. Quando $u=v$, dizemos que $a$ é um laço e se existem $a, e \in A$ tais que $\psi(a)=\psi(e)$, dizemos que $a$ e $e$ são paralelos. Dizemos que um grafo orientado é simples se não possui laços nem arcos paralelos. De forma similar ao caso de um grafo simples, quando temos um grafo orientado simples, a função $\psi$ fica implicitamente definida pelo conjunto de arcos que estão em $A(D)$. Neste caso, se $\psi(a)=(u, v)$, abreviaremos esse fato escrevendo $a=u v$. No resto desta dissertação só trataremos de grafos orientados simples, portanto omitiremos a menção à função $\psi$. Em particular, no restante desta seção $D$ denota um grafo orientado simples.

Seja $D^{\prime}=\left(V^{\prime}, A^{\prime}\right)$ um grafo orientado simples. Se $V^{\prime} \subseteq V$ e $A^{\prime} \subseteq A$, dizemos que $D^{\prime}$ é subgrafo de $D$. Para $S \subseteq V$, o subgrafo de $D$ induzido por $S$ é o subgrafo $D[S]:=(S, F)$, onde $F \subseteq A$ é o subconjunto dos arcos de $A$ com ambas as pontas em $S$. Além disso, denotamos por $D-S$ o subgrafo $D[V \backslash S]$, e se $F \subseteq A$, denotamos por $D-F$ o grafo orientado $(V, A \backslash F)$. Se $\alpha$ é um vértice ou um arco de $D$, escrevemos simplesmente $D-\alpha$ em vez de $D-\{\alpha\}$. Seja $v \in V(D)$. O grau de saida de $v$ em $D$, denotado por $g_{D}^{+}(v)$ ou simplesmente $g^{+}(v)$, é o número de arcos com ponta inicial em $v$. O grau de entrada de $v$ em $D$, denotado por $g_{D}^{-}(v)$ ou simplesmente $g^{-}(v)$ é o número de arcos com ponta final em $v$.

Um caminho $P$, em $D$, é uma sequência $P:=\left\langle v_{1}, a_{1}, v_{2}, \ldots, a_{k}, v_{k+1}\right\rangle$, onde $v_{1}, \ldots, v_{k+1}$ são vértices distintos de $D$ e $a_{i}$ é um arco que sai de $v_{i}$ e entra em $v_{i+1}$ para $i=1,2, \ldots, k$. Neste caso, dizemos que $P$ é um caminho com início em $v_{1}$ e término em $v_{k+1}$, e tem comprimento $k$. Algumas vezes representamos um caminho $P$ apenas pela sequência de seus vértices, escrevendo abreviadamente $P=\left\langle v_{1}, \ldots, v_{k+1}\right\rangle$. O grafo subjacente a $D=(V, A)$ é o grafo simples $G$ com conjunto de vértices $V(G)=V$ e conjunto de arestas $E(G)=\{u v: u v \in A$ ou $v u \in A\}$. 


\section{Capítulo 3}

\section{Empacotamento em grafos completos}

Em 1976, A. Gyárfás e J. Lehel [13] perguntaram se é possível empacotar qualquer sequência de árvores $T_{1}, T_{2}, \ldots, T_{n}$ no $K_{n}$. Lembramos que $T_{i}$ denota uma árvore de ordem $i$. Como $T_{i}$ tem $i-1$ arestas, para empacotar uma tal sequência precisamos de pelo menos $\left(\begin{array}{l}n \\ 2\end{array}\right)$ arestas, que é o mesmo número de arestas do $K_{n}$. Então, encontrar um empacotamento de $T_{1}, T_{2}, \ldots, T_{n}$ no $K_{n}$ é equivalente a encontrar uma decomposição do $K_{n}$ em subgrafos $H_{1}, H_{2}, \ldots, H_{n}$ tais que $H_{i}$ é isomorfo a $T_{i}$ para $i=1, \ldots, n$.

A maioria das provas deste capítulo envolve o uso de indução no tamanho da sequência. Algumas vezes, dada uma sequência $T_{1}, T_{2}, \ldots, T_{n}$, definimos uma outra sequência $T_{1}^{\prime}, \ldots, T_{s}^{\prime}, s<n$, retirando algumas folhas das árvores de maior ordem e algumas árvores da sequência original, e a empacotamos no $K_{s}$. Depois, adicionamos $n-s$ vértices ao $K_{s}$ e arestas necessárias para obter o grafo $K_{n}$. Finalmente, indicamos como estender cada árvore $T_{i}^{\prime}$ e como completar o empacotamento (exemplo deste tipo de prova pode ser visto nas Seções 3.1.1 e 3.2.1). Em outros casos, pela hipótese de indução, temos um empacotamento da sequência $T_{1}, \ldots, T_{n-1}$ no $K_{n-1}$. Adicionando um vértice, digamos $v$, e $n-1$ arestas incidentes a $v$ obtemos o grafo $K_{n}$. Note que, se $T_{n}$ não é uma estrela, precisamos fazer mudanças no empacotamento feito no $K_{n-1}$ para conseguirmos empacotar $T_{n}$. Nesses casos, a ideia é usar o vértice $v$ no empacotamento das árvores $T_{1}, \ldots, T_{n-1}$ de forma que as arestas livres induzam um grafo isomorfo a $T_{n}$. Para isso, podemos definir estruturas (outros grafos) auxiliares baseados no empacotamento no $K_{n-1}$ (para um exemplo veja a Seção 3.5).

Este capítulo está organizado da seguinte maneira. Na Seção 3.1 restringimos o diâmetro das árvores que desejamos empacotar e mostramos resultados positivos quando as árvores têm diâmetro no máximo três. Depois, na Seção 3.2 apresentamos o caso em que a classe de árvores está restrita a estrelas ou caminhos. A seguir, na Seção 3.3, apresentamos uma generalização dos resultados obtidos nas seções anteriores. Mostramos uma subclasse de lagartas e aranhas para a qual a conjectura é verdadeira; também exibimos uma classe de lagartas onde a mesma técnica não pode ser usada. Na Seção 3.4 apresentamos o resultado obtido por Bollobás [1] quando restringimos o tamanho da sequência. Finalmente, na Seção 3.5 apresentamos outros resultados conhecidos que envolvem outras classes específicas de árvores e uma questão relacionada à conjectura de Gyárfás \& Lehel [13]. 


\section{1 Árvores de diâmetro limitado}

\subsubsection{Estrelas}

Quando restringimos as classes de árvores a serem empacotadas, um primeiro resultado fácil de provar é quando cada árvore $T_{i}$ é uma estrela $S_{i}$. Para mostrar isso, podemos começar com o grafo $K_{1} \cong S_{1}$. Depois, vamos adicionando um a um os vértices do $K_{n}$, digamos $v_{2}, v_{3}, \ldots, v_{n}$. Cada vez que adicionamos um vértice $v_{i}$, ligamos $v_{i}$ a todos os vértices anteriores. Claramente, podemos usar $v_{i}$ e as arestas incidentes nele para empacotar $S_{i}$. Assim, tem-se um empacotamento da sequência $S_{1}, S_{2}, \ldots, S_{n}$ no $K_{n}$.

Uma forma de se generalizar o resultado anterior é reduzindo o número de estrelas na sequência. A esse respeito, Gyárfás \& Lehel [13] mostraram um resultado positivo quando no máximo duas das árvores da sequência não são estrelas.

Teorema 4 (Gyárfás \& Lehel, 1976). Uma sequência de árvores $T_{1}, T_{2}, \ldots, T_{n}$ pode ser empacotada no $K_{n}$ se no máximo duas das árvores não são estrelas.

Prova. Por indução em $n$. Se $n=1,2$, note que $T_{1} \cong K_{1}$ e $T_{2} \cong K_{2}$. Logo, a base da indução é satisfeita. Suponha que $n \geqslant 3$. Distinguimos três casos.

Caso 1: $T_{n}$ é uma estrela.

Neste caso, pela hipótese de indução, existe um empacotamento da sequência $T_{1}, \ldots, T_{n-1}$ no $K_{n-1}$. Para completar o empacotamento, tomamos um novo vértice e o ligamos com todos os vértices de $K_{n-1}$, gerando dessa forma uma estrela isomorfa a $T_{n}$. Com isso fica provada a afirmação.

Caso 2: $T_{n-1}$ é uma estrela.

Tome uma folha, digamos $x$, de $T_{n}$ e considere $T_{n-1}^{\prime}=T_{n}-x$. Pela hipótese de indução, existe um empacotamento da sequência $T_{1}, \ldots, T_{n-2}, T_{n-1}^{\prime}$ no $K_{n-1}$. Para completar o empacotamento, adicionamos ao $K_{n-1}$ um vértice, digamos $v$, como no caso anterior. Depois, estendemos o empacotamento de $T_{n-1}^{\prime}$ (obtendo um empacotamento de $T_{n}$ ) escolhendo apropriadamente uma das arestas incidentes a $v$; e usamos as $n-2$ arestas restantes incidentes a $v$ para empacotar a estrela $T_{n-1}$.

Caso 3: $T_{n}$ e $T_{n-1}$ são diferentes de uma estrela.

Neste caso, claramente, $n \geqslant 5$. Sejam $x_{1}$ e $x_{2}$ (respectivamente, $y_{1}$ e $y_{2}$ ) folhas de $T_{n}$ (respectivamente, $\left.T_{n-1}\right)$ que não são adjacentes a um mesmo vértice. Considere as árvores $T_{n-2}^{\prime}=T_{n}-\left\{x_{1}, x_{2}\right\}$ e $T_{n-3}^{\prime}=T_{n-1}-\left\{y_{1}, y_{2}\right\}$. Então, pela hipótese de indução, existe um empacotamento da sequência $T_{1}, \ldots, T_{n-4}, T_{n-3}^{\prime}, T_{n-2}^{\prime}$ no $K_{n-2}$. Para estender o empacotamento, tomamos dois novos vértices, digamos $v$ e $w$, e os ligamos entre si e aos vértices do $K_{n-2}$. Note que, pela escolha de $\left\{x_{1}, x_{2}\right\}$ e $\left\{y_{1}, y_{2}\right\}$, podemos estender o empacotamento de $T_{n}$ e $T_{n-1}$ usando, em cada um dos casos, duas arestas incidentes a $v$ e $w$ (cujo outro extremo pertence a $K_{n-2}$ ). Finalmente, como $v$ e $w$ têm cada qual $n-4$ arestas livres incidentes ao $K_{n-2}$, e considerando a aresta $v w$, podemos empacotar $T_{n-2}$ e $T_{n-3}$ mapeando o seu centro em $v$ e $w$ respectivamente (veja na Figura $3.1 \mathrm{um}$ exemplo de como estender o empacotamento de $T_{n-2}^{\prime}$ e $T_{n-3}^{\prime}$ quando os vizinhos de $x_{i}$ e $y_{i}$ são mapeados a três vértices no $\left.K_{n-2}\right)$. 


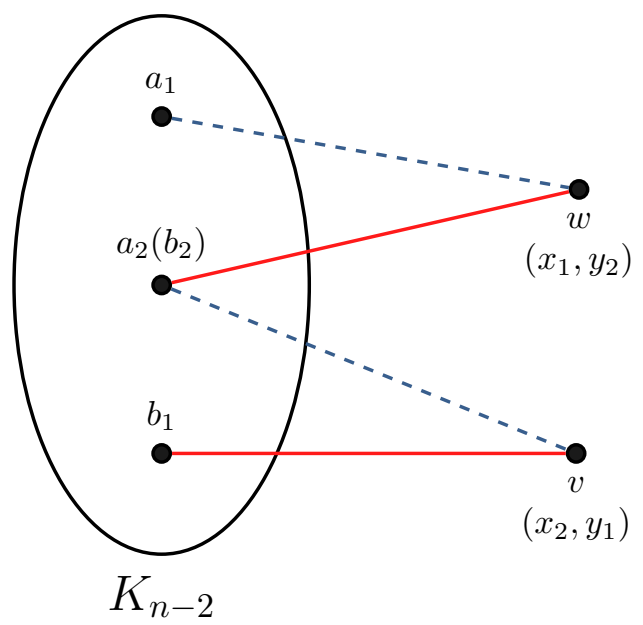

Figura 3.1: Estendendo o empacotamento de $T_{n-2}^{\prime}$ e $T_{n-3}^{\prime}$.

\subsubsection{Biestrelas}

Outra maneira de generalizar o resultado sobre empacotamento de estrelas é considerar árvores de diâmetro maior. Nesse sentido, Hobbs et al. [14] mostraram que, quando as árvores que desejamos empacotar têm diâmetro no máximo 3, também é possível empacotá-las no $K_{n}$. Suponha que uma sequência $T_{1}, T_{2}, \ldots, T_{n-1}$ pode ser empacotada no $K_{n-1}$. Se $T_{n}$ é uma estrela, pelo visto no início do capítulo, já sabemos como fazer o seu empacotamento. A seguir, falaremos sobre uma condição suficiente que garante o empacotamento de uma biestrela $T_{n}$.

Sejam $T_{n}$ uma biestrela e $v$ o vértice adicionado a $K_{n-1}$ para obter o grafo $K_{n}$. Note que, se mapeamos um centro de $T_{n}$ em $v$ (para realizar o empacotamento), precisamos realizar mudanças no empacotamento em $K_{n-1}$ para empacotar $T_{n}$. Especificamente, devemos usar o vértice $v$ no empacotamento das árvores $T_{1}, \ldots, T_{n-1}$. Suponha que associamos a cada árvore $T_{i}$ a cor $i$ e colorimos as arestas de $K_{n-1}$ segundo o empacotamento da sequência $T_{1}, T_{2}, \ldots, T_{n-1}$. Então, para qualquer vértice $w \in V\left(K_{n-1}\right)$, podemos considerar todas as arestas de uma certa cor, digamos a cor $j$. Seja $S_{j}$ a vizinhança de $w$ (no $K_{n-1}$ ) induzida por essa cor. Se retirarmos a cor $j$ das arestas com um extremo em $w$ e outro em $S_{j}$, e colorirmos com a cor $j$ as arestas incidentes em $v$ que têm o outro extremo em $S_{j}$, teremos um empacotamento da sequência $T_{1}, \ldots, T_{n-1}$ no $K_{n}$ onde $v$ é usado no empacotamento de $T_{j}$. Claramente, o procedimento anterior pode ser generalizado tomando um subconjunto de cores incidentes ao vértice $w$.

Seja $x$ um dos centros da biestrela $T_{n}$ (a ser mapeado a $w$ ). Pelo que argumentamos anteriormente, se existem um vértice $w$ em $K_{n-1}$ e um subconjunto de cores tais que o número de arestas incidentes a $w$ induzido por essas cores é $m:=g_{T_{n}}(x)-1$, então podemos empacotar a sequência $T_{1}, T_{2}, \ldots, T_{n}$ no $K_{n}$ de forma que o centro $x$ de $T_{n}$ é mapeado a $w$ e o outro centro é mapeado a $v$. Hobbs et al. [14] mostraram que a existência de um vértice $w$ com essas características sempre está garantida. Para fazer a prova, precisamos do seguinte lema.

Lema 5. Sejam $n$ e $k$ inteiros positivos, tais que $k>n / 2$. Sejam $p_{1}, \ldots, p_{k}$ inteiros tais que $p_{1} \geqslant$ $p_{2} \geqslant \ldots \geqslant p_{k} \geqslant 1$, e $\sum_{i=1}^{k} p_{i}=n$. Então, para todo inteiro $m, 1 \leqslant m \leqslant n$, existe um subconjunto de indices $\mathcal{I} \subseteq\{1,2, \ldots, k\}$ tal que $m=\sum_{i \in \mathcal{I}} p_{i}$. 
Prova. Sejam $x$ e $y$ tais que

$$
\begin{aligned}
& x=\left|\left\{i: p_{i}=1,1 \leqslant i \leqslant k\right\}\right|, \\
& y=\left|\left\{i: p_{i}=2,1 \leqslant i \leqslant k\right\}\right| .
\end{aligned}
$$

Como $k>n / 2$, segue que $x>0$. Se $p_{1}=1$, o resultado é trivial. Vamos supor então que $p_{1} \geqslant 2$. Distinguimos dois casos.

Caso 1: $p_{1}=2$.

Neste caso, geramos todos os números entre 1 e $x$ usando só uns. Para gerar um número maior que $x$, digamos $m$, verificamos a paridade de $m-x$. Se $m-x$ é par (respectivamente, ímpar) usamos $x$ (respectivamente, $x-1$ ) uns e completamos o que falta (para atingir $m$ ) com a quantidade necessária de dois.

Caso 2: $p_{1}>2$.

Seja $z=\max \left\{i: p_{i}>2,1 \leqslant i \leqslant k\right\}$. Note que

$$
\frac{\sum_{i=1}^{z} p_{i}+2 y+x}{x+y+z}=\frac{n}{k}<2
$$

Da desigualdade acima concluímos que $\sum_{i=1}^{z}\left(p_{i}-2\right)<x$, donde segue que $p_{1}-1 \leqslant x$. Para gerar os números entre 1 e $p_{1}-1$ usamos só uns. Como $p_{1} \geqslant p_{2}$, temos que $x \geqslant p_{2}-1$. Então, para gerar números entre $p_{1}+1$ e $p_{1}+p_{2}-1$ usamos $p_{1}$ e completamos com uns. De uma forma análoga, podemos gerar os números entre 1 e $\sum_{i=1}^{z} p_{i}$. Finalmente, para gerar números maiores que $\sum_{i=1}^{z} p_{i}$ usamos um processo similar ao caso anterior.

A seguir, expomos a prova apresentada por Hobbs et al. [14]. Esta prova usa o lema anterior para mostrar como empacotar $T_{1}, \ldots, T_{n}$ no $K_{n}$, quando $T_{n}$ é uma biestrela, dado um empacotamento da sequência $T_{1}, \ldots, T_{n-1}$ no $K_{n-1}$.

Teorema 6 (Hobbs et al., 1987). Seja $T_{1}, T_{2}, \ldots, T_{n}, n \geqslant 2$, uma sequência de árvores, onde $T_{i}$ tem diâmetro no máximo 3 . Se existe um empacotamento da sequência $T_{1}, T_{2}, \ldots, T_{n-1}$ no $K_{n-1}$, então a sequência $T_{1}, T_{2}, \ldots, T_{n}$ pode ser empacotada no $K_{n}$.

Prova. Por indução em $n$. Se $n \leqslant 3$, o resultado segue trivialmente. Se $n>3$, pela hipótese de indução existe um empacotamento da sequência $T_{1}, \ldots, T_{n-1}$ no $K_{n-1}$. Distinguimos dois casos.

Caso 1: $T_{n}$ é uma estrela.

Neste caso, adicionamos um novo vértice e o ligamos a todos os vértices de $K_{n-1}$. Claramente, podemos empacotar $T_{n}$ usando as arestas incidentes ao novo vértice.

Caso 2: $T_{n}$ é uma biestrela.

Considere o empacotamento da sequência $T_{2}, \ldots, T_{n-1}$ no $K_{n-1}$. (Note que omitimos $T_{1}$, já que o empacotamento de $T_{1}$ é imediato). Vamos contar quantas vezes um vértice do $K_{n-1}$, na média, é usado para empacotar as árvores da sequência em consideração. Temos, no total, $\left((n-1)^{2}+n-3\right) / 2$ vértices. Logo, cada vértice do $K_{n-1}$ é usado no empacotamento de $(n-1) / 2+1-2 /(n-1)$ árvores em média. Neste caso, existe um vértice, digamos $w$, que é usado no empacotamento de $k$ árvores, onde $k>(n-1) / 2$. Então, temos uma partição das $n-2$ arestas incidentes a $w$ em $k>(n-2) / 2$ partes, que chamaremos de cores (sendo cada cor correspondente a uma árvore distinta). Suponha 
que para cada uma dessas cores $i$ existam $p_{i}$ arestas com a cor $i$. Pelo Lema 5, temos que para todo $m, 1 \leqslant m \leqslant n-2$, existe um subconjunto das cores atribuídas às arestas incidentes ao vértice $w$ tais que a soma dos correspondentes $p_{i}$ 's é precisamente $m$. Vamos denotar por $\mathcal{P}(m)$ o conjunto das arestas correspondentes a esse subconjunto de cores.

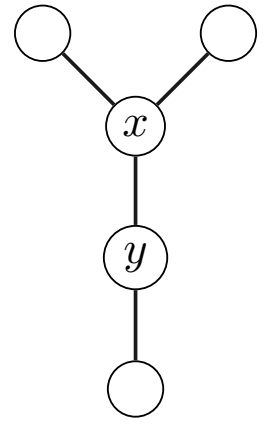

(a) Biestrela $T_{5}$.

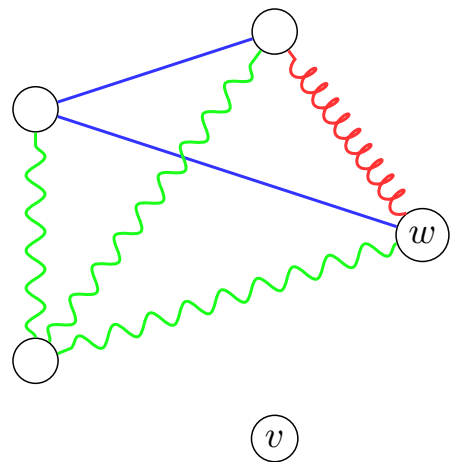

(b) Empacotamento de $T_{1}, \ldots, T_{4}$ no $K_{4}$.

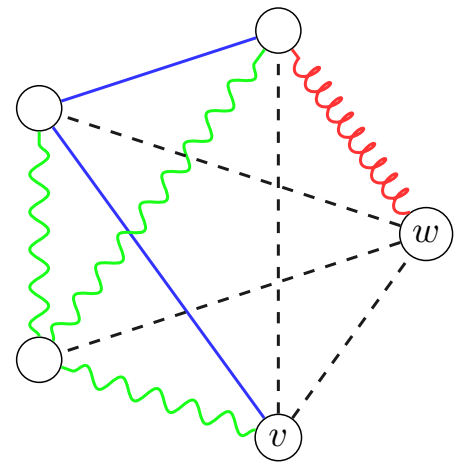

(c) Empacotamento de $T_{1}, \ldots, T_{5}$ no $K_{5}$.

Figura 3.2: Empacotamento de biestrelas no $K_{5}$

Sejam $x$ e $y$ os centros da biestrela $T_{n}$ e seja $m:=g_{T_{n}}(x)-1$. (Note que $m \leqslant n-2$.) Para estender o empacotamento, adicionamos um novo vértice $v$ ao $K_{n-1}$ (que estamos considerando) e o ligamos a todos os vértices de $K_{n-1}$. Vamos empacotar $T_{n}$ mapeando $x$ ao vértice $w$, e $y$ ao vértice $v$. Para isso, para toda aresta de $\mathcal{P}(m)$ trocamos o extremo $w$ por $v$ (ou seja, precisamente $m$ arestas incidentes a $v$ recebem as cores correspondentes às arestas de $\mathcal{P}(m))$. Dessa forma, as $m$ arestas de $T_{n}$ incidentes a $x$ que não incidem em $y$ podem ser mapeadas às $m$ arestas que antes pertenciam a $\mathcal{P}(m)$. É fácil ver que podemos mapear as demais arestas de $T_{n}$ à aresta $v w$ e às arestas não coloridas incidentes ao vértice $v$. Veja na Figura 3.2 um exemplo de empacotamento de biestrelas no $K_{5}$

\subsection{Estrelas ou caminhos}

No início do capítulo mostramos como empacotar estrelas. Vimos uma maneira de generalizar esse resultado na seção anterior, onde consideramos árvores de diâmetro no máximo três. Outra maneira de procurar uma resposta afirmativa à conjectura é considerar outras classes de árvores que, junto com as estrelas, possam ser empacotadas no $K_{n}$.

Nessa direção, Gyárfás \& Lehel [13] e Zaks \& Liu [18] mostraram de forma independente que, se as classes de árvores a serem empacotadas são restritas a estrelas e caminhos, o empacotamento de uma sequência de árvores $T_{1}, \ldots, T_{n}$ no $K_{n}$ é possível. O objetivo desta seção é mostrar o seguinte teorema.

Teorema 7. Uma sequência de árvores $T_{1}, T_{2}, \ldots, T_{n}$ tal que $T_{i}$ é uma estrela ou um caminho, para $i=1,2, \ldots, n$, pode ser empacotada no $K_{n}$.

A seguir, apresentamos duas provas para essa afirmação. Embora a prova dada por Zaks \& Liu [18] seja muito mais curta e simples, ela dificilmente poderia ser estendida para outras classes de árvores (como veremos na Seção 3.3). Por outro lado, a prova obtida por Gyárfás \& Lehel [13] 
mostra um resultado um pouco mais forte que a do Teorema 7. Ao longo desta seção, vamos supor que $T_{i}$ é uma estrela ou um caminho, para $i=1, \ldots, n$.

\subsubsection{Prova de Gyárfás \& Lehel}

Seja $T_{1}, \ldots, T_{n}$ uma sequência de árvores. Denotamos por $\mathcal{I}$ o conjunto de índices $r, 1 \leqslant r \leqslant n$, tais que $T_{r}$ é uma estrela. Lembramos que $T_{1}, T_{2}$ e $T_{3}$ são estrelas, e portanto, $\mathcal{I} \neq \varnothing$. Além disso, vamos supor que as árvores $T_{k}, T_{\ell}$ e $T_{m}$ denotam as três estrelas de maior ordem da sequência, de forma que $k<\ell<m$. Logo, $T_{m+1}, \ldots, T_{n}$ são caminhos. Seja $Z=\left\{z_{m+1}, z_{m+2}, \ldots, z_{n}\right\}$ um subconjunto de vértices do $K_{n}$. Se existe um empacotamento da sequência $T_{1}, \ldots, T_{n}$ no $K_{n}$ de maneira que, para $i=m+1, \ldots, n$, um dos extremos do caminho $T_{i}$ é mapeado ao vértice $z_{i}$, dizemos que $z_{i}$ representa o caminho $T_{i}$, e que $Z$ é um conjunto de representantes dos caminhos de maior ordem. A seguinte proposição implica o Teorema 7.

Proposição 8 (Gyárfás \& Lehel, 1976). Seja $T_{1}, T_{2}, \ldots, T_{n}$ uma sequência de árvores tal que $T_{i}$ é uma estrela ou um caminho para $i=1,2 \ldots, n$. Então, a sequência $T_{1}, T_{2}, \ldots, T_{n}$ pode ser empacotada no $K_{n}$ de forma que exista um conjunto de representantes $Z \subset V\left(K_{n}\right)$ dos caminhos de maior ordem.

Para provar a proposição anterior precisaremos do seguinte lema.

Lema 9 (Gyárfás \& Lehel, 1976). Seja $D=(V, A)$ um grafo orientado $e V^{\prime} \subset V$ um subconjunto não vazio de vértices tal que $V^{\prime}=\left\{v_{1}, \ldots, v_{m}\right\}$ e $g^{+}\left(v_{i}\right) \geqslant i$, para $i=1, \ldots, m$. Então, existe uma cobertura de $V^{\prime}$ por caminhos (em D) disjuntos nos vértices tal que, para todo caminho da cobertura, apenas o término pertence a $V \backslash V^{\prime}$.

Prova. Faremos a prova por indução em $m:=\left|V^{\prime}\right|$. Se $m=1$, basta usar o arco que sai de $v_{1}$ para obter o caminho. Agora, suponha que $m>1$ e considere o conjunto $V^{*}=V^{\prime} \backslash\left\{v_{m}\right\}$. Pela hipótese de indução, existe uma família de caminhos $\left\{P_{1}, \ldots, P_{s}\right\}$ que cobrem $V^{*}$ com as propriedades desejadas. Sejam $u_{i}$ e $w_{i}$ o início e o término, respectivamente, do caminho $P_{i}$, para $i=1,2, \ldots, s$. Distinguimos os seguintes casos.

Caso 1: $v_{m}=w_{i}$ para algum $i$.

Neste caso, note que podemos conectar dois caminhos (se $v_{m}$ é a ponta inicial de um arco incidente em algum $u_{j}, j \neq i$ ), ou podemos acrescentar um vértice de $V \backslash V^{\prime}$ ao final do caminho $P_{i}$. A seguir, verificamos que isso ocorre. Para isso, considere os conjuntos $S=\left\{u_{j}: 1 \leqslant j \leqslant s, j \neq i\right\}$, e $T=\left\{w_{j}: 1 \leqslant j \leqslant s, j \neq i\right\}$. Seja $Y=\left(V^{*} \backslash S\right) \cup T$ o conjunto dos vértices que não podem ser usados para completar a cobertura. Como $|Y|=m-1$ e $g^{+}\left(v_{m}\right) \geqslant m$, existe um arco com ponta inicial em $v_{m}$ e ponta final em $V \backslash Y$. Portanto, podemos cobrir $V^{\prime}$.

Caso 2: $v_{m} \neq w_{i}$ para todo $i$.

Neste caso, afirmamos que existe um novo caminho com início em $v_{m}$. Se existe um arco com ponta inicial em $v_{m}$ e ponta final em algum $u_{i}$ ou em algum vértice de $V \backslash V^{\prime}$, então podemos completar a cobertura. Considere os conjuntos $S=\left\{u_{j}: 1 \leqslant j \leqslant s\right\}, T=\left\{w_{j}: 1 \leqslant j \leqslant s\right\}$, e o conjunto $Y=\left(V^{*} \backslash S\right) \cup T$ dos vértices que não podem ser usados para completar a cobertura. Como $|Y|=m-1$ e $g^{+}\left(v_{m}\right) \geqslant m$, a afirmação segue. 
A seguir, apresentamos a prova da Proposição 8 obtida por Gyárfás \& Lehel. Dado um empacotamento (parcial) no $K_{n-2}$, o lema anterior é usado para estender os caminhos de maior ordem da sequência de forma a garantir a existência de um conjunto de representantes.

Prova da Proposição 8. Faremos a prova por indução em $n$. Se $n \leqslant 3$ o empacotamento é trivial. Logo, suponha que $n \geqslant 4$. Distinguimos os seguintes casos.

Caso 1: $m=n$.

Se $m=n$, notamos que $Z=\varnothing$. Pela hipótese de indução, podemos empacotar a sequência $T_{1}, T_{2}, \ldots, T_{n-1}$ no $K_{n-1}$. Para completar o empacotamento, basta adicionarmos um novo vértice e o ligarmos a todos os vértices do $K_{n-1}$. Claramente, podemos usar as arestas incidentes nesse novo vértice para empacotar a estrela $T_{n}$.

Caso 2: $m=n-1$.

Retiramos um dos extremos do caminho $T_{n}$, e consideramos o caminho $T_{n}^{\prime}$ resultante. Pela hipótese de indução, existe um empacotamento da sequência $T_{1}, \ldots, T_{n-2}, T_{n}^{\prime}$ no $K_{n-1}$. Para completar o empacotamento, adicionamos ao $K_{n-1}$ um vértice, digamos $v$, e o ligamos a todos os vértices do $K_{n-1}$. Claramente, podemos usar uma aresta incidente a $v$ para estender o empacotamento de $T_{n}^{\prime}$ (obtendo um empacotamento de $T_{n}$ ), e as $n-2$ arestas restantes para empacotar a estrela $T_{n-1}$. Note que $Z=\{v\}$.

Caso 3: $m<n-1$.

Neste caso, considere a sequência de árvores $T_{1}^{\prime}, \ldots, T_{n-2}^{\prime}$ definida da seguinte maneira

$$
T_{i}^{\prime}=\left\{\begin{array}{rc}
T_{i+2}-\left\{x_{i}, y_{i}\right\}, & m-1 \leqslant i \leqslant n-2, \\
T_{i+1}-x_{i}, & \ell \leqslant i<m-1 \\
T_{i}, & i<\ell
\end{array}\right.
$$

onde $x_{i}$ e $y_{i}$ são extremos do caminho $T_{i}$. Pela hipótese de indução existe um empacotamento da sequência $T_{1}^{\prime}, T_{2}^{\prime}, \ldots, T_{n-2}^{\prime}$ no $K_{n-2}$ e um conjunto de vértices $Z^{\prime}=\left\{z_{k+1}^{\prime}, \ldots, z_{n-2}^{\prime}\right\}$ (do $K_{n-2}$ ) tal que $z_{i}^{\prime}$ representa o caminho $T_{i}^{\prime}$ para todo $i=m+1, \ldots, n-2$. Para completar o empacotamento, adicionamos os vértices $v$ e $w$ ao $K_{n-2}$. A ideia será mapear os centros das estrelas $T_{m}$ e $T_{\ell}$ nos vértices $v$ e $w$, e adicionar arestas que tenham um extremo num vértice do $K_{n-2}$ e outro extremo em $v$ ou em $w$ para estender o empacotamento dos caminhos $T_{\ell}^{\prime}, \ldots, T_{n-2}^{\prime}$ e empacotar as estrelas $T_{\ell}$ e $T_{m}$.

Sejam $Z_{1}^{\prime}=\left\{z_{n-3}^{\prime}, z_{n-4}^{\prime}, \ldots, z_{m-1}^{\prime}\right\}$ e $Z_{2}^{\prime}=\left\{z_{n-2}^{\prime}, z_{m-2}^{\prime}, \ldots, z_{\ell}^{\prime}\right\}$. Dado um empacotamento da sequência $T_{1}^{\prime}, \ldots, T_{n-2}^{\prime}$ no $K_{n-2}$, construímos um grafo orientado $D$ tomando $V(D)=V\left(K_{n-2}\right)$ e $A(D)=\left\{z_{i}^{\prime} u: z_{i}^{\prime} \in Z_{1}^{\prime}, u \notin V\left(T_{i}^{\prime}\right)\right\}$. Note que

$$
g_{D}^{+}\left(z_{i}^{\prime}\right)=n-2-i \text { para } k<i<n-2
$$

Então, pelo Lema 9, existe em $D$ uma cobertura do conjunto $Z_{1}^{\prime}$ por caminhos disjuntos nos vértices de forma que, o término de cada caminho pertence a $V\left(K_{n-2}\right) \backslash Z_{1}^{\prime}$. Seja $\mathcal{C}$ uma tal cobertura e $P$ um caminho qualquer de $\mathcal{C}$. Denotamos por $|P|$ o número de vértices de $P$ que pertencem a $Z_{1}^{\prime}$. Vamos classificar cada caminho da seguinte maneira. 
Tipo I: $\quad$ Se o término de $P$ pertence a $Z_{2}^{\prime}$.

Tipo II: $\quad$ Se $|P|$ é par e o término de $P$ não pertence a $Z_{2}^{\prime}$.

Tipo III: Se $|P|$ é ímpar e o término de $P$ não pertence a $Z_{2}^{\prime}$.

A seguir, descrevemos como usar a cobertura $\mathcal{C}$ para estender o empacotamento dos caminhos $T_{\ell}^{\prime}, \ldots, T_{n-2}^{\prime}$ no $K_{n-2}$. Considere $P=\left\{a_{1}, a_{2}, \ldots, a_{r}\right\}$. Em primeiro lugar, suponha que $i<r$ e que $a_{i}$ representa a árvore $T_{j}^{\prime}$. Como $a_{i} \in Z_{1}^{\prime}$, precisamos de duas arestas para estender o caminho $T_{j}^{\prime}$. Logo, podemos adicionar as arestas $\left\{a_{i} v, a_{i+1} v\right\}$ ou $\left\{a_{i} w, a_{i+1} w\right\}$ para estender $T_{j}^{\prime}$ (obtendo um empacotamento de $T_{j+2}$ no $K_{n}$ ). No caso em que $i=r$, só precisamos adicionar uma aresta se $P$ é do Tipo I. Então, para estender cada caminho representado por um vértice de $P$ podemos usar os vértices $v$ e $w$ de forma alternada (veja um exemplo na Figura 3.3).

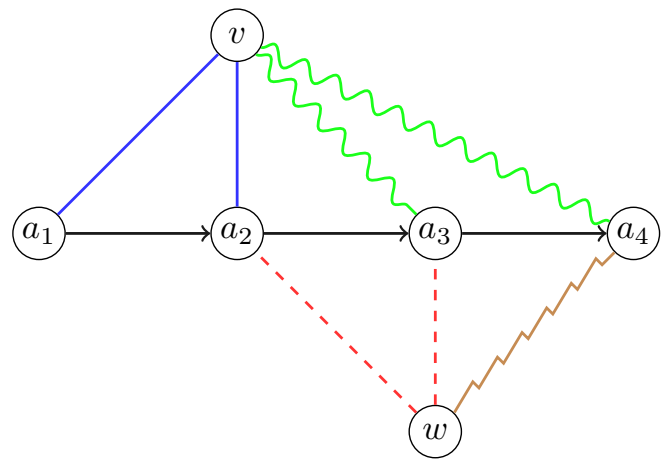

(a)

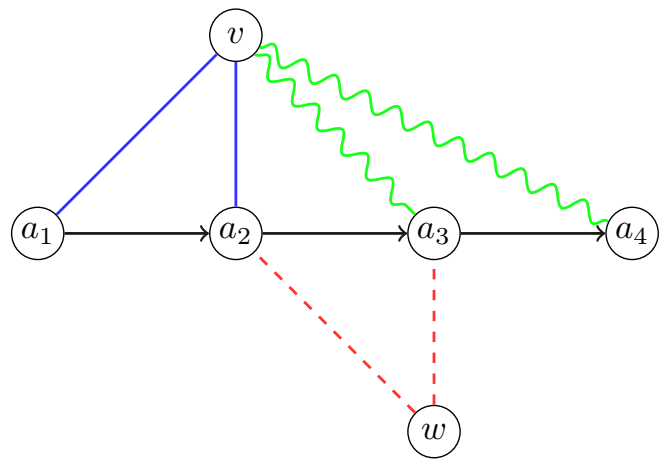

(b)

Figura 3.3: Adicionando arestas aos vértices de um caminho (a) do Tipo I e (b) do Tipo II.

Notamos que valem as seguintes propriedades ao estender todas as árvores representadas pelos vértices de um caminho $P$ da cobertura. Se $P$ é do Tipo I, adicionamos $|P|+1$ (respectivamente, $|P|$ ) arestas no vértice que usamos para estender os caminhos representados pelos vértices $a_{i}$ cujo índice é ímpar (respectivamente, par). Se $P$ é do Tipo II, adicionamos $|P|$ arestas em ambos casos. Finalmente, se $P$ é do Tipo III adicionamos $|P|+1$ e $|P|-1$ arestas, respectivamente. A seguir, exibimos um algoritmo para estender o empacotamento dos caminhos $T_{\ell}^{\prime}, \ldots, T_{n-2}^{\prime}$. No algoritmo, quando estendemos as árvores representadas pelos vértices de um caminho $P$ da cobertura, só mencionamos quantas arestas são adicionadas ao vértice $v$. Omitimos essa informação no caso do vértice $w$, já que está implícita no tipo de $P$. Por outro lado, o algoritmo garante que, o número de arestas adicionadas incidentes a $v$ e $V\left(K_{n-2}\right)$ é $\left|Z_{1}^{\prime}\right|$. Então, existem $n-2-\left|Z_{1}^{\prime}\right|=m-1$ vértices que não são adjacentes a $v\left(\right.$ no $\left.K_{n-2}\right)$. Claramente, podemos ligar $v$ a esses vértices para empacotar a estrela $T_{m}$. De forma similar podemos mapear o centro da estrela $T_{\ell}$ em $w$.

1. Escolha o maior número par de caminhos do Tipo III. Adicione $|P|-1$ e $|P|+1$ arestas incidentes a $v$ de forma alternada para estender as árvores representadas pelos vértices de $P$.

2. Se o número de caminhos do Tipo III for ímpar, seja $P^{\prime}$ o caminho que ainda não foi processado. Distingimos dois casos.

(a) Se existe $z_{i}^{\prime} \in Z_{2}^{\prime}$ que não é usado na cobertura $\mathcal{C}$, estendemos a árvore representada por $z_{i}^{\prime}$ adicionando a aresta $z_{i}^{\prime} v$. Depois, adicionamos $\left|P^{\prime}\right|-1$ arestas incidentes a $v$ para estender as árvores representadas por $V\left(P^{\prime}\right)$.

(b) Caso contrário, seja $P^{\prime \prime}$ um caminho do Tipo I (existe já que $Z_{2}^{\prime}$ é não vazio). Adiciona- 
mos $\left|P^{\prime}\right|-1$ (respectivamente, $\left|P^{\prime \prime}\right|+1$ ) arestas incidentes a $v$ para estender os caminhos com extremo nos vértices de $P^{\prime}$ (respectivamente, $P^{\prime \prime}$ ).

(c) Após os passos anteriores, só temos caminhos do Tipo I ou do Tipo II. Então, adicionamos $|P|$ arestas incidentes a $v$ para estender cada um desses caminhos.

3. Para todo $z_{i}^{\prime} \in Z_{2}^{\prime}$ tal que o caminho $T_{i}^{\prime}$ ainda não foi estendido, adicionamos a aresta $z_{i}^{\prime} w$.

4. Note que, o caminho $T_{n-2}^{\prime}$ foi estendido por uma aresta nos passos anteriores. Portanto, adicionamos a aresta $v w$ para completar o empacotamento de $T_{n-2}$.

Notamos que, no total adicionamos $\sum_{P \in \mathcal{C}}|P|=\left|Z_{1}^{\prime}\right|$ arestas incidentes a $v$ e a $V\left(K_{n-2}\right)$. Agora, vamos mostrar que o algoritmo anterior garante a existência de um conjunto de representantes. Considere $P=\left\{a_{1}, \ldots, a_{r}\right\}$. Note que, se $a_{i} \in Z_{1}^{\prime}$ é o extremo que representa o caminho $T_{j}^{\prime}$, então $a_{i+1}$ representa o caminho $T_{j+2}$ no $K_{n}$, e o caminho $T_{n}$ é representado por $v$ ou $w$. Portanto, existe um conjunto de representantes para $T_{m+1}, \ldots, T_{n}$.

\subsubsection{Prova de Zaks \& Liu}

Diferentemente da demonstração anterior, a prova de Zaks \& Liu [18] decompõe o grafo completo em dois subgrafos disjuntos nas arestas e empacota as árvores de ordem ímpar num deles e as árvores de ordem par no outro subgrafo. Os autores descrevem de forma bem sucinta a ideia da prova. Em primeiro lugar, essa decomposição é descrita em termos da matriz de adjacência do $K_{n}$ e uma desigualdade que determina o conjunto de arestas de cada subgrafo. Depois, identificam que uma estrela corresponde a um conjunto, vertical ou horizontal, de entradas consecutivas, e um caminho é uma "escada" de entradas na matriz. A seguir, apresentamos uma prova mais detalhada.

Prova do Teorema 7. Seja $V\left(K_{n}\right)=\{1,2, \ldots, n\}$. Vamos decompor o grafo $K_{n}$ em dois subgrafos, digamos $A_{n}$ e $B_{n}$, da seguinte maneira (veja na Figura 3.4 um exemplo para $K_{6}$ ). Definimos

$$
\begin{aligned}
& E\left(A_{n}\right)=\{i j: i+j \leqslant n\} \quad \mathrm{e} \\
& E\left(B_{n}\right)=\{i j: i+j>n\} .
\end{aligned}
$$

A seguir, mostramos por indução em $n$ que, se $n$ é par (respectivamente, ímpar) a sequência de árvores $T_{2}, T_{4}, \ldots, T_{n}$ (respectivamente, $T_{1}, T_{3}, \ldots, T_{n}$ ) pode ser empacotada em $B_{n}$.

Se $n=1,2$, temos que $B_{n} \cong K_{n}$. Logo, a base da indução é satisfeita. Suponha que $n>2$. Considere $F \subset E\left(B_{n}\right)$ definido da seguinte maneira

$$
F= \begin{cases}\{i n: 1 \leqslant i<n\}, & \text { se } T_{n} \text { é uma estrela } \\ \{i j: n+1 \leqslant i+j \leqslant n+2\}, & \text { se } T_{n} \text { é um caminho. }\end{cases}
$$




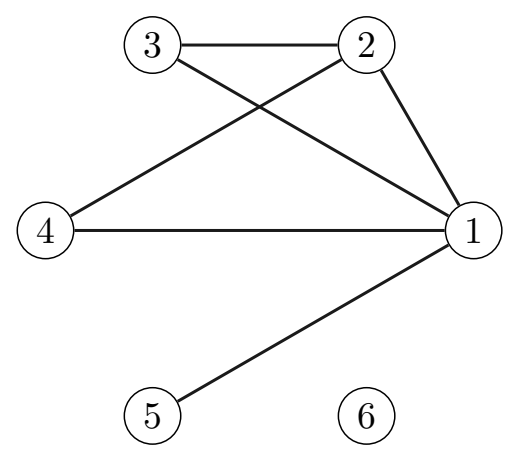

(a) $A_{6}$

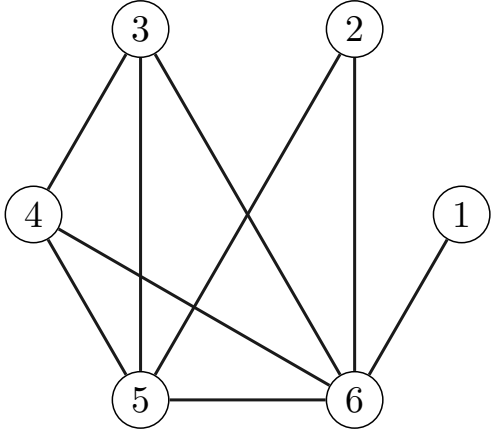

(b) $B_{6}$

Figura 3.4: Decomposição do $K_{6}$

Note que, se $T_{n}$ é um caminho, $F$ induz o caminho $P_{n}=\langle 1, n, 2, n-1, \ldots, n / 2, n / 2+1\rangle$ em $B_{n}$. No outro caso, $F$ induz a estrela $S_{n}$. Portanto, podemos empacotar $T_{n}$ em $B_{n}$. Veja na Figura 3.5 um exemplo no caso de $B_{6}$.

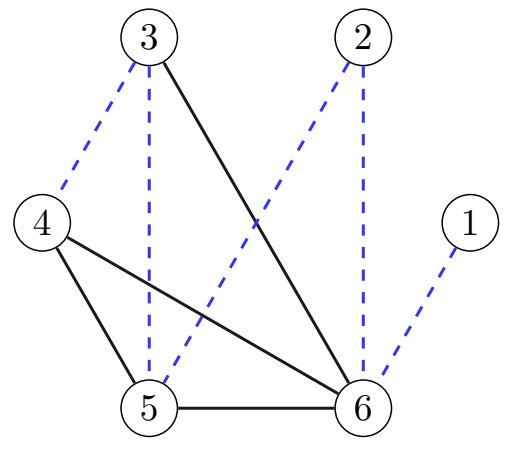

(a) Quando $T_{6}=P_{6}$

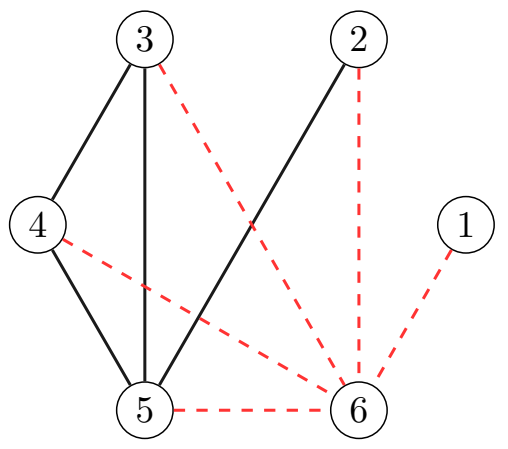

(b) Quando $T_{6}=S_{6}$

Figura 3.5: Subgrafo $F$ de $B_{6}$

Agora, vamos mostrar que $B_{n}-F$ contém um subgrafo isomorfo a $B_{n-2}$. Pela hipótese de indução, existe um empacotamento de $T_{2}, T_{4}, \ldots, T_{n-2}$ ou $T_{1}, T_{3}, \ldots, T_{n-2}$ em $B_{n}-F$ dependendo da paridade de $n$. Para mostrar o isomorfismo, vamos analisar os dois casos possíveis.

Caso 1: $T_{n}$ é uma estrela.

Seja $\phi:\{2, \ldots, n-1\} \rightarrow\{1,2, \ldots, n-2\}$, tal que $\phi(i)=i-1$. Seja $i j \in E\left(B_{n}\right)-F$ uma aresta qualquer. Como $\phi(i)+\phi(j)=i+j-2>n-2$, segue que $\phi(i) \phi(j) \in E\left(B_{n-2}\right)$. Agora, se $i j \in E\left(B_{n-2}\right)$, então $i+j>n-2$. Portanto, $\phi^{-1}(i)+\phi^{-1}(j)>n$, o que prova a afirmação.

Caso 2: $T_{n}$ é um caminho.

Seja $\phi:\{3, \ldots, n\} \rightarrow\{1, \ldots, n-2\}$, tal que $\phi(i)=i-2$. Note que

$$
E\left(B_{n}\right)-F=\{i j: i+j>n+2\}
$$

Logo, se $i j \in E\left(B_{n}\right)-F$, então $\phi(i)+\phi(j)>n-2$. De forma análoga, se $i j \in E\left(B_{n-2}\right)$, então temos $\phi^{-1}(i)+\phi^{-1}(j)>n+2$. Portanto, a função $\phi$ define um isomorfismo entre $B_{n}-F$ e $B_{n-2}$.

De forma similar mostramos que a sequência $T_{1}, T_{3}, \ldots, T_{n-1}$ (respectivamente, $T_{2}, T_{4}, \ldots, T_{n-1}$ ) pode ser empacotada em $A_{n}$ se $n$ é par (respectivamente, ímpar). Para isso, considere $F \subset E\left(B_{n}\right)$ 
definido da seguinte maneira

$$
F= \begin{cases}\{1 j: 1<j<n\}, & \text { se } T_{n-1} \text { é uma estrela, } \\ \{i j: n-1 \leqslant i+j \leqslant n\}, & \text { se } T_{n-1} \text { é um caminho. }\end{cases}
$$

Para mostrar que $A_{n}-F$ contém um subgrafo isomorfo a $A_{n-2}$ consideramos a função

$$
\phi(i)= \begin{cases}i-1, & \text { se } T_{n-1} \text { é uma estrela } \\ i, & \text { se } T_{n-1} \text { é um caminho. }\end{cases}
$$

A prova é simétrica ao caso anterior, por isso a omitimos.

Notamos que a demonstração anterior nos leva a pensar na seguinte pergunta, cuja resposta, se positiva, implicaria a conjectura de Gyárfás \& Lehel: é possivel empacotar $T_{n}$ (respectivamente, $T_{n-1}$ ) e $B_{n}$ (respectivamente, $A_{n}$ ) em $B_{n+2}$ (respectivamente, $A_{n+2}$ )? Na seção seguinte mostraremos que a resposta para a pergunta anterior é negativa. Porém, veremos como caracterizar os grafos $A_{n}$ e $B_{n}$ segundo a sua sequência de graus, e como generalizar o resultado anterior incluindo outras classes de árvores.

\subsection{Lagartas e aranhas}

Nas seções anteriores vimos como empacotar uma sequência de estrelas e biestrelas ou uma sequência de estrelas e caminhos no $K_{n}$. Nesta seção mostramos como empacotar classes mais gerais de árvores. Quando Zaks \& Liu [18] mostraram como empacotar uma sequência de estrelas e caminhos, eles dividiram a sequência original em duas sequências menores, uma composta pelas árvores de ordem ímpar e outra composta pelas árvores de ordem par. Depois, exibiram uma decomposição do grafo $K_{n}$ em dois subgrafos tais que a sequência de árvores de ordem ímpar pode ser empacotada num desses subgrafos e a sequência de árvores de ordem par pode ser empacotada no outro subgrafo. Notamos que essa ideia é similar à usada para mostrar a Asserção 1 (que veremos na Seção 3.5) onde consideramos separadamente as sequências de índice ímpar e as sequências de índice par para conseguir uma matriz com a propriedade desejada. É por isso que Fishburn [11] aplica essa mesma ideia no caso da conjectura de Gyárfás \& Lehel. Fishburn [11] consegue melhorar o resultado obtido por Zaks \& Liu e Gyárfás \& Lehel, logrando empacotar classes de árvores que incluem as estrelas, biestrelas e caminhos. Além disso, o autor mostra uma classe de árvores onde a mesma técnica não pode ser usada.

Em primeiro lugar, exibimos uma família de grafos $H_{n}$ tais que para todo $n \geqslant 2, H_{n-1}$ e $H_{n}$ definem uma decomposição do $K_{n}$. Para $k \geqslant 1, H_{2 k}$ denota o grafo de ordem $2 k$ com sequência de graus $(2 k-1,2 k-2, \ldots, k, k, k-1, \ldots, 1)$. De forma similar, $H_{2 k+1}$ é um grafo de ordem $2 k+1$ e sequência de graus $(2 k, 2 k-1, \ldots, k, k, k-1, \ldots, 1)$. Notamos que os grafos $H_{2 k}$ e $H_{2 k+1}$ são únicos a menos de isomorfismo. Para o caso de $H_{2 k}$, considere $V\left(H_{2 k}\right)=\left\{b_{1}, \ldots b_{k}, a_{1}, \ldots, a_{k}\right\}$ e $E\left(H_{2 k}\right)=\left\{b_{i} b_{j}: 1 \leqslant i<j \leqslant k\right\} \cup\left\{b_{i} a_{j}: i \leqslant j\right\}$. Então

$$
\begin{array}{ll}
g\left(b_{i}\right)=2 k-i, & i=1,2, \ldots, k, \\
g\left(a_{i}\right)=i, & i=1,2, \ldots, k .
\end{array}
$$

Para o caso de $H_{2 k+1}$, a construção é análoga. A única diferença é que adicionamos um novo 
vértice $a_{n+1}$ e o ligamos a cada vértice $b_{i}$. Veja na Figura 3.6 os grafos de $H_{6}$ e $H_{7}$.

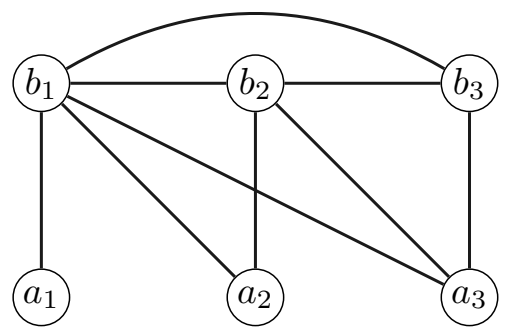

(a) $H_{6}$.

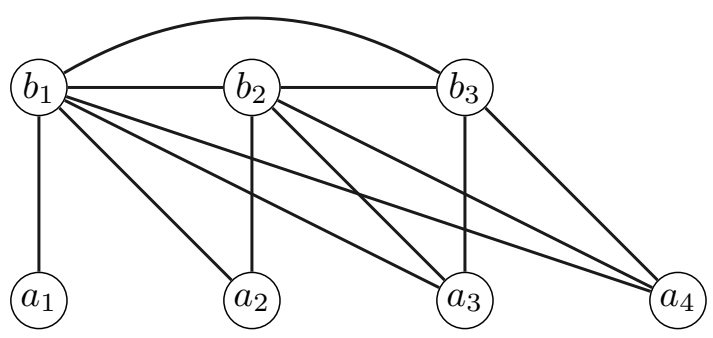

(b) $H_{7}$.

Figura 3.6: Grafos $H_{2 k}$ e $H_{2 k+1}$ para $k=3$.

Agora, mostraremos que $H_{2 k}$ e $H_{2 k+1}$ definem uma decomposição do $K_{2 k+1}$. Sejam

$$
\begin{aligned}
V\left(H_{2 k}\right) & =\left\{b_{1}^{\prime}, \ldots, b_{k}^{\prime}, a_{1}^{\prime}, \ldots, a_{k}^{\prime}\right\} \\
V\left(H_{2 k+1}\right) & =\left\{b_{1}, \ldots, b_{k}, a_{1}, \ldots, a_{k}, a_{k+1}\right\} .
\end{aligned}
$$

Considere a seguinte função $\phi: V\left(H_{2 k}\right) \rightarrow V\left(H_{2 k+1}\right)$,

$$
\phi(x)= \begin{cases}a_{i}, & \text { se } x=b_{i}^{\prime}, \\ a_{k+1}, & \text { se } x=a_{k}^{\prime}, \\ b_{i+1}, & \text { se } x=a_{i}^{\prime}, i<k\end{cases}
$$

Notamos que, ao sobrepor o grafo $H_{2 k}$ sobre $H_{2 k+1}$ usando a função $\phi$, cada vértice de $H_{2 k+1}$ fica com grau $2 n$. Portanto, o grafo resultante é isomorfo ao $K_{2 k+1}$. De forma semelhante podemos mostrar que $H_{2 k-1}$ e $H_{2 k}$ definem uma decomposição do $K_{2 k}$.

Por outro lado, o grafo $H_{n}$ é isomorfo ao grafo $B_{n}$ (visto na Seção 3.2.2). Para mostrar isso, sem perda de generalidade, suponha que $n$ é ímpar. Notemos que, em $B_{n}$, os vértices $n, n-1, \ldots,(n+1) / 2$ têm grau $n-1, n-2, \ldots,(n-1) / 2$, respectivamente, e os vértices restantes $(n-1) / 2, \ldots, 1$ têm grau $(n-1) / 2, \ldots, 1$, respectivamente. Portanto, $B_{n}$ tem a mesma sequência de graus que $H_{n}$. Além disso, notamos que para todo $n>1$ o grafo $A_{n}$ (sem considerar vértices isolados) é isomorfo a $B_{n-1}$. Essa afirmação segue considerando-se a sequência de graus de $B_{n}$ e o fato que $A_{n}$ é o complemento de $B_{n}$. Portanto, podemos considerar o resultado principal desta seção como uma extensão da prova de Zacks \& Liu para o Teorema 7.

Agora, definimos as classes de árvores que serão objeto de nosso interesse nesta seção. Seja $T$ uma lagarta. Uma lagarta de diâmetro 4 será chamada de triestrela. Notamos que uma triestrela tem exatamente três vértices de grau maior do que 1. Além disso, um desses vértices, que chamamos de centro, é adjacente aos outros dois vértices não-folhas (que são os vértices penúltimos de $T$ ). Se $T$ é uma triestrela, dizemos que $T$ é unimodal se o grau do centro de $T$ é maior ou igual ao grau de algum vértice penúltimo de $T$. 


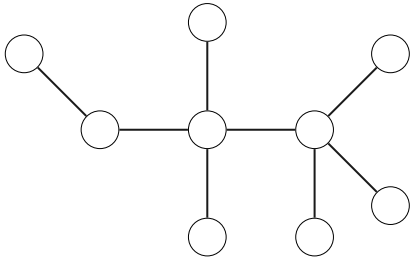

(a) Triestrela unimodal.

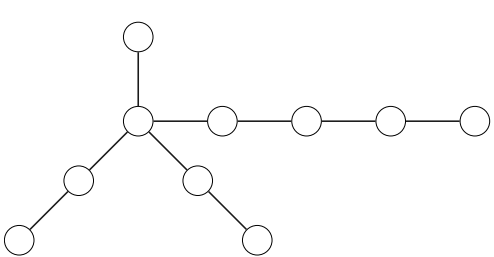

(b) Escorpião.

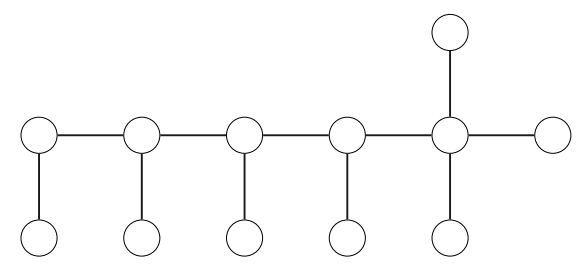

(c) Lagarta 3-interior.

Figura 3.7: Exemplos de lagartas e escorpião.

Dizemos que uma lagarta é 3-interior se tem diâmetro pelo menos 4, pelo menos um vértice penúltimo tem grau 2, e os vértices interiores têm grau exatamente três. Um escorpião é uma aranha onde no máximo uma das suas pernas tem comprimento maior que 2. A seguir, apresentamos o teorema mais importante desta seção. Ele garante o empacotamento de um subconjunto de lagartas e aranhas no $K_{n}$.

Teorema 10 (Fishburn, 1983). Para $n \geqslant 2$, se $T_{n+2}$ é um caminho, ou uma estrela, ou uma biestrela, ou uma triestrela unimodal, ou uma lagarta 3 -interior ou um escorpião, então $H_{n}$ e $T_{n+2}$ podem ser empacotados em $H_{n+2}$.

Prova. Omitimos os casos em que $T_{n+2}$ é uma estrela ou um caminho, já que a prova é análoga à obtida por Zaks \& Liu para o Teorema 7. Faremos a prova apenas para o caso em que $n$ é par. Quando $n$ é ímpar, a prova é similar. Seja $k$ um inteiro tal que $n=2 k$. Considere o conjunto de vértices $V\left(H_{2 k}\right)=\left\{b_{1}, \ldots, b_{k}, a_{1}, \ldots, a_{k}\right\}$. Vamos definir $H$, um supergrafo de $H_{2 k}$, de forma que o conjunto de arestas adicionadas ao grafo $H_{2 k}$ (para obter $H$ ) induza a árvore $T_{2 k+2}$ e $H \cong H_{2 k+2}$. Considere $V(H)=V\left(H_{2 k}\right) \cup\{v, w\}$. Distinguimos os seguintes casos.

Caso 1: $T_{2 k+2}$ é uma biestrela.

Sejam $x$ e $y$ os centros da biestrela $T_{2 k+2}$. Seja $r$ (respectivamente, $s$ ) o grau de $x$ (respectivamente, $y$ ) em $T_{2 k+2}$. Suponha que $r \leqslant s$. A ideia será mapear o vértice $x$ no vértice $b_{r-1}$ e o vértice $y$ no vértice $w$. Em primeiro lugar, adicionamos as arestas $\left\{b_{r-1} a_{j}: 1 \leqslant j \leqslant r-2\right\}$ e $\left\{b_{r-1} v, b_{r-1} w\right\}$ para mapear as arestas incidentes a $x$ em $T_{2 k+2}$. Note que, se consideramos o subgrafo induzido pelas arestas adicionadas, existem $2 k+1-r=s-1$ vértices não adjacentes a $b_{r-1} \mathrm{em} H$. Então, ligamos o vértice $w$ a cada um desses $s-1$ vértices para terminar o empacotamento da biestrela $T_{2 k+2}$.

Seja $V\left(H_{2 k+2}\right)=\left\{b_{1}^{\prime}, \ldots, b_{k+1}^{\prime}, a_{1}^{\prime}, \ldots, a_{k+1}^{\prime}\right\}$. Considere a função $\phi: V(H) \rightarrow V\left(H_{2 k+2}\right)$ definida da seguinte maneira:

$$
\phi(u)= \begin{cases}a_{1}^{\prime}, & \text { se } u=v, \\ a_{i+1}^{\prime}, & \text { se } u=a_{i}, \\ b_{i+1}^{\prime}, & \text { se } u=b_{i}, i \neq r-1, \\ b_{1}^{\prime}, & \text { se } u=b_{r-1}, \\ b_{r}^{\prime}, & \text { se } u=w .\end{cases}
$$


Notamos que $\phi$ define um isomorfismo entre $H$ e $H_{2 k}$. Veja na Figura 3.8 um exemplo de empacotamento de $H_{4}$ e uma biestrela em $H_{6}$.

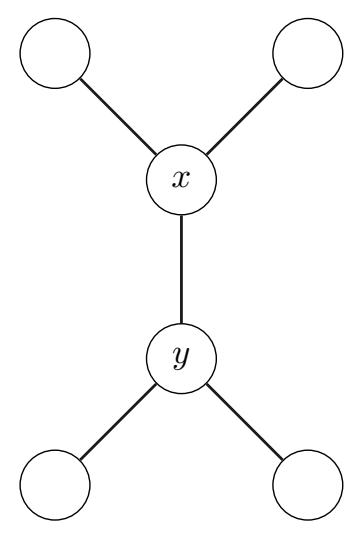

(a) $T_{6}$.

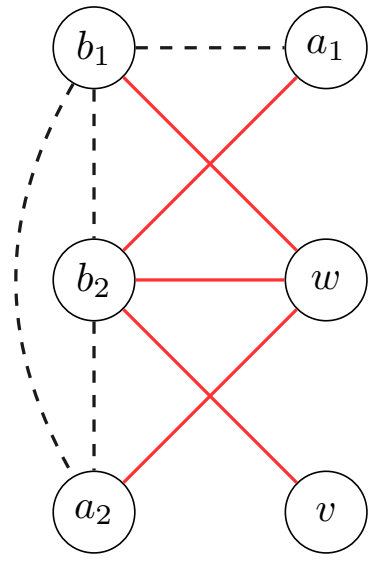

(b) $H_{6}$.

Figura 3.8: Empacotamento de uma biestrela em $H_{6}$.

Caso 2: $T_{2 k+2}$ é uma triestrela unimodal.

Seja $x$ o centro e $y, z$ os vértices penúltimos de $T_{2 k+2}$. Sejam $r, s$ e $t$ os graus, em $T_{2 k+2}$, dos vértices $y, x$ e $z$, respectivamente. Além disso, suponha que $r \leqslant s$ e $r \leqslant t$. A ideia será mapear $y$ no vértice $b_{r-1}, x$ no vértice $w$, e o vértice $z$ num vértice de $H_{2 k}$. Em primeiro lugar, adicionamos as arestas $\left\{b_{r-1} a_{j}: 1 \leqslant j \leqslant r-2\right\}$ e $\left\{b_{r-1} v, b_{r-1} w\right\}$ para mapear as arestas incidentes a $y$.

Para mapear as arestas incidentes ao vértice $x$ em $T_{2 k+2}$, começamos adicionando as arestas $\left\{b_{1} w, \ldots, b_{r-2} w\right\}$. Antes de completar o mapeamento das arestas incidentes a $x$, mapeamos as arestas incidentes ao vértice $z$. Seja $u \in V\left(H_{2 k}\right)$ tal que $g_{H_{2 k}}(u)=r-1$. Note que $g\left(a_{r-1}\right) \leqslant s-1$ e $g\left(b_{r}\right) \geqslant s-1$. Logo, $u \in\left\{b_{r}, \ldots, b_{k}, a_{r-1}, \ldots, a_{k}\right\}$. Além disso, o número de vértices de $H_{2 k}$ aos quais podemos ligar o vértice $u$ adicionando uma aresta é $(2 k-1)-(r-2)-(s-1)=t-1$. Então, ligamos $u$ a esses vértices e adicionamos a aresta $u v$ para completar o mapeamento das arestas incidentes a $z$ (em $T_{2 k+2}$ ). Finalmente, ligamos $w$ a todo vértice de $H_{2 k}$ que ainda não foi usado no empacotamento da triestrela $T_{2 k+2}$.

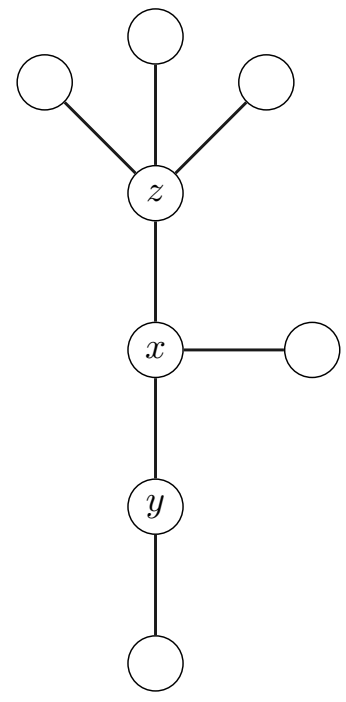

(a) $T_{8}$.

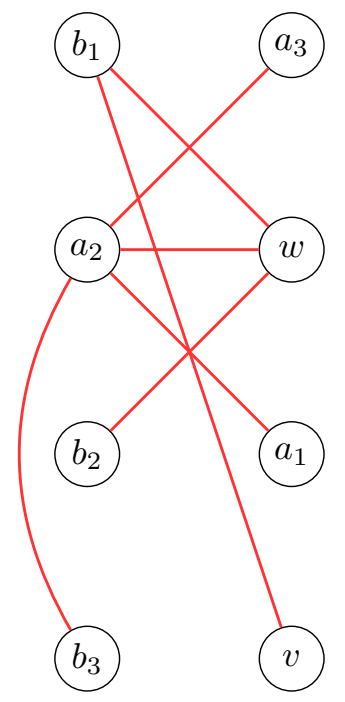

(b) $H_{8}$.

Figura 3.9: Empacotamento de uma triestrela em $H_{8}$. 
Agora, mostramos que $H$ é isomorfo a $H_{2 k+2}$. Em primeiro lugar, os vértices $v$ e $w$ têm grau 1 e $r$, respectivamente. Em $H$, os vértices $a_{1}, \ldots, a_{r-2}$ têm grau $2, \ldots, r-1$, respectivamente, já que foi adicionada exatamente uma aresta incidente em cada um desses vértices. De forma análoga, os vértices $b_{s}, \ldots, b_{k}$ têm grau $2 k-r+3, \ldots, 2 k$, respectivamente. O vértice $b_{r-1}$ tem grau $2 k+1$ e o vértice $u$ tem grau $2 k-r+2$. Finalmente, os outros vértices de $H_{2 k}$ completam a sequência de graus $2 k-r+1,2 k-r, \ldots, s$, com $k+1$ repetido uma vez se $r \neq k+1$.

Caso 3: $T_{2 k+2}$ é um lagarta 3-interior.

Seja $m$ o número de vértices interiores de $T_{2 k+2}$. Suponha que $m>1$ (se $m=1, T_{n+2}$ é uma triestrela unimodal). A seguir tratamos o caso em que $m$ é par. Omitimos o caso de $m$ ímpar já que é similar. Sejam $y$ e $z$ os vértices penúltimos de $T_{2 k+2}$. Suponha que $y$ tem grau 2. Em primeiro lugar, mapeamos y a $b_{1}$. Para isso, adicionamos as arestas $b_{1} v$ e $b_{1} w$. Seja $\left\{x_{1}, \ldots, x_{m}\right\}$ o conjunto de vértices interiores de $T_{n+2}$. Para empacotar esses vértices, começamos mapeando o vértice $x_{1}$ a $w$. Adicionamos as arestas $b_{2} w$ e $b_{3} w$ para mapear as arestas incidentes a $x_{1}\left(\mathrm{em} T_{2 k+2}\right)$. Depois, para $r=1,2, \ldots, m / 2$, mapeamos o vértice $x_{2 r}$ no vértice $b_{2 r+1}$. Para isso, adicionamos as arestas $\left\{b_{2 r+1} a_{2 r-1}, b_{2 r} a_{2 r}\right\}$. Para terminar o mapeamento dos vértices interiores de $T_{2 k+2}$, mapeamos o vértice $x_{2 r+1}$ no vértice $a_{2 r}$ adicionando as arestas $\left\{a_{2 r} b_{2 r+1}, a_{2 r} b_{2 r+2}\right\}$, para $r=1, \ldots, m / 2-1$. Para completar o empacotamento de $T_{2 k+2}$, mapeamos $z$ no vértice $a_{m}$. Para isso, ligamos $a_{m}$ a todo vértice de $H_{2 k}$ que ainda não foi usado no empacotamento. Veja na Figura 3.10 um empacotamento de uma lagarta 3 -interior de ordem 10 (omitimos as arestas de $H_{8}$ ).

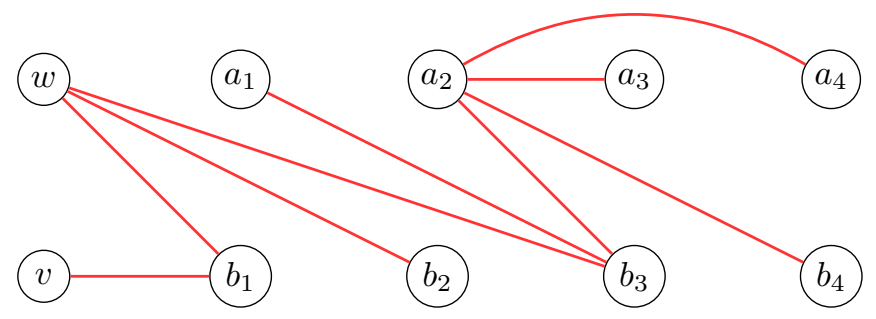

Figura 3.10: Empacotando uma lagarta 3-interior em $H_{10}$.

Para mostrar que $H$ é isomorfo a $H_{2 k+2}$, notamos que os vértices $v$ e $w$ têm grau 1 e 3 , respectivamente. Em $H$, os vértices $a_{1}, a_{3}, \ldots, a_{m-1}$ têm grau $2,4, \ldots, m$, respectivamente. Além disso, os vértices $a_{2}, a_{4}, \ldots, a_{m-2}$ têm grau $5,7, \ldots, m+1$, respectivamente. Por último, os vértices $a_{m+1}, \ldots, a_{k}$ têm grau $m+2, \ldots, k+1$, respectivamente. Com isso, descrevemos os vértices em $H$ com sequência de graus $k+1, k, \ldots, 1$. De forma semelhante, podemos mostrar que, em $H$, os graus dos vértices $b_{1}, \ldots, b_{k}, a_{m}$ são $2 k+1,2 k, \ldots, k+1$ (não necessariamente nessa ordem).

Caso 4: $T_{2 k+2}$ é um escorpião.

Seja $m$ o comprimento de uma perna mais longa de $T_{2 k+2}$. A seguir, tratamos o caso quando $m$ é par. Omitimos o caso de $m$ ímpar já que é similar. Para mapear essa perna, adicionamos o conjunto de arestas induzido pela seguinte sequência de vértices

$$
v, w, a_{1}, b_{1}, a_{2}, b_{2}, \ldots, b_{m / 2-2}, a_{m / 2-1}
$$

Notamos que, se $m=2$ a junção do escorpião $T_{2 k+2}$ é mapeada no vértice $w$ ou, no vértice $a_{m / 2-1}$, caso contrário. Sem perda de generalidade, suponha que $m>2$. Seja $r$ o número de pernas de $T_{2 k+2}$ que têm comprimento dois. Para mapear essas pernas em $H$, adicionamos a $H_{2 k}$ as ares- 
tas $\left\{a_{m / 2-1} b_{m / 2+j}, b_{m / 2+j} a_{m / 2+j}: 0 \leqslant j \leqslant r-1\right\}$. Para terminar o empacotamento do escorpião, ligamos o vértice $a_{m-2 / 2}$ a todo vértice de $H_{2 k}$ que ainda não foi usado no empacotamento. Veja na Figura 3.11 um empacotamento de um escorpião de ordem 10 (omitimos as arestas de $H_{8}$ )

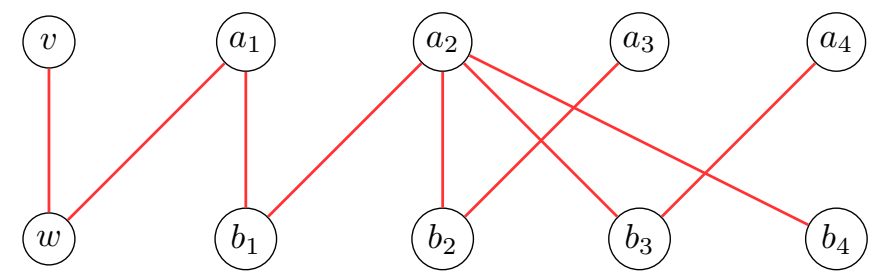

Figura 3.11: Empacotando um escorpião em $H_{10}$.

Para mostrar que $H$ é isomorfo a $H_{2 k+2}$, notamos que os vértices $v$ e $w$ têm grau 1 e 2 , respectivamente. Em $H$, os vértices $a_{1}, a_{2}, \ldots, a_{m / 2-2}$ têm grau $3,4, \ldots, m / 2$, respectivamente, já que foram adicionadas duas arestas incidentes em cada um desses vértices. De forma semelhante, os vértices $a_{m / 2}, \ldots, a_{k}$ têm grau $m / 2+1, \ldots, k+1$, respectivamente. Finalmente, em $H$, os graus dos vértices $b_{k}, \ldots, b_{1}$ e $a_{m / 2-1}$ são $2 k+1,2 k, \ldots, k+1$ (não necessariamente nessa ordem)..

O corolário a seguir é consequência imediata do lema anterior.

Corolário 11 (Fishburn, 1983). Seja $T_{2}, T_{3}, \ldots, T_{n}$ uma sequência de árvores. Se cada $T_{i}$ é um caminho, ou uma estrela, ou uma biestrela, ou uma triestrela unimodal, ou uma lagarta 3-interior ou um escorpião, então tal sequência pode ser empacotada no $K_{n}$.

Prova. Sem perda de generalidade, suponha que $n$ é par. Pelo teorema anterior a sequência de árvores $T_{1}, T_{3}, \ldots, T_{n-1}$ pode ser empacotada em $H_{n-1}$. Da mesma forma, a sequência de árvores $T_{2}, T_{4}, \ldots, T_{n}$ pode ser empacotada em $H_{n}$. Como $H_{n-1}$ e $H_{n}$ definem uma decomposição do $K_{n}$, o resultado segue.

Por outro lado, Fishburn [10] mostrou uma classe de árvores com as quais não podemos usar a mesma técnica.

Teorema 12 (Fishburn, 1983). Se $T_{n+2}$ é uma triestrela não-unimodal, então $H_{n}$ e $T_{n+2}$ não podem ser empacotados em $\mathrm{H}_{n+2}$.

Prova. Seja $x$ o centro e $y, z$ os vértices penúltimos da triestrela $T_{n+2}$. Sejam $r, s$ e $t$ os graus de $x, y$ e $z$, respectivamente. Como $T_{n+2}$ não é unimodal, temos que $r<\min \{s, t\}$ e $r<n / 2$. Suponha por contradição que $T_{n+2}$ e $H_{n}$ podem ser empacotados em $H_{n+2}$. Notemos que qualquer empacotamento deve satisfazer as seguintes propriedades.

(i) Exatamente um dos vértices $x, y, z$ é mapeado num dos vértices novos adicionado a $H_{n}$.

(ii) Um dos outros dois vértices (não usados em (i)) deve ser mapeado num vértice de $H_{n}$, de forma que o grau desse vértice seja $n+1$ em $H_{n+2}$.

(iii) $\mathrm{O}$ vértice novo que não foi usado em (i) deve ter grau $1 \mathrm{em} H_{n+2}$.

Note que, se mapeamos $x, y$ e $z$ em três vértices distintos de $H_{n}$, duas folhas de $T_{n+2}$ serão mapeadas aos vértices novos adicionados a $H_{n}$. Logo, a sequência de graus do grafo resultante terá dois elementos iguais a 1, uma contradição. Por outro lado, se mapeamos quaisquer dois vértices, entre $x, y$ e $z$, aos dois vértices novos adicionados a $H_{n}$, todas as folhas de $T_{n+2}$ serão mapeadas a vértices de $H_{n}$. Portanto, no grafo resultante nenhum vértice terá grau 1. Então, a condição (i) 
é necessária em qualquer empacotamento de $H_{n}$ e $T_{n+2}$ em $H_{n+2}$. Para mostrar que (ii) também é necessário, note que, se só mapeamos folhas de $T_{n+2}$ nos vértices de $H_{n}$, nenhum vértice poderá atingir grau $n+1$, já que todo vértice terá grau no máximo $n$. Finalmente, (iii) segue do fato que, após o empacotamento, todo vértice de $H_{n}$ tem seu grau incrementado. Logo, precisamos garantir a existência de um vértice de grau 1. Baseado nas propriedades (i), (ii), e (iii), distinguimos os seguintes casos.

Caso 1: $x$ é mapeado num vértice novo.

Sem perda de generalidade, suponha que mapeamos $y$ a um vértice de $H_{n}$, digamos $u$, de forma que o grau de $u$, após o empacotamento, é $n+1$. Como $r<s$, segue que $u \notin\left\{b_{1}, \ldots, b_{r-1}\right\}$. Então, $u$ não é adjacente a $a_{r-1} \mathrm{em} H_{n}$. Por (iii), segue que uma das folhas adjacentes a $y$ em $T_{n+2}$ deve ser mapeada num vértice novo adicionado a $H_{n}$. Logo, precisamos de $s-2$ vértices de $H_{n}$ para mapear as demais folhas adjacentes a $y$ em $T_{n+2}$. Como $g_{H_{n}}(u)=n-s+1$, existe exatamente $s-2$ vértices não adjacentes a $u \mathrm{em} H_{n}$. Portanto, o vértice $a_{r-1}$ (não adjacente a $u \mathrm{em} H_{n}$ ) deve ser usado para mapear uma das folhas adjacente a $y$ em $T_{n+2}$. Porém, isso implica que o grafo resultante tem dois vértices de grau $r<n / 2$, uma contradição.

Caso 2: $y$ é mapeado num vértice novo.

Neste caso, o vértice $x$ é mapeado a um vértice de $H_{n}$, digamos $u$, de forma que o grau de $u$ em $H_{n+2}$ é $n+1$. Caso contrário, o vértice $z$ seria mapeado num vértice de $H_{n}$. Porém, como y e $z$ não são adjacentes em $T_{n+2}$, não é possível atingir o grau $n+1$. Então, o vértice $x$ deve ser mapeado no vértice $b_{r-1}$. Por (iii), uma folha de $T_{n+2}$ deve ser mapeada num vértice novo adicionado a $H_{n}$. Como $b_{r-1}$ (o vértice onde mapeamos $x$ ) tem grau $n+1$ em $H_{n+2}$, a folha que foi mapeada no vértice novo deve ser adjacente a $x$ em $T_{n+2}$ (segue que $r \geqslant 3$ ). Notamos que as outras $r-3$ folhas adjacentes a $x$ devem ser mapeadas nos vértices $\left\{a_{1}, a_{2}, \ldots, a_{r-2}\right\}$. Portanto, o vértice $z$ deve ser mapeado a um vértice $a_{j}, j \in\{1, \ldots, r-2\}$. Mas, isso implica que ao completar o empacotamento não temos um vértice com grau $j+1$, já que $z$ não é folha de $T_{n+2}$. Uma contradição.

O caso em que $z$ é mapeado num vértice novo é análogo ao caso anterior. Portanto, o resultado segue.

\subsection{Limitando o tamanho da sequência}

Quando não impomos nenhuma condição sobre as árvores a serem empacotadas, outra forma de procurar uma resposta afirmativa é restringir o número de árvores que se deseja empacotar. Neste sentido, o melhor limite superior foi obtido por Bollobás [1]. A ideia da prova é empacotar cada árvore $T_{i}$ num subgrafo com grau mínimo pelo menos $i-1$. Note que qualquer árvore de ordem $i$ pode ser empacotada em tal subgrafo.

A seguir mostramos um limite inferior para o número de arestas de um grafo $G$ que garante a existência de um subgrafo $H \operatorname{com} \delta(H) \geqslant r$.

Proposição 13. Seja $G$ um grafo de ordem $n>r$. Se

$$
|E(G)| \geqslant\left(\begin{array}{l}
r \\
2
\end{array}\right)+(r-1)(n-r)+1
$$

então $G$ contém um subgrafo $H$ tal que $\delta(H) \geqslant r$. 
Prova. Por indução em $n$. Se $n=r+1$ segue que

$$
|E(G)| \geqslant\left(\begin{array}{l}
r \\
2
\end{array}\right)+(r-1)+1=\left(\begin{array}{c}
r+1 \\
2
\end{array}\right) .
$$

Logo, $G \cong K_{r+1}$ e a base da indução é satisfeita.

Considere $n>r+1$. Claramente, se $\delta(G) \geqslant r$ a afirmação é válida trivialmente. Portanto, suponha que $\delta(G) \leqslant r-1$ e seja $v \in V(G)$ tal que $g(v)=\delta(G)$. Considere o grafo $G^{\prime}=G-v$. Segue que,

$$
\begin{aligned}
\left|E\left(G^{\prime}\right)\right| & \geqslant\left(\begin{array}{l}
r \\
2
\end{array}\right)+(r-1)(n-r)+1-\delta(G) \\
& \geqslant\left(\begin{array}{l}
r \\
2
\end{array}\right)+(r-1)(n-r)+1-(r-1) \\
& =\left(\begin{array}{l}
r \\
2
\end{array}\right)+(r-1)(n-1-r)+1 .
\end{aligned}
$$

Logo, como $G^{\prime}$ tem ordem $n-1$, pela hipótese de indução, o grafo $G^{\prime}$ contém um subgrafo $H$ tal que $\delta(H) \geqslant r$. Como $H$ é subgrafo de $G$ o resultado segue.

Note que a prova anterior não fornece uma maneira de achar um tal subgrafo $H$. Observamos que um algoritmo para encontrar um subgrafo com grau mínimo pelo menos $r$ consiste em remover, um a um, vértices que têm grau menor do que $r$. Pode-se mostrar por contradição que esse processo termina com um grafo não-vazio.

Observamos que, o limite inferior dado pela Proposição 13 é justo, no sentido que existem grafos com $\left(\begin{array}{l}r \\ 2\end{array}\right)+(r-1)(n-r)$ arestas que não contêm um subgrafo com grau mínimo $r$. Para mostrar isso, considere a união do grafo $K_{r}$ e $\bar{K}_{n-r}$, e para cada vértice de $\bar{K}_{n-r}$ o ligamos arbitrariamente a $r-1$ vértices do $K_{r}$. O grafo resultante tem o número de arestas desejado, porém ele não contém um subgrafo com grau mínimo $r$. Veja na Figura 3.12 um exemplo para $n=5$ e $r=3$.

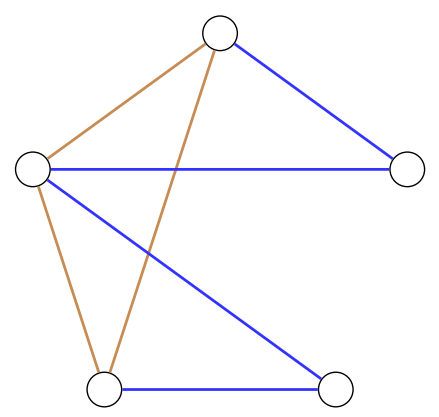

Figura 3.12: Grafo que não contém um subgrafo $H$ tal que $\delta(H) \geqslant 3$.

Teorema 14 (Bollobás, 1983). Sejam s e $n$ inteiros positivos e $T_{1}, \ldots, T_{n}$ uma sequência de árvores. Se $3 \leqslant s \leqslant \frac{\sqrt{2}}{2}$, então um empacotamento de $T_{k+1}, T_{k+2}, \ldots, T_{s}$ no $K_{n}$ pode ser estendido a um empacotamento de $T_{k}, T_{k+1}, \ldots, T_{s}$ no $K_{n}$, para todo $k, 1 \leqslant k \leqslant s$.

Prova. Suponha que exista um empacotamento de $T_{k+1}, T_{k+2}, \ldots, T_{s}$ no $K_{n}$. Seja $G$ o grafo obtido 
ao retirar do $K_{n}$ as arestas usadas no empacotamento da sequência $T_{k+1}, T_{k+2}, \ldots, T_{s}$. Note que

$$
\begin{aligned}
|E(G)| & =\left(\begin{array}{l}
n \\
2
\end{array}\right)-\sum_{i=k+1}^{s}(i-1) \\
& =\frac{1}{2}(n(n-1)-(s-k)(s-k-1)) .
\end{aligned}
$$

A seguir, mostramos que $|E(G)|>\left(\begin{array}{c}k-1 \\ 2\end{array}\right)+(k-2)(n-k+1)$ e, portanto, o grafo $G$ contém um subgrafo $G^{\prime}$ tal que $\delta\left(G^{\prime}\right) \geqslant k-1$. Suponha, por contradição, que essa afirmação seja falsa. Nesse caso,

$$
|E(G)| \leqslant\left(\begin{array}{c}
k-1 \\
2
\end{array}\right)+(k-2)(n-k+1)
$$

Das duas relações anteriores segue que

$$
2(n-k+2)^{2}-\frac{(n+2)^{2}}{2}+n^{2}+3 n-s^{2}+s \leqslant 0,
$$

ou seja,

$$
2(n-k+2)^{2} \leqslant \frac{(n+2)^{2}}{2}-\left(n^{2}+3 n-s^{2}+s\right) .
$$

Porém, se $3 \leqslant s \leqslant \frac{\sqrt{2}}{2} n$, então $(n+2)^{2} / 2<\left(n^{2}+3 n-s^{2}+s\right)$. Como $(n-k+2)^{2} \geqslant 0$, temos uma contradição. Logo, $G$ contém um subgrafo $G^{\prime}$ tal que $\delta\left(G^{\prime}\right) \geqslant k-1$. Portanto, podemos empaco$\operatorname{tar} T_{k}$ em $G$, e o resultado segue.

Do teorema anterior segue imediatamente o seguinte resultado.

Corolário 15 (Bollobás, 1983). Qualquer sequência de árvores $T_{1}, \ldots, T_{s}$ pode ser empacotada no $K_{n}$ se $s \leqslant\lfloor n / \sqrt{2}\rfloor$.

É importante notar que o resultado anterior depende do limite inferior no número de arestas dado pela Proposição 13. Porém, essa restrição é mais forte do que o necessário, no sentido que ela garante mais do que a existência de qualquer árvore de ordem $k$. A respeito dessa questão, Erdôs \& Sós [9] conjeturaram que um grafo de ordem $n$ e mais do que $n(r-2) / 2$ arestas contém qualquer árvore de ordem $r$, onde $r \leqslant n$. Note que esse limite inferior é justo. Para mostrar isso, suponha sem perda de generalidade, que $n$ é múltiplo de $r-1$ e considere a união de $n /(r-1)$ cópias do $K_{r-1}$. Claramente, esse grafo tem $n(r-2) / 2$ arestas, mas não contém nenhuma árvore de ordem $r$. De todo modo, supondo que essa conjectura seja verdadeira, e usando o mesma técnica da prova do Teorema 15 podemos obter a seguinte desigualdade

$$
(n+1-2 k)^{2}+3 n^{2}+2 n-4 s^{2}+4 s \leqslant 0,
$$

que é falsa se $s \leqslant \frac{\sqrt{3}}{2} n$. Ou seja, sob a hipótese de que a conjectura de Erdős \& Sós é verdadeira, é possível empacotar qualquer sequência $T_{1}, \ldots, T_{s}$ no $K_{n}$ se $s \leqslant \frac{\sqrt{3}}{2} n$.

\subsection{Outros resultados relacionados}

Nesta seção apresentamos outros resultados relacionados à conjectura de Gyárfás \& Lehel. Em primeiro lugar, mostramos uma classe especial de árvores para a qual a conjectura é verdadeira. 
Estas árvores, que chamaremos de quase-estrelas, caracterizam-se por possuírem um vértice que é adjacente a pelo menos $f(i)$ folhas, onde $f$ é uma função definida em termos da ordem $i$. Finalmente, mostramos a validade de uma conjectura levantada por Graham [11, 14], onde queremos achar uma matriz com certas restrições na soma das linhas e colunas para um dado conjunto de sequências de inteiros.

\subsubsection{Quase-estrelas}

Para achar uma resposta positiva para a pergunta de Gyárfás \& Lehel, Dobson [6] impõe a seguinte restrição: em cada árvore $T_{i}$ existe um vértice $x_{i}$ tal que pelo menos $n-\sqrt{6(i-1)} / 4$ folhas são adjacentes a $x_{i}$. Chamaremos essa classe de árvores de quase-estrelas, seguindo a terminologia de Dobson [6]. Dado um empacotamento da sequência $T_{1}, \ldots, T_{n-1}$ no $K_{n-1}$, essa restrição sobre as árvores $T_{i}$ garante a existência de um empacotamento da sequência $T_{1}, \ldots, T_{n}$ no $K_{n}$, possivelmente após trocas no empacotamento no $K_{n-1}$.

Considere $V\left(K_{n}\right)=\{1,2, \ldots, n\}$. Suponha que podemos empacotar a sequência $T_{1}, \ldots, T_{n-1}$ no $K_{n-1}$. No restante desta seção, consideramos que $K_{n-1}=K_{n}-n$ e que a sequência $T_{1}, \ldots, T_{n-1}$ é uma decomposição do $K_{n-1}$, ou seja, $T_{i}$ é um subgrafo do $K_{n-1}$, para $i=1, \ldots, n-1$. A seguir, explicamos qual é a técnica usada para empacotar uma árvore $T_{n}$ no $K_{n}$, dado um empacotamento da sequência $T_{1}, \ldots, T_{n-1}$ no $K_{n-1}$. Em primeiro lugar, mapeamos um vértice de $T_{n}$, digamos $x$, no vértice $n$ do $K_{n}$. Depois, precisamos encontrar um subgrafo isomorfo a $T_{n}-x$ em $K_{n-1}$. Se $T_{n}$ não é uma estrela, precisamos fazer trocas no empacotamento feito no $K_{n-1}$ para encontrar um subgrafo isomorfo a $T_{n}-x$. Agora, descrevemos a ideia básica para encontrar o subgrafo isomorfo a $T_{n}-x$ no $K_{n-1}$. Seja $i j \in E\left(T_{k}\right), k<n$, tal que $g_{T_{k}}(j)=1$. Considere a árvore $T_{k}^{\prime}=\left(T_{k}-i j\right)+i n$. Notamos que, $T_{k}^{\prime} \cong T_{k}$ e que existe um empacotamento da sequência $T_{1}, \ldots, T_{k}^{\prime}, \ldots, T_{n-1}$ no $K_{n}$ que não usa a aresta $i j$. Dobson [6] usa essa observação de forma indutiva para completar o empacotamento da sequência $T_{1}, \ldots, T_{n}$ no $K_{n}$.

A seguir, fazemos algumas definições e apresentamos um lema que formaliza o argumento anterior. Sejam $T$ uma árvore e $x$ um vértice de $T$. Denotamos por $\vec{T}(x)$ a árvore enraizada em $x$, obtida orientando-se as arestas de $T$ (ao caminhar) em direção ao vértice $x$. Se $T$ é uma floresta desconexa, para obter $\vec{T}(x)$, escolhemos para cada componente de $T$, que não contém o vértice $x$, um vértice qualquer $y$, e enraizamos esse subgrafo em $y$. Por último, enraizamos em $x$ a componente que o contém. Por outro lado, dado um empacotamento da sequência $T_{1}, \ldots, T_{n-1}$ no $K_{n-1}$, escolhemos um vértice $x_{i} \in V\left(T_{i}\right)$ de forma que para quaisquer par de índices $i, j$ tal que $i \neq j$ temos que $x_{i} \neq x_{j}$. Depois, considere os conjuntos de $\operatorname{arcos} F_{i}=\left\{x_{i} k: x_{i} k \in E\left(T_{i}\right), g_{T_{i}}(k)=1\right\}$, para $i=1, \ldots, n-1$.

Lema 16 (Dobson, 1997). Suponha que a sequência de florestas $T_{1}, \ldots T_{n-1}$ pode ser empacotada no $K_{n-1}$ e considere a notação anteriormente definida. Considere um grafo orientado $D$ tal que $V(D)=V\left(K_{n-1}\right)$ e $A(D)=\bigcup_{i=1}^{n-1} F_{i}$. Seja $T_{n}$ uma floresta de ordem $n$. A sequência de florestas $T_{1}, T_{2}, \ldots, T_{n}$ pode ser empacotada no $K_{n}$ se para algum $x \in V\left(T_{n}\right), D$ contém um subgrafo isomorfo a $\overrightarrow{T_{n}}(x)-x$ e x é mapeado ao vértice $n$ (acrescentado ao $K_{n-1}$ ).

Prova. Sem perda de generalidade, suponha que $T_{n}$ é uma árvore. Seja $x$ um vértice de $T_{n}$ tal que $D$ contém um subgrafo isomorfo a $\overrightarrow{T_{n}}(x)-x$. Faremos a prova por indução em $m:=\left|E\left(T_{n}-x\right)\right|$. Se $m=0$, então $T_{n}$ é uma estrela e o resultado segue trivialmente. Suponha que $m>0$. Como $T_{n}-x$ 
é uma floresta não trivial, existe uma aresta $z y \in E\left(T_{n}-x\right)$ tal que $g_{T_{n}}(z)=1$. Considere a floresta $T_{n}^{*}=T_{n}-z y$. Notamos que $\left|E\left(T_{n}^{*}-x\right)\right|=m-1$ e que $D$ contém um subgrafo isomorfo a $\overrightarrow{T_{n}^{*}}(x)-x$. Logo, pela hipótese de indução, a sequência de florestas $T_{1}, \ldots, T_{n-1}, T_{n}^{*}$ pode ser empacotada no $K_{n}$, e $x$ é mapeado a $n$. Como $z y \in A(D)$, então $z=x_{k}$ para algum $k \in\{1, \ldots, n-1\}$. Considere a floresta $T_{k}^{\prime}=\left(T_{k}-x_{k} y\right)+x_{k} n$. Note que $T_{k}^{\prime} \cong T_{k}$. Além disso, o empacotamento da sequência $T_{1}, \ldots, T_{n}^{*}$ no $K_{n}$ induz um empacotamento da sequência $T_{1}, \ldots, T_{k}^{\prime}, \ldots, T_{n}^{*}$ no $K_{n}$ que não usa a aresta $x_{k} y$. Como $T_{n}^{*}=T_{n}-x_{k} y$, segue que podemos empacotar a sequência $T_{1}, \ldots, T_{n}$ no $K_{n}$.

O lema anterior fornece uma estrutura (o grafo orientado $D$ ) que nos permite, dado um empacotamento de $T_{1}, \ldots, T_{n-1}$ no $K_{n-1}$, empacotar a árvore $T_{n}$ junto com tal sequência no $K_{n}$. Porém, precisamos garantir a existência de um subgrafo isomorfo a $\overrightarrow{T_{n}}(x)-x$ em $D$, para algum $x \in V\left(T_{n}\right)$. A seguir, definimos um grafo orientado que garante essa condição. Um torneio transitivo $D^{\prime}$ de $n$ vértices é um grafo orientado tal que, se ordenamos de forma não decrescente os graus de saída dos vértices de $D^{\prime}$, obtemos a sequência $0,1, \ldots, n-1$. Notemos que, um torneio transitivo contém qualquer árvore enraizada com o mesmo número de vértices.

A seguir, apresentamos um lema mostrado por Bollobás \& Thomason [2] que garante a existência de um subgrafo isomorfo ao $K_{t}$, num grafo $G$, se $G$ contém um número suficiente de arestas.

Lema 17 (Bollobás \& Thomason, 1997). Sejam $n$ e $t$ inteiros positivos tais que $n \geqslant t^{2}$. Se $G$ é um grafo de ordem $n$ tal que $|E(\bar{G})| \leqslant \frac{n^{2}}{2 t}$, então $G$ contém um subgrafo isomorfo ao $K_{t}$.

Prova. Suponha por contradição que $G$ não contém um subgrafo isomorfo ao $K_{t}$. Pelo Teorema de Turán, segue que $|E(G)| \leqslant T(n, t)$, onde $T(n, r)$ denota ao grafo de Turán de ordem $n$ e $r$ classes (na partição). Logo,

$$
\begin{aligned}
|E(\bar{G})| & \geqslant \sum_{i=0}^{t-2}\left(\begin{array}{c}
\lfloor(n+i) /(t-1)\rfloor \\
2
\end{array}\right) \\
& \geqslant(t-1)\left(\begin{array}{c}
n /(t-1) \\
2
\end{array}\right) \\
& =\frac{n(n-t+1)}{2(t-1)} \\
& >\frac{n^{2}}{2 t}
\end{aligned}
$$

uma contradição. Portanto, $G$ contém um subgrafo isomorfo ao $K_{t}$.

Seja $G$ um grafo. Denotamos por $n_{1}(G)$ o número de vértices de $G$ que têm grau pelo menos 1 . A seguir, apresentamos o resultado principal desta seção.

Teorema 18 (Dobson, 1997). Seja $T_{1}, T_{2}, \ldots, T_{n}$ uma sequência de árvores tal que para cada $T_{i}$ existe $x_{i} \in V\left(T_{i}\right)$ com a seguinte propriedade

$$
n_{1}\left(T_{i}-x_{i}\right) \leqslant \sqrt{6(i-1)} / 4
$$

Então, a sequência $T_{1}, T_{2}, \ldots, T_{n}$ pode ser empacotada no $K_{n}$ de forma que $x_{i}$ é mapeado no vértice $i \in V\left(K_{n}\right)$ para $i=1,2, \ldots, n$.

Prova. Faremos a prova por indução em $n$. Se $n<12$, então $n_{1}\left(T_{i}-x_{i}\right) \leqslant\lfloor\sqrt{6(i-1)} / 4\rfloor<2$. Portanto, $n_{1}\left(T_{i}-x_{i}\right)=0$ para $i=1, \ldots, n$. Logo, cada $T_{i}$ é uma estrela e o resultado segue 
trivialmente. Agora, suponha que $n \geqslant 12$. Pela hipótese de indução, a sequência $T_{1}, T_{2}, \ldots, T_{n-1}$ pode ser empacotada no $K_{n-1}$ de forma que $x_{i} \in V\left(T_{i}\right)$ é mapeado ao vértice $i$ para $i=1, \ldots, n-1$. Considere o grafo orientado $D$ definido da seguinte maneira

$$
\begin{aligned}
& V(D)=\{1,2, \ldots, n-1\} \\
& A(D)=\left\{i j: i j \in E\left(T_{i}\right), g_{T_{i}}(j)=1\right\} .
\end{aligned}
$$

Como $n_{1}\left(T_{i}-x_{i}\right) \leqslant \sqrt{6(i-1)} / 4$, segue que $g_{D}^{+}(i) \geqslant(i-1)-\sqrt{6(i-1)} / 4$, para $i=1, \ldots, n-1$. Pela forma como é feito o empacotamento da sequência $T_{1}, \ldots, T_{n-1}$ no $K_{n-1}$, se existe $i j \in A(D)$ tal que $j>i$, então $i j \in E\left(T_{k}-x_{k}\right)$ para algum $k>i$. Para garantir o empacotamento, estamos interessados só nos arcos com ponta inicial em $x_{i}$ e ponta final numa folha de $T_{i}$, para $i=1, \ldots, n-1$. Considere o seguinte subgrafo $D^{\prime}$ de $D$,

$$
A\left(D^{\prime}\right)=\{i j: i j \in A(D), i>j\} .
$$

Pelo Lema 16 , se $D^{\prime}$ contém um subgrafo isomorfo a $\overrightarrow{T_{n}}\left(x_{n}\right)-x_{n}$ podemos completar o empacotamento da sequência $T_{1}, \ldots, T_{n}$ no $K_{n}$ de forma que $x_{i}$ é mapeado ao vértice $i$, para $i=1, \ldots, n$. Para isso, é suficiente garantir que $D^{\prime}$ contém um torneio transitivo de $\sqrt{6(n-1)} / 4$ vértices como subgrafo. Note que isso é equivalente a mostrar que o grafo subjacente a $D^{\prime}$ contém um subgrafo isomorfo ao $K_{t}$, onde $t=\sqrt{6(n-1)} / 4$. Se $G$ é o grafo subjacente a $D^{\prime}$, então

$$
\begin{aligned}
E(G) & \geqslant \sum_{i=1}^{n-1}(i-1)-2 \frac{\sqrt{6(i-1)}}{4} \\
& =\left(\begin{array}{c}
n-1 \\
2
\end{array}\right)-2 \sum_{i=1}^{n-1} \frac{\sqrt{6(i-1)}}{4} \\
& \geqslant\left(\begin{array}{c}
n-1 \\
2
\end{array}\right)-\frac{\sqrt{6}}{2} \int_{0}^{n-1} \sqrt{i} \mathrm{~d} i \\
& =\left(\begin{array}{c}
n-1 \\
2
\end{array}\right)-\frac{\sqrt{6}}{3}(n-1)^{3 / 2}
\end{aligned}
$$

Logo, $|E(\bar{G})| \leqslant \frac{\sqrt{6}}{3}(n-1)^{3 / 2}$. Considere $t=\sqrt{6(n-1)} / 4$. Então $|E(\bar{G})| \leqslant(n-1)^{2} / 2 t$. Pelo Lema 17 , o grafo $G$ contém um subgrafo isomorfo ao $K_{t}$. Portanto, podemos completar o empacotamento da sequência $T_{1}, \ldots, T_{n}$ no $K_{n}$ com as propriedades desejadas.

Dobson [7, 8] mostra outros dois resultados relacionados à conjectura. Porém, a técnica usada é fundamentalmente a mesma. Em um desses resultados, Dobson [7] limita o tamanho da sequência e usa o limitante inferior usado na Seção 3.4 para procurar um subgrafo de grau mínimo $k$. Enunciamos o resultado a seguir.

Teorema 19 (Dobson, 2002). Sejam s um inteiro e c um número tais que $0<c \leqslant 0.076122$ e $s \leqslant(1-c) n$. Seja $T_{1}, T_{2}, \ldots, T_{s}$ uma sequência de árvores. Se para cada árvore $T_{i}$ existe um vértice $x_{i}$ tal que $n_{1}\left(T_{i}-x_{i}\right) \leqslant c(1-i) /(1-c)$, então a sequência $T_{1}, T_{2}, \ldots, T_{s}$ pode ser empacotada no $K_{n}$.

No outro resultado, Dobson [8] limita o diâmetro das árvores que deseja-se empacotar e mantém uma restrição quanto ao número mínimo de folhas que devem ser adjacentes a um vértice especial 
em cada árvore. A seguir, enunciamos o resultado.

Teorema 20 (Dobson, 2007). Sejam d um inteiro positivo, c um número e $T_{1}, T_{2}, \ldots, T_{n}$ uma sequência de árvores. Se $c=\left(\sqrt{2+(d+1)^{2}}-(d+1)\right)^{2} / 2$ e em cada $T_{i}$ existe um vértice $x_{i}$ tal que $n_{1}\left(T_{i}-x_{i}\right) \leqslant(1-c)(i-1)$, e a distância entre $x_{i}$ e qualquer vértice de $T_{i}$ é no máximo $d+1$, então a sequência $T_{1}, T_{2}, \ldots, T_{n}$ pode ser empacotada no $K_{n}$.

\subsubsection{Empacotamento de matrizes}

Nesta seção discutiremos uma questão relacionada à conjectura de Gyárfás \& Lehel. Em primeiro lugar, notamos que a soma dos graus dos vértices de uma árvore de ordem $i+1$ é $2 i$. Por outro lado, dado um empacotamento de qualquer sequência de árvores $T_{2}, T_{3}, \ldots, T_{n}$ no $K_{n}$, para todo vértice $x \in V\left(K_{n}\right)$ podemos particionar o conjunto de $n-1$ arestas incidentes a $x$ em $n-1$ classes, considerando como elementos da classe $i$ as arestas usadas para empacotar a árvore $T_{i}$. Note que algumas classes podem ser vazias. Baseado nesses fatos, Graham [10, 14] notou que se a conjectura de Gyárfás \& Lehel fosse verdadeira, teria como consequência a seguinte asserção.

Asserção 1. Para cada inteiro $i \geqslant 1$, seja $s_{i}$ uma sequência de $i+1$ números inteiros positivos cuja soma é $2 i$. Considere uma sequência $s_{1}, s_{2}, \ldots, s_{n-1}$. Então existe uma matriz $M$ de dimensão $n-1 \times n$ tal que cada linha $i$ de $M$ é uma permutação de $s_{i}$ (possivelmente aumentada por zeros) e cada coluna de $M$ tem soma $n-1$.

Graham conjecturou que a Asserção 1 é verdadeira. Para entendermos a relação entre tais sequências e a conjectura de Gyárfás \& Lehel, chame de $s_{i}^{\prime}$ a sequência que resulta de $s_{i}$ ordenandoa não-crescentemente. Então $s_{i}^{\prime}$ pode ser vista como a sequência dos graus de uma árvore com $i+1$ vértices, digamos $T_{i+1}$. Se a conjectura de Gyárfás \& Lehel fosse verdadeira, então a sequência de árvores $T_{2}, T_{3}, \ldots, T_{n}$ poderia ser empacotada no $K_{n}$. De fato, considere que a linha $i$ da matriz $M$ representa a árvore $T_{i+1}$ e a coluna $j$ representa o vértice $v_{j} \in V\left(K_{n}\right)$. Nesse caso, a entrada $m_{i j}$ nos diz quantas arestas incidentes ao vértice $v_{j}$ foram usadas para empacotar a árvore $T_{i+1}$ (veja um exemplo na Figura 3.13). Em 1983, Fishburn [10] mostrou uma prova para a Asserção 1.

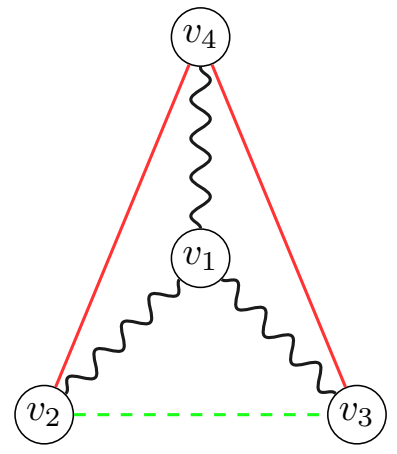

(a) Empacotamento de estrelas no $K_{4}$.

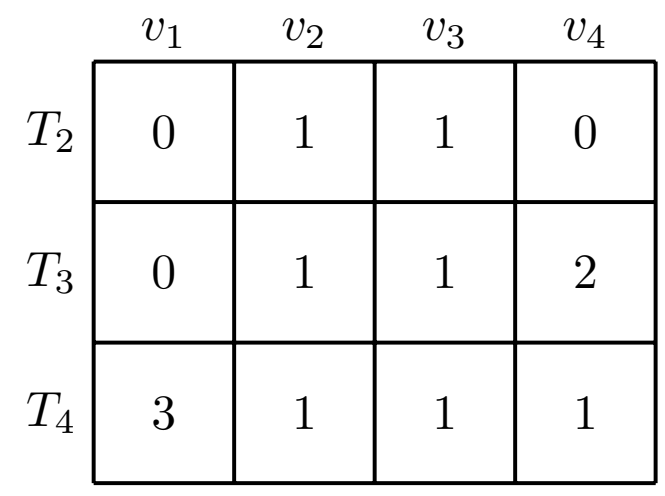

(b) $M$.

Figura 3.13: Matriz $M$ induzida pelo empacotamento de estrelas.

A seguir, enunciamos um lema que é fundamental na prova da Asserção 1.

Lema 21 (Fishburn, 1983). Seja s uma sequência de $n$ inteiros positivos cuja soma é $2 n-1$. Considere a sequência de inteiros $t=(0,0,1,2, \ldots, n-2)$. Então, existem permutações $s^{\prime}$ e $t^{\prime}$ de $s$ e $t$, respectivamente, tais que $s_{i}^{\prime}+t_{i}^{\prime}=i$, para $i=1,2, \ldots, n$. 
Suponha que $n$ é ímpar. Seja $s_{i}^{*}$ a sequência que resulta após retirar um elemento igual a 1 de $s_{i}$, para $i=1, \ldots, n-1$. Para mostrar a Asserção 1, Fishburn [10] considera separadamente as sequências $s_{1}^{*}, s_{3}^{*}, \ldots, s_{n-2}^{*}$ e $s_{2}^{*}, s_{4}^{*}, \ldots, s_{n-1}^{*}$. Usando o Lema 21, Fishburn mostrar que, após de possivelmente aumentar por zeros e permutar cada $s_{i}^{*}$, se somarmos, termo a termo, cada uma das sequências obteríamos as sequências $(0,1, \ldots, n-1)$, e $(n, n-1, \ldots, 1)$, respectivamente. Claramente, isso prova a Asserção 1, já que podemos acrescentar um termo igual a 1 em cada $s_{i}^{*}$ para encontrar a matriz $M$ com as propriedades desejadas. 


\section{Capítulo 4}

\section{Variantes da conjectura}

Como vimos no capítulo anterior, desde que a pergunta de Gyárfás \& Lehel foi levantada, diferentes restrições na conjectura original têm sido consideradas. Paralelamente, diferentes variantes da conjectura têm aparecido. Em 1987, Hobbs, Bourgeois e Kasiraj [14] conjeturaram que qualquer sequência de árvores $T_{1}, \ldots, T_{n}$ pode ser empacotada no $K_{[n / 2], n-1}$. Outra variante dessa conjectura surge quando consideramos para $n$ ímpar o grafo $K_{(n-1) / 2, n}$ no lugar do $K_{[n / 2], n-1}$. Essas conjecturas são as que têm suscitado maior interesse. Para ambas foram provados alguns resultados análogos aos obtidos para a conjectura de Gyárfás \& Lehel. Em 2013, Hollingsworth [15] obteve resultados sobre empacotamento de uma subclasse de árvores de ordem par no grafo $K_{n, n}$.

Outra variante interessante apareceu em 2012. Gerbner, Keszegh e Palmer [12] conjecturaram a seguinte asserção: Qualquer sequência de árvores $T_{1}, \ldots, T_{k}$ pode ser empacotada em um grafo k-cromático. Notamos que, diferentemente da pergunta levantada por Hobbs et al., essa asserção implica a conjectura de Gyárfás \& Lehel.

Na primeira parte deste capítulo apresentamos os resultados conhecidos a respeito da seguinte pergunta: é possivel empacotar qualquer sequência de árvores $T_{1}, \ldots, T_{n}$ no $K_{n / 2, n-1}$ (respectivamente, $K_{(n-1) / 2, n}$ ) se $n$ é par (respectivamente, impar)? Na seção seguinte nos restringimos ao empacotamento de uma sequência de árvores balanceadas no grafo $K_{n, n}$ e apresentamos os resultados obtidos por Hollingsworth para esta variante. Finalmente, apresentamos o resultado obtido por Gerbner et al. para o caso de empacotamento de uma sequência de $k$ árvores num grafo $k$-cromático.

\subsection{Empacotamento em grafos bipartidos completos}

Nesta seção, apresentamos uma resposta parcial para a seguinte pergunta feita por Hobbs et al. [14]: é possivel empacotar qualquer sequência de árvores $T_{1}, T_{2}, \ldots, T_{n}$ no $K_{[n / 2], n-1}$ ? Também apresentamos uma resposta parcial para uma outra variante dessa pergunta que tem sido estudada para o caso em que $n$ é ímpar: é possível empacotar qualquer sequência de árvores $T_{1}, \ldots, T_{n}$ no $K_{(n-1) / 2, n}$ ?

\subsubsection{Estrelas e caminhos}

Uma classe de árvores para a qual é fácil responder positivamente à pergunta de Hobbs et al. é a classe das estrelas. 
Proposição 22. Seja $n$ um inteiro par. Uma sequência de estrelas $S_{1}, S_{2}, \ldots, S_{n}$ pode ser empacotada no $K_{n / 2, n-1}$.

Prova. Seja $(X, Y)$ uma bipartição do $K_{n / 2, n-1}$ tal que

$$
\begin{aligned}
& X=\left\{x_{1}, x_{2}, \ldots, x_{n / 2}\right\} \quad \mathrm{e} \\
& Y=\left\{y_{1}, y_{2}, \ldots, y_{n-1}\right\} .
\end{aligned}
$$

Em primeiro lugar, mostraremos como empacotar as estrelas $S_{n / 2+1}, \ldots, S_{n}$. Mapeamos o centro da estrela $S_{n / 2+i}$ no vértice $x_{i}$, para $i=1, \ldots, n / 2$. As arestas incidentes no centro de $S_{n / 2+i}$ são mapeadas nas arestas $\left\{x_{i} y_{j}: 1 \leqslant j \leqslant n / 2+i-1\right\}$, para $i=1, \ldots, n / 2$. Note que, após o passo anterior, podemos usar exatamente $i-1$ arestas incidentes ao vértice $y_{n / 2+i-1}$, para $i=1, \ldots, n / 2$, no empacotamento do resto de estrelas. Logo, podemos completar o empacotamento mapeando o centro das estrelas $S_{1}, \ldots, S_{n / 2}$ nos vértices $y_{n / 2}, \ldots, y_{n-1}$, respectivamente.

De forma similar pode-se provar que, se $n$ é ímpar, podemos empacotar a sequência $S_{1}, S_{2}, \ldots, S_{n}$ no $K_{(n-1) / 2, n}$. Zaks \& Liu [18] mostraram um resultado mais forte: se cada $T_{i}$ é uma estrela ou um caminho, é possível empacotar a sequência $T_{1}, \ldots, T_{n}$ no $K_{n / 2, n-1}$ (respectivamente, $K_{(n-1) / 2, n}$ ) se $n$ é par (respectivamente, ímpar).

Teorema 23 (Zaks \& Liu, 1977). Seja $T_{1}, T_{2}, \ldots, T_{n}$ uma sequência de árvores tal que $T_{i}$ é uma estrela ou um caminho para $i=1, \ldots, n$. Então, podemos empacotar tal sequência no $K_{n / 2, n-1}$ (respectivamente, $K_{(n-1) / 2, n}$ ) se $n$ é par (respectivamente, impar).

Prova. A prova é similar à do Teorema 7. Vamos descrever, em linhas gerais, a prova quando $n$ é par (o caso de $n$ ímpar é similar). Seja $r:=n / 2$ e seja $(X, Y)$ a bipartição do $K_{r, 2 r-1}$ tal que

$$
\begin{aligned}
X & =\{1,2, \ldots, r\} \text { e } \\
Y & =\{r+1, \ldots, 3 r-1\} .
\end{aligned}
$$

Decompomos $K_{r, 2 r-1}$ em dois subgrafos, digamos $A_{n}$ e $B_{n}$, definidos da seguinte maneira (veja na Figura 4.1 um exemplo de $A_{6}$ e $\left.B_{6}\right)$ :

$$
\begin{aligned}
& E\left(A_{n}\right)=\{i j: i \in X, j \in Y, i+j \geqslant n+1 \text { e } j-i \leqslant n-1\} \quad \text { e } \\
& E\left(B_{n}\right)=E\left(K_{r, 2 r-1}\right)-E\left(A_{n}\right) .
\end{aligned}
$$




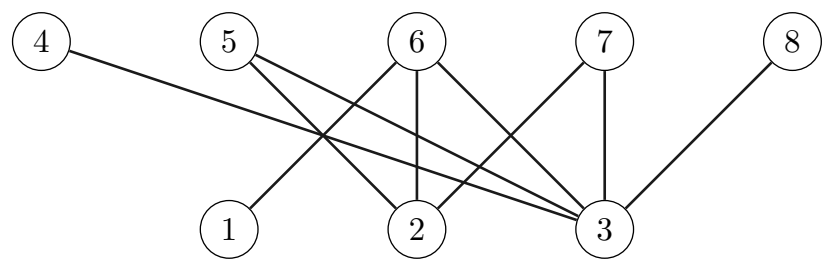

(a) $A_{6}$

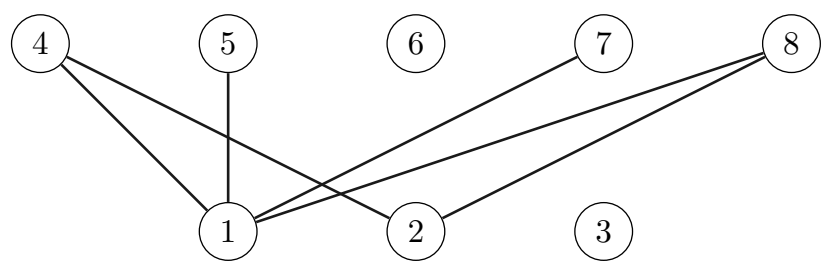

(b) $B_{6}$

Figura 4.1: Decomposição de $K_{3,5}$

Depois, mostra-se por indução em $n$ que a sequência de árvores $T_{2}, T_{4}, \ldots, T_{n}$ (respectivamente, $T_{1}, T_{3}, \ldots, T_{n-1}$ ) pode ser empacotada em $A_{n}$ (respectivamente, $B_{n}$ ). Para o caso da sequência de árvores de ordem par, considere o seguinte subgrafo $F$ de $A_{n}$. Se $T_{n}$ é uma estrela considere $E(F)=\{r j: r+1 \leqslant j \leqslant 2 r-1\}$, caso contrário ( $T_{n}$ é um caminho) $E(F)$ é o conjunto de arestas induzidas pelo caminho $\langle 1,2 r, 2,2 r+1, \ldots, r, 3 r-1\rangle$ em $A_{n}$. (Na Figura 4.2 indicamos $F$ com arestas tracejadas.) Para concluir a prova, deve-se mostrar que $A_{n}-E(F)$ contém um subgrafo isomorfo a $A_{n-2}$. A prova do empacotamento da sequência de árvores de ordem ímpar no $B_{n}$ é simétrica.

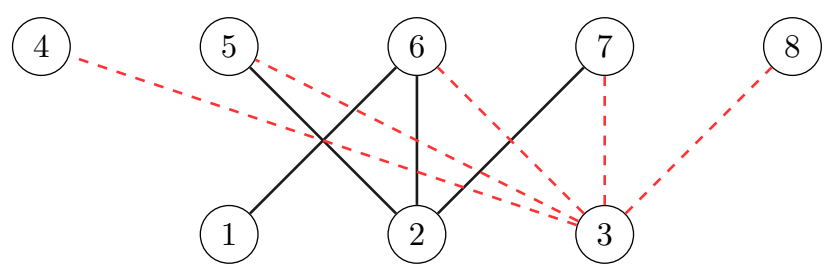

(a) Subgrafo $F$ de $A_{6}$ quando $T_{6}=S_{6}$

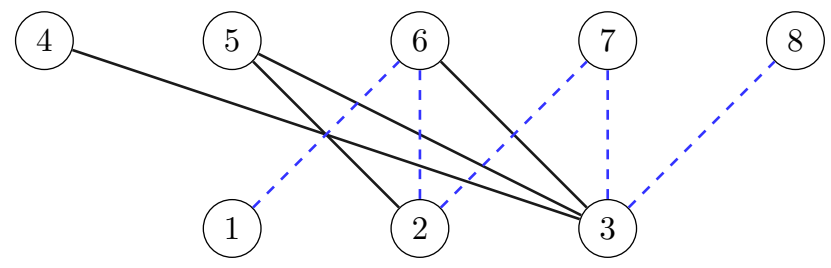

(b) Subgrafo $F$ de $A_{6}$ quando $T_{6}=P_{6}$

Figura 4.2: Subgrafo $F$ de $A_{6}$

\subsubsection{Limitando o tamanho da sequência}

Um primeiro resultado, quando se limita o tamanho da sequência a ser empacotada foi obtido por Caro \& Roditty [4], que provaram o seguinte.

Teorema 24 (Caro \& Roditty, 1990). Sejam s e $n$ inteiros tais que $3 \leqslant s \leqslant(\sqrt{13}-3) n / 2$ e $n$ é par. Então qualquer sequência de árvores $T_{1}, T_{2}, \ldots, T_{s}$ pode ser empacotada no $K_{n / 2, n-1}$. 
Prova. A prova é por indução no tamanho da sequência e segue os mesmos passos da demonstração do Teorema 15. Claramente, podemos empacotar a árvore $T_{s}$ no $K_{n / 2, n-1}$. Por hipótese de indução, podemos empacotar a sequência $T_{k+1}, \ldots, T_{s}$ no $K_{n / 2, n-1}$ para algum $k, 1<k<s$. Seja $G$ o grafo que resulta após retirar do $K_{n / 2, n-1}$ as arestas usadas para empacotar as árvores $T_{k+1}, \ldots, T_{s}$. Notamos que

$$
|E(G)|=\frac{n(n-1)}{2}-\frac{(s+k-1)(s-k)}{2} .
$$

Suponha, por contradição, que $G$ não contém um subgrafo de grau mínimo $k-1$. Como $G$ tem ordem $3 n / 2$, pela Proposição 13 temos que

$$
|E(G)| \leqslant\left(\begin{array}{c}
k-1 \\
2
\end{array}\right)+(k-2)\left(\frac{3 n}{2}-k\right) .
$$

As relações anteriores implicam que

$$
s^{2}-s-n^{2}-5 n+3 k n-2 k^{2}+2 k \geqslant 0 .
$$

Porém, isso contradiz a escolha de $s$. Portanto, $G$ contém um subgrafo $H$ tal que $\delta(H) \geqslant k-1$. Claramente, a árvore $T_{k}$ pode ser empacotada em $H$, concluindo a prova.

Em 1997, Yuster [17] melhorou o resultado anterior. Para isso, ele mostra uma condição suficiente para que um grafo bipartido, digamos $R$, esteja contido num outro grafo bipartido $H$ dependendo do número de arestas de $H$.

Lema 25 (Yuster, 1997). Sejam $H$ um grafo $\left(H_{1}, H_{2}\right)$-bipartido e $R$ uma árvore com bipartição $\left(R_{1}, R_{2}\right)$ tais que $\left|R_{i}\right|=r_{i} \leqslant h_{i}=\left|H_{i}\right|$, para $i=1,2 . S e$

$$
|E(H)| \geqslant r_{2} h_{1}+r_{1} h_{2}+r_{1}+r_{2}-h_{1}-h_{2}-r_{1} r_{2},
$$

então $H$ contém um subgrafo isomorfo a $R$.

Prova. Para fazer a prova, exibiremos um algoritmo que encontra um subgrafo de $H$ tal que todo vértice de $H_{1}$ tem grau pelo menos $r_{2}$ e todo vértice de $H_{2}$ tem grau pelo menos $r_{1}$. A seguir apresentamos o algoritmo

1. Enquanto existe $u \in H_{1}$ ou $v \in H_{2}$, tal que $g(u)<r_{2}$ ou $g(v)<r_{1}$,

(a) se existe $u \in H_{1}$ tal que $g(u)<r_{2}$, considere $H:=H-u$;

(b) caso contrário, considere $H:=H-v$.

Agora, suponha por contradição que o algoritmo anterior não seja correto. Logo, existe um instante no algoritmo no qual $H_{1}$ tem $r_{1}-1$ vértices ou $H_{2}$ tem $r_{2}-1$ vértices. Sem perda de generalidade, suponha que isso acontece primeiro para $H_{1}$. Então, todo vértice restante de $H_{2}$ tem grau no máximo $r_{1}-1$. Notamos que nesse processo eliminamos $h_{1}-r_{1}+1$ vértices de $H_{1}$ com grau no máximo $r_{2}-1$ e todos os vértices de $H_{2}$. Então,

$$
\begin{aligned}
|E(H)| & \leqslant\left(r_{2}-1\right)\left(h_{1}-r_{1}+1\right)+\left(r_{1}-1\right) h_{2} \\
& =h_{1} r_{2}+r_{1} h_{2}+r_{1}+r_{2}-h_{1}-h_{2}-r_{1} r_{2}-1
\end{aligned}
$$

uma contradição. Portanto, quando o algoritmo termina, todos os vértices de $H_{1}$ têm grau pelo menos $r_{2}$ e todos os vértices de $H_{2}$ têm grau pelo menos $r_{1}$. Claramente, podemos empacotar $R$ 
em $H$.

O corolário a seguir fornece um limite inferior para o número de arestas que um grafo bipartido deve conter para que contenha um subgrafo isomorfo a qualquer árvore de ordem par.

Corolário 26 (Yuster, 1997). Sejam n e r inteiros positivos tais que $n$ é par e $n \geqslant 2 r$. Seja H um subgrafo de $K_{n / 2, n-1}$. Se $|E(H)|>(r-1)(3 n / 2-r)$, então $H$ contém qualquer árvore de ordem $2 r$.

Prova. Suponha, por contradição, que a afirmação seja falsa. Seja $T$ uma árvore de ordem $2 r$ e bipartição $\left(R_{1}, R_{2}\right)$ tal que $r_{i}=\left|R_{i}\right|$, para $i=1,2$, e $r_{1} \leqslant r_{2}$. Então, $r_{1} \leqslant n / 2$ e $r_{2} \leqslant n-1$. Pelo lema anterior, temos que

$$
|E(H)| \leqslant \frac{n r_{2}}{2}+r_{1}(n-1)+r_{1}+r_{2}-r_{1} r_{2}-\frac{3 n}{2} .
$$

Substituindo $r_{2}$ por $2 r-r_{1}$ na expressão anterior segue que

$$
|E(H)| \leqslant n r+r_{1} \frac{n}{2}+2 r-2 r r_{1}+r_{1}^{2}-r_{1}-\frac{3 n}{2} .
$$

Considerando a expressão anterior como uma função de $r_{1}$, notamos que ela atinge seu valor máximo quando $r_{1}=r$. Então, $|E(H)| \leqslant(r-1)(3 n / 2-r)$, uma contradição.

O corolário anterior nos permite mostrar o seguinte resultado.

Teorema 27 (Yuster, 1997). Sejam s e n inteiros tais que $3 \leqslant s \leqslant \sqrt{5 / 8}$. Então, qualquer sequência de árvores $T_{1}, T_{2}, \ldots, T_{s}$ pode ser empacotada no $K_{n / 2, n-1}$ (respectivamente, $K_{(n-1) / 2, n}$ ) se $n$ é par (respectivamente, impar).

Prova. Faremos a prova por indução no tamanho da sequência. Suponha que $n$ é par (omitiremos a prova para o caso de $n$ ímpar, já que é análoga). Claramente, $T_{s}$ pode ser empacotado no $K_{n / 2, n-1}$. Pela hipótese de indução, a sequência $T_{k+1}, \ldots, T_{s}$ pode ser empacotada no $K_{n / 2, n-1}$ para algum $k, 1<k<s$. Considere o grafo $G$ que resulta após retirar do $K_{n / 2, n-1}$ as arestas usadas para empacotar as árvores $T_{k+1}, \ldots, T_{s}$. Note que,

$$
|E(G)|=\left(\begin{array}{l}
n \\
2
\end{array}\right)-\left(\begin{array}{l}
s \\
2
\end{array}\right)+\left(\begin{array}{l}
k \\
2
\end{array}\right)
$$

Distinguimos dois casos.

Caso 1: $k$ é par.

Neste caso, temos que mostrar que $|E(G)|>(k / 2-1)(3 n / 2-k / 2)$. Notamos que

$$
|E(G)|-(k / 2-1)(3 n / 2-k / 2)=\frac{n^{2}}{2}+n-\frac{s^{2}}{2}+\frac{s}{2}+\frac{3 k^{2}}{4}-k-\frac{3 n k}{4} .
$$

Considerando a última expressão como uma função de $k$, notamos que, ela atinge seu valor mínimo quando $k=n / 2+2 / 3$. Assim, substituindo $k$ por $n / 2+2 / 3$, obtemos

$$
\frac{5 n^{2}}{16}+\frac{n}{2}-\frac{1}{3}-\frac{s^{2}}{2}+\frac{s}{2}
$$

que é positiva se $s \leqslant\lfloor\sqrt{5 / 8} n\rfloor$. Portanto, o resultado segue. 
Caso 2: $k$ é ímpar.

Neste caso, é suficiente mostrar que $|E(G)|>(k / 2-1 / 2)(3 n / 2-k / 2-1 / 2)$. Notamos que

$$
|E(G)|-(k / 2-1 / 2)(3 n / 2-k / 2-1 / 2)=\frac{n^{2}}{2}+\frac{n}{4}-\frac{s^{2}}{2}+\frac{s}{2}+\frac{3 k^{2}}{4}-\frac{k}{2}-\frac{3 n k}{4}-\frac{1}{4} .
$$

Considerando a última expressão como uma função de $k$, notamos que ela atinge seu valor mínimo quando $k=n / 2+1 / 3$. Assim, substituindo $k$ por $n / 2+1 / 3$, obtemos

$$
\frac{5 n^{2}}{16}-\frac{2}{3}-\frac{s^{2}}{2}+\frac{s}{2}
$$

que é positiva se $s \leqslant\lfloor\sqrt{5 / 8} n\rfloor$. Portanto, o resultado segue.

\subsection{Empacotamento de árvores balanceadas}

Nesta seção apresentamos uma variante da conjectura de Gyárfás \& Lehel que trata de empacotamento de uma subclasse de árvores de ordem par no grafo $K_{n, n}$. Dizemos que uma árvore $T$ é balanceada se ao realizar uma bicoloração de $T$, as classes da bipartição induzidas por essa coloração têm a mesma cardinalidade. No resto desta seção uma árvore balanceada de ordem $2 k$ será denotada por $\hat{T}_{k}$. Notamos que o número de arestas de uma árvore balanceada de ordem $2 k$ é $2 k-1$. Logo, o número total de arestas de uma sequência de árvores balanceadas $\hat{T}_{1}, \ldots, \hat{T}_{n}$ é

$$
\sum_{i=1}^{n}(2 i-1)=n^{2}
$$

que é também o número de arestas do grafo bipartido completo $K_{n, n}$. Essa coincidência levou Hollingsworth [15] a levantar a seguinte pergunta: é possivel empacotar qualquer sequência de árvores balanceadas $\hat{T}_{1}, \ldots, \hat{T}_{n}$ no $K_{n, n}$ ? Hollingsworth obteve duas respostas positivas para variantes dessa pergunta. Em primeiro lugar, a autora restringiu o tamanho da sequência que se deseja empacotar no $K_{n . n}$. Para obter um resultado para esse caso, ela usa o Lema 25 para mostrar que um subgrafo do $K_{n, n}$ com um certo número mínimo de arestas contém qualquer árvore balanceada de ordem $2 k$.

Corolário 28 (Hollingsworth, 2013). Sejam $n$ e $k$ inteiros positivos tais que $k \leqslant n$. Seja $H$ um subgrafo do $K_{n, n}$. Se $|E(H)| \geqslant 2 n(k-1)+2 k-k^{2}$, então $H$ contém qualquer árvore balanceada $\hat{T}_{k}$.

Prova. Segue usando o Lema $25 \operatorname{com} h_{1}=h_{2}=n$ e $r_{1}=r_{2}=k$. Note que neste caso temos que

$$
\begin{aligned}
|E(H)| & \geqslant k n+k n+2 k-2 n-k^{2} \\
& =2 n(k-1)+2 k-k^{2} .
\end{aligned}
$$

Agora, mostraremos que qualquer sequência de árvores balanceadas $\hat{T}_{1}, \ldots, \hat{T}_{s}$ pode ser empacotada no $K_{n, n}$ se $s<\lfloor\sqrt{7 / 18} n\rfloor$.

Teorema 29 (Hollingsworth, 2013). Sejam $n$ e s inteiros tais que $n \geqslant 3$ e $s<\lfloor\sqrt{7 / 18} n\rfloor$. Então, qualquer sequência de árvores $\hat{T}_{1}, \ldots, \hat{T}_{s}$ pode ser empacotada no $K_{n, n}$. 
Prova. Faremos a prova por indução no tamanho da sequência. Claramente, podemos empacotar qualquer árvore $\hat{T}_{s}$ no $K_{n, n}$. Pela hipótese de indução, existe um empacotamento da sequência $\hat{T}_{k+1}, \ldots, \hat{T}_{s}$ para algum $k, 1<k<s$. Considere o grafo $H$ que resulta após retirar do $K_{n, n}$ as arestas usadas para empacotar as árvores $\hat{T}_{k+1}, \ldots, \hat{T}_{s}$. Então,

$$
\begin{aligned}
|E(H)| & =n^{2}-\sum_{i=k+1}^{s}(2 i-1) \\
& =n^{2}-s^{2}+(k-1)^{2} .
\end{aligned}
$$

Pelo corolário anterior, $H$ contém um subgrafo isomorfo a $\hat{T}_{k}$ se

$$
n^{2}-s^{2}+2 k^{2}-4 k+2 n-2 k n+1 \geqslant 0 .
$$

Considerando a função $f(k)=n^{2}-s^{2}+2 k^{2}-4 k+2 n-2 k n+1$, notamos que ela atinge seu mínimo quando $k=(n+2) / 2$. Como $f((n+2) / 2) \geqslant n^{2}-s^{2}-2$, quando $n \geqslant 3$ e $s<\lfloor\sqrt{7 / 18} n\rfloor$, temos que $f(k)>0$. Portanto, o resultado segue.

Notamos que, se tentamos empacotar as árvores de maior ordem primeiro, podemos ter casos nos quais o número de árvores empacotadas é menor. Na Figura 4.3 mostramos um exemplo de empacotamento de duas árvores balanceadas $\hat{T}_{4}$ e $\hat{T}_{5}$ (linha tracejada) no $K_{5,5}$.

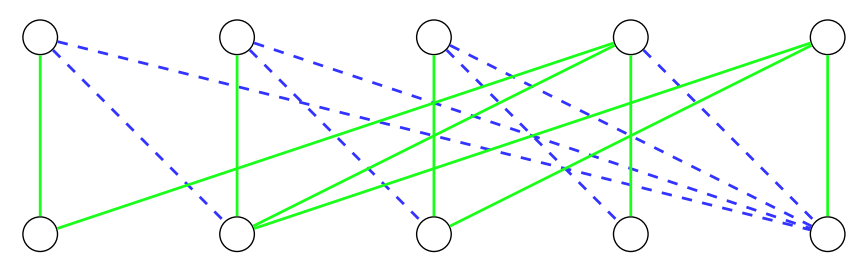

Figura 4.3: Empacotamento de $\hat{T}_{4}$ e $\hat{T}_{5}$ no $K_{5,5}$.

Considere o grafo $H$ que resulta após retirar do $K_{5,5}$ as arestas usadas para empacotar $\hat{T}_{4}$ e $\hat{T}_{5}$. Se tentarmos empacotar uma biestrela de ordem 6, onde cada um dos centros têm grau 3, vemos que não é possível fazer o empacotamento, já que não existem dois vértices adjacentes em $H$ de grau 3.

Agora, mostraremos que sempre existe uma sequência de árvores balanceadas $\hat{T}_{1}, \ldots, \hat{T}_{n}$ que pode ser empacotada no $K_{n, n}$. Veremos um resultado mais forte, já que podemos especificar, para cada uma das árvores da sequência, a sequência de graus de uma das classes da bipartição. Para mostrar esse resultado, usamos o Lema 21 e a ideia de dividir a sequência de árvores em duas partes dependendo da paridade da ordem de cada árvore.

Seja $G$ um grafo $(X, Y)$ bipartido. A matriz de biadjacência de $G$ é a matrix $M_{G}:=\left(m_{x y}\right)$ sobre $X \times Y$ definida da seguinte maneira. Para cada par de vértices $x \in X$ e $y \in Y$,

$$
m_{x y}= \begin{cases}1, & \text { se } x \text { e } y \text { são adjacentes } \\ 0, & \text { caso contrário. }\end{cases}
$$

Agora, exibimos uma família de grafos $\hat{H}_{n}$ tais que, para todo $n \geqslant 2, \hat{H}_{n-1}$ e $\hat{H}_{n}$ constituem uma decomposição do $K_{n, n}$. Para $n \geqslant 1, \hat{H}_{n}$ denota o grafo bipartido de ordem $2 n$, tal que cada classe da bipartição tem $n$ vértices e sequência de graus $n, n-1, \ldots, 1$. Notamos que $\hat{H}_{n}$ é único a 
menos de isomorfismo. No resto desta seção consideramos que $\hat{H}_{n}$ é um grafo $(U, W)$-bipartido tal que $U=\left\{u_{1}, \ldots, u_{n}\right\}, W=\left\{w_{1}, \ldots, w_{n}\right\}$ e $E\left(\hat{H}_{n}\right)=\left\{u_{i} w_{j}: 1 \leqslant j \leqslant i \leqslant n\right\}$, para $n \geqslant 1$. Seja $\hat{M}_{n}$ a matriz de biadjacência de $\hat{H}_{n}$. Para $1 \leqslant i, j \leqslant n$, considere que a linha $i$ e a coluna $j$ representam os vértices $u_{i}$ e $w_{j}$, respectivamente. Logo, a matriz $\hat{M}_{n}$ é uma matriz triangular inferior com todas as entradas acima da diagonal iguais a zero e as demais entradas iguais a 1. Com isso, mostramos que $\hat{H}_{n}$ e $\hat{H}_{n-1}$ constituem uma decomposição do $K_{n, n}$.

Lema 30 (Hollingsworth, 2013). Seja s uma sequência de $n$ inteiros positivos cuja soma é $2 n-1$. Então, existe uma árvore balanceada $T$ tal que a sequência de graus de uma das classes da bipartição de $T$ é uma permutação de s.

Prova. Considere as sequências $t^{n}=(1,2, \ldots, n)$ e $t^{n-2}=(0,0,1,2, \ldots, n-2)$. Pelo Lema 21 existe uma permutação $s^{\prime}$ de $s$ tal que a sequência $r$, que resulta de $t^{n}$ após subtrair, termo a termo, a sequência $s^{\prime}$, é uma permutação de $t^{n-2}$. Seja $T$ um grafo $(X, Y)$-bipartido de ordem $2 n$ tal que $X=\left\{x_{1}, \ldots, x_{n}\right\}, Y=\left\{y_{1}, \ldots, y_{n}\right\}$ e cuja matriz de biadjacência $M_{T}:=\left(m_{x_{i} y_{j}}\right)$ está definida da seguinte maneira

$$
m_{x_{i} y_{j}}= \begin{cases}1, & \text { se } i \geqslant j \text { e } i-s_{i}^{\prime}<j, \\ 0, & \text { caso contrário. }\end{cases}
$$

A seguir, mostramos que $T$ é uma árvore. Em primeiro lugar, notamos que a linha $i$ de $M_{T}$ contém $s_{i}^{\prime}$ entradas não nulas e $r_{i}$ entradas nulas. Como $s^{\prime}$ é uma permutação de $s$, temos no total $2 n-1$ arestas em $T$. Agora, mostramos que $T$ é um grafo conexo. Suponha por contradição que $T$ é desconexo. Notamos que na linha $i$, as colunas $i-s_{i}^{\prime}+1, \ldots, i$ contêm as entradas não nulas dessa linha. Usando esse fato, pode-se mostrar que se $T$ é desconexo, a matriz $M_{T}$ contém um bloco de zeros como o mostrado na Figura 4.4.

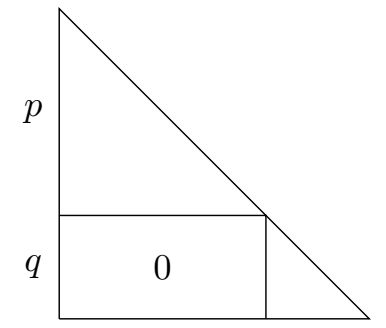

Figura 4.4: Matriz de biadjacência de T, caso $T$ fosse desconexo.

Considere a matriz $M_{T}$ como na figura anterior. Como $r$ é uma permutação de $t^{n-2}$ e $r_{i} \geqslant p$, para $i=p+1, \ldots, n$, temos que as últimas $q$ linhas de $M_{T}$ contêm pelo menos $p q+\sum_{i=p+1}^{n-2}(i-p)$ entradas nulas, ou seja, no máximo $2 q-1$ entradas iguais a 1 . Por um argumento similar, as $p$ primeiras linhas de $M_{T}$ contêm no máximo $2 p-1$ entradas não nulas. Então, $T$ contém no máximo $2(p+q)-2=2 n-2$ arestas, uma contradição. Portanto, $T$ é uma árvore com as propriedades desejadas.

A seguir, mostramos que podemos empacotar $T$ e $\hat{H}_{n-2}$ no $\hat{H}_{n}$. Para empacotar a árvore balanceada $T$ no $\hat{H}_{n}$ mapeamos os vértices $x_{i}$ e $y_{j}$ nos vértices $u_{i}$ e $w_{j}$, respectivamente. Seja $G$ o grafo que resulta após retirar de $\hat{H}_{n}$ as arestas usadas no empacotamento de $T$. Notamos que a sequência de graus de cada classe da bipartição de $G$ é uma permutação de $t^{n-2}$. Portanto, $G$ contém um subgrafo isomorfo a $\hat{H}_{n-2}$.

Usando o lema anterior, obtemos o seguinte resultado. 
Teorema 31 (Hollingsworth, 2013). Para $i \geqslant 1$, seja $s_{i}$ uma sequência de $i$ inteiros positivos cuja soma é $2 i-1$. Então, existe uma sequência de árvores balanceadas $\hat{T}_{1}, \ldots, \hat{T}_{n}$ que pode ser empacotada no $K_{n, n}$ tal que a sequência de graus de uma das classes da bipartição de $T_{i}$ é uma permutação de $s_{i}$, para $i=1, \ldots, n$.

Prova. Sem perda de generalidade suponha que $n$ é par. Pelo lema anterior, podemos mostrar que existem sequências $\hat{T}_{2}, \hat{T}_{4}, \ldots, \hat{T}_{n}$ e $\hat{T}_{1}, \hat{T}_{3}, \ldots, \hat{T}_{n-1}$, com as propriedades desejadas, que podem ser empacotadas em $\hat{H}_{n}$ e $\hat{H}_{n-1}$, respectivamente. Como $\hat{H}_{n}$ e $\hat{H}_{n-1}$ constituem uma decomposição do $K_{n, n}$ o resultado segue.

\subsection{Empacotamento em grafos $k$-cromáticos}

Em 2012, Gerbner, Keszegh e Palmer [12] generalizaram um dos resultados vistos no Capítulo 3. Eles reformularam a pergunta feita por Gyárfás \& Lehel da seguinte maneira: é possivel empacotar qualquer sequência de árvores $T_{2}, \ldots, T_{k}$ num grafo $k$-cromático? Notemos que uma resposta positiva para essa pergunta implica a conjectura original, já que o grafo $K_{n}$ tem número cromático $n$. Gerbner et al. [12] mostraram que, se no máximo três das árvores de tal sequência não são estrelas, a resposta para essa pergunta é positiva. O seguinte resultado será o foco desta seção.

Teorema 32. Sejam $T_{2}, \ldots T_{k}$ uma sequência de árvores e $G$ um grafo k-cromático. Se, no máximo três das árvores não são estrelas, então a sequência $T_{2}, \ldots, T_{k}$ pode ser empacotada em $G$.

No restante desta seção, $G$ denotará um grafo $k$-cromático minimal no seguinte sentido: para todo vértice $v \in V(G)$, o grafo $G-v$ tem número cromático $k-1$. Notamos que $\delta(G) \geqslant k-1$. Seja $\mathcal{C}$ uma coloração minima de $G$ tal que $C_{1}, \ldots, C_{k}$ são as classes da partição de $V(G)$ induzidas por $\mathcal{C}$ (ou seja, para cada $x \in C_{i}, x$ tem pelo menos um vizinho em cada uma das classes $C_{1}, \ldots, C_{i-1}$ ). Denotamos por $G_{i}$ o subgrafo induzido pelas classes $C_{k}, C_{k-1}, \ldots, C_{k-i+1}$, para $i=1, \ldots, k$. Note que $G_{i}$ tem número cromático $i$.

Agora, definimos alguns termos que usaremos com frequência na prova do Teorema 32. Seja $T$ uma árvore. Seja $u$ um vértice de $T$ tal que $g_{T}(u) \geqslant 2$ e $u$ tem um único vizinho, digamos $v$, que não é folha de $T$. Seja $S$ o subgrafo induzido pelo vértice $u$ e todas as folhas adjacentes a $u$. Dizemos que $S$ é uma estrela pendurada (em $v$ ) e que $v$ é o vizinho de $S$. Além disso, se $T$ é uma aranha com diâmetro no máximo 4 , no resto desta seção, chamamos $T$ simplesmente de aranha. A seguir, apresentamos a prova do Teorema 32

Prova do Teorema 32. Faremos a prova por indução em $k$. Se $k=2, \delta(G) \geqslant 1$. Notamos que podemos empacotar a estrela $T_{2}$ usando qualquer aresta de $G$. Suponha que $k \geqslant 3$. Ao longo da prova, ao usar a hipótese de indução numa sequência menor, adotaremos a seguinte convenção. Seja $T$ uma árvore e seja $y$ um vértice de $T$. Se, pela hipótese de indução, temos um empacotamento de $T$ em $G$, o vértice ao qual $y$ é mapeado em $G$ também será chamado $y$.

A prova do Teorema 32 compõe-se de diferentes asserções e casos dependendo da estrutura das árvores da sequência $T_{1}, \ldots, T_{k}$. Em primeiro lugar, notamos o seguinte.

Asserção 33. Se $T_{k}$ ou $T_{k-1}$ é uma estrela, então podemos empacotar a sequência $T_{2}, \ldots, T_{k}$ em $G$. 
Prova. Distinguimos dois casos.

Caso 1: $T_{k}$ é uma estrela.

Pela hipótese de indução, podemos empacotar a sequência $T_{2}, \ldots, T_{k-1}$ em $G_{k-1}$. Seja $v$ um vértice qualquer de $C_{1}$. Como $g_{G}(v) \geqslant k-1$, podemos usar $k-1$ arestas incidentes a $v$ para empacotar a estrela $T_{k}$.

Caso 2: $T_{k-1}$ é uma estrela.

Seja $x$ uma folha de $T_{k}$. Considere a árvore $T_{k}^{\prime}=T_{k}-x$. Pela hipótese de indução, existe um empacotamento da sequência $T_{2}, \ldots, T_{k-2}, T_{k}^{\prime}$ em $G_{k-1}$. Seja $y$ o vizinho de $x$ em $T_{k}$. Notemos que existe um vértice $v \in C_{1}$ tal que $v$ é adjacentes a $y$ em $G$. Para estender o empacotamento de $T_{k-1}^{\prime}$, mapeamos $x$ no vértice $v$, e usamos a aresta $y v$ para obter um empacotamento de $T_{k}$ em $G$. Depois, como $g_{G}(v) \geqslant k-1$, existem $k-2$ arestas incidentes a $v$ que ainda não foram usadas pelo empacotamento. Note que podemos empacotar a estrela $T_{k-1}$ usando essas arestas.

Note que a Asserção 33 implica o Teorema 32 para $k=4$. Além disso, podemos considerar que as árvores $T_{k}$ e $T_{k-1}$ não são estrelas. A seguir, mostramos uma asserção que restringe a classe das árvores $T_{k-2}$ e $T_{k-3}$.

Asserção 34. Suponha que $k \geqslant 5$. Se $T_{k}$ e $T_{k-1}$ não são estrelas, e $T_{k-2}$ e $T_{k-3}$ são estrelas, então podemos empacotar a sequência $T_{2}, \ldots, T_{k}$ em $G$.

Prova. Como $T_{k}$ não é uma estrela, existem duas folhas $x_{1}$ e $x_{2}$ não adjacentes ao mesmo vértice. Sejam $y_{1}$ e $y_{2}$ os vizinhos (em $T_{k}$ ) de $x_{1}$ e $x_{2}$, respectivamente. Pelo mesmo argumento, existem duas folhas $x_{1}^{\prime}$ e $x_{2}^{\prime}$ em $T_{k-1}$ que são adjacentes a vértices distintos $y_{1}^{\prime}$ e $y_{2}^{\prime}$, respectivamente. Considere as árvores $T_{k}^{\prime}=T_{k}-\left\{x_{1}, x_{2}\right\}$ e $T_{k-1}^{\prime}=T_{k-1}-\left\{x_{1}^{\prime}, x_{2}^{\prime}\right\}$. Pela hipótese de indução, podemos empacotar a sequência $T_{1}, \ldots, T_{k-4}, T_{k-1}^{\prime}, T_{k}^{\prime}$ em $G_{k-2}$. Sem perda de generalidade, suponha que $y_{1} \neq y_{1}^{\prime}$ e $y_{2} \neq y_{2}^{\prime}$ em $G_{k-2}$. Seja $v$ (respectivamente, $\left.v^{\prime}\right)$ um vertice de $C_{1}$ adjacente a $y_{1}$ (respectivamente, $y_{1}^{\prime}$ ). Seja $u$ (respectivamente, $u^{\prime}$ ) um vertice de $C_{2}$ adjacente a $y_{2}$ (respectivamente, $y_{2}^{\prime}$ ).

A seguir, mostramos como estender o empacotamento de $T_{k}^{\prime}$ e $T_{k-1}^{\prime}$ para obter um empacotamento de $T_{k}$ e $T_{k-1}$ em $G$. Para o caso de $T_{k}$, mapeamos o vértice $x_{1}$ em $v$ e o vértice $x_{2}$ em $u$. Usando as arestas $v y_{1}$ e $u y_{2}$ obtemos um empacotamento de $T_{k}$ em $G$. Para obter um empacotamento de $T_{k-1}$, mapeamos o vértice $x_{1}^{\prime}$ em $v^{\prime}$ e o vértice $x_{2}^{\prime}$ em $u^{\prime}$. Usando as arestas $v^{\prime} y_{1}^{\prime}$ e $u^{\prime} y_{2}^{\prime}$ obtemos um empacotamento de $T_{k-1}$ em $G$. Notamos que, após o passo anterior, existem $k-3$ (respectivamente, $k-4$ ) arestas incidentes em $v$ (respectivamente, $u$ ) que ainda não foram usadas no empacotamento. Claramente, mapeando os centros das estrelas $T_{k-2}$ e $T_{k-3}$ nos vértices $v$ e $u$, respectivamente, podemos completar o empacotamento da sequência $T_{2}, \ldots, T_{k}$ em $G$.

Note que, a Asserção 34 implica o Teorema 32 para $k=5$. A seguir, mostramos uma asserção que limita a estrutura das árvores de maior ordem na sequência $T_{2}, \ldots, T_{k}$.

Asserção 35. Se a árvore $T_{k}$ tem uma estrela pendurada de ordem s e $T_{k-s}$ é uma estrela, então existe um empacotamento da sequência $T_{2}, \ldots, T_{k}$ em $G$.

Prova. Seja $S$ uma estrela pendurada de $T_{k}$ tal que $S$ tem $s$ vértices. Seja $y$ o vizinho de $S$ em $T_{k}$. Considere a árvore $T_{k}^{\prime}=T_{k}-S$. Pela hipótese de indução, existe um empacotamento de $T_{2}, \ldots, T_{k}^{\prime}, T_{k-s+1}, \ldots, T_{k-1}$ em $G_{k-1}$. Seja $v \in C_{1}$ um vértice adjacente a $y$ em $G$. Como $v$ 
tem grau pelo menos $k-1$, existem $s-1$ vértices, digamos $u_{1}, \ldots, u_{s-1}$, adjacentes a $v$ em $G$ que não foram usados no empacotamento de $T_{k}^{\prime}$. Para estender o empacotamento de $T_{k}^{\prime}$ e obter um empacotamento de $T_{k}$ em $G$, mapeamos o centro de $S$ no vértice $v$ e usamos as arestas $v y$ e $v u_{1}, \ldots, v u_{s-1}$ para completar o empacotamento de $T_{k}$ em $G$. Notamos que, após o passo anterior, o vértice $v$ tem $k-s-1$ arestas que ainda não foram usadas pelo empacotamento. Claramente, podemos empacotar a estrela $T_{k-s}$ usando essas arestas.

Agora, mostramos uma asserção que implica o Teorema 32 no caso $k=6$.

Asserção 36. Se $k \leqslant 6$, a sequência $T_{2}, \ldots, T_{k}$ pode ser empacotada em $G$.

Prova. Pelas asserções anteriores, podemos considerar que: $k=6$, a árvore $T_{4}$ é um caminho e cada uma das árvores $T_{5}$ e $T_{6}$ é um caminho ou uma aranha. Faremos a prova para o caso em que $T_{6}$ é um caminho (o caso em que $T_{6}$ é uma aranha é similar, por isso o omitimos). Sejam $T_{4}=\left\langle x_{1}, \ldots, x_{4}\right\rangle$ e $T_{6}=\left\langle y_{1}, \ldots, y_{6}\right\rangle$. Considere os caminhos $T_{4}^{\prime}=T_{4}-x_{4}$ e $T_{6}^{\prime}=T_{6}-\left\{y_{5}, y_{6}\right\}$. Pela hipótese de indução, a sequência $T_{2}, \ldots, T_{4}^{\prime}, T_{6}^{\prime}, T_{5}$ pode ser empacotada em $G_{5}$. Distinguimos dois casos.

Caso 1: Os extremos de $T_{4}^{\prime}$ coincidem com os extremos de $T_{6}$ em $G$.

Sem perda de generalidade, suponha que $x_{1}=y_{1}$ e $x_{3}=y_{4}$ em $G$. Seja $v \in C_{1}$ um vértice adjacente a $y_{1}$ em $G$. Como $g(v) \geqslant 5$, existe um vértice $w$ adjacente a $v$ tal que $u$ não é usado no empacotamento de $T_{6}^{\prime}$. Para obter um empacotamento de $T_{6}$ em $G$, usamos as arestas $y_{1} v$ e $v w$. Depois, seja $u \in C_{1}$ um vértice adjacente a $x_{3}$ (note que pode acontecer que $u=v$ ). Usamos a aresta $x_{3} u$ para obter um empacotamento de $T_{4}$ em $G$. Finalmente, podemos mapear o centro da estrela $T_{3}$ no vértice $v$ para completar o empacotamento da sequência, já que existem pelo menos 2 arestas incidentes a $v$ que ainda não foram usadas.

Caso 2: Existe um extremo de $T_{6}^{\prime}$ que não coincide com nenhum extremo de $T_{4}^{\prime}$.

Sem perda de generalidade, suponha que $y_{1} \neq x_{1}$ e $y_{1} \neq x_{3}$. Seja $v$ um vértice de $C_{1}$ que é adjacente a $y_{1}$. Note que existe um vértice adjacente a $v$, digamos $w$, que não foi usado no empacotamento de $T_{6}^{\prime}$. Então, usamos as arestas $y_{1} v$ e $v w$ para obter um empacotamento do caminho $T_{6}$ em $G$. Notamos que existe um extremo de $T_{4}^{\prime}$ que é diferente de $w$ em $G$. Sem perda de generalidade, suponha que $x_{3} \neq w$. Seja $u \in C_{1}$ um vértice adjacente a $x_{3}$ (note que pode acontecer que $u=v$ ). Usamos a aresta $x_{3} u$ para obter um empacotamento de $T_{4}$ em $G$. Finalmente, podemos mapear o centro da estrela $T_{3}$ no vértice $v$ para completar o empacotamento da sequência, já que existem pelo menos 2 arestas incidentes a $v$ que ainda não foram usadas.

Pelas asserções anteriores, podemos supor o seguinte: $k \geqslant 7$, as árvores $T_{k}$ e $T_{k-1}$ não são estrelas e exatamente uma das árvores $T_{k-2}$ e $T_{k-3}$ não é uma estrela. Além disso, pela Asserção 35, todas as estrelas penduradas em $T_{k}$ têm no máximo 3 vértices. A seguir, distinguimos dois casos principais e dividimos o segundo caso em diferentes subcasos.

Caso 1: $T_{k-3}$ não é uma estrela.

Neste caso, todas as estrelas penduradas de $T_{k}$ têm três vértices. Sejam $S$ uma estrela pendurada de $T_{k}$ e $z$ o vizinho de $S$ em $T_{k}$. Como $k \geqslant 7$, existem em $T_{k}$ vértices $x$ e $y$ tais que $x$ é adjacente a $y, x$ é folha de $T_{k}-S$ e $y \neq z$. Seja $x^{\prime}$ uma folha de $T_{k-1}$ e $y^{\prime}$ o seu único vizinho. Considere as árvores $T_{k}^{\prime}=\left(T_{k}-S\right)-x$ e $T_{k-1}^{\prime}=T_{k-1}-x^{\prime}$. Pela hipótese de indução, podemos empacotar a sequência $T_{2}, \ldots, T_{k-5}, T_{k}^{\prime}, T_{k-3}, T_{k-1}^{\prime}$ em $G_{k-2}$. Sejam $v \in C_{1}$ e $u \in C_{2}$ vértices adjacentes a $z$ 
e $y$, respectivamente. Agora, mostramos como estender o empacotamento de $T_{k}^{\prime}$ para obter um empacotamento de $T_{k}$ em $G$. Note que $u$ tem pelo menos $k-2$ vizinhos diferentes a $v$. Além disso, como $T_{k}^{\prime}$ tem ordem $k-4$, existem dois vértices adjacentes a $u$, digamos $w_{1}$ e $w_{2}$, que não foram usados no empacotamento de $T_{k}^{\prime}$ e que são diferentes a $v$. Então, para estender o empacotamento de $T_{k}$, mapeamos o vértice $x$ em $v$, e o centro de $S$ no vértice $u$. Usando as arestas $\left\{v y, u z, u w_{1}, u w_{2}\right\}$ obtemos um empacotamento de $T_{k}$ em $G$. Agora, mostramos como estender o empacotamento de $T_{k-1}^{\prime}$ para obter um de $T_{k-1}$ em $G$. Note que $y^{\prime}$ pode coincidir com $y$ ou $z$ em $G$. Em qualquer caso, existe uma aresta com um extremo em $y^{\prime}$ e outro em $C_{1} \cup C_{2}$. Usamos essa aresta para obter um empacotamento de $T_{k-1}$ em $G$. Após o passo anterior, nos vértices $v$ e $u$ incidem $k-3$ e $k-4$ ou $k-2$ e $k-5$ arestas livres, respectivamente. Claramente, podemos empacotar as estrelas $T_{k-2}$ e $T_{k-4}$ mapeando os seus centros nos vértices $v$ e $u$, respectivamente.

Caso 2: $T_{k-2}$ não é uma estrela.

Neste caso, todas as estrelas penduradas de $T_{k}$ têm ordem 2. Distinguimos dois casos dependendo se $T_{k}$ é uma aranha ou não.

Caso 2.1: $T_{k}$ não é uma aranha.

Neste caso, existem em $T_{k}$ duas estrelas penduradas $S_{1}$ e $S_{2}$ cujos vizinhos são vértices diferentes. Sejam $y$ e $z$ os vizinhos de $S_{1}$ e $S_{2}$ respectivamente. De forma similar, sejam $y^{\prime}$ e $z^{\prime}$ vértices distintos de $T_{k-1}$ tais que pelo menos uma folha de $T_{k-1}$ é adjacente em cada um deles. Considere a árvore $T_{k}^{\prime}=\left(T_{k}-S_{1}\right)-S_{2}$ e seja $T_{k-1}^{\prime}$ a árvore que resulta após retirar de $T_{k-1}$ duas folhas, uma adjacente a $y^{\prime}$ e outra adjacente a $z^{\prime}$. Pela hipótese de indução, podemos empacotar a sequência $T_{2}, \ldots, T_{k-4}, T_{k}^{\prime}, T_{k-1}^{\prime}, T_{k-2}$ em $G_{k-2}$. Suponha, sem perda de generalidade, que $y \neq y^{\prime}$ e $z \neq z^{\prime}$ em $G$. Seja $v \in C_{1}$ (respectivamente, $u \in C_{2}$ ) um vértice adjacente a $y$ (respectivamente, $z$ ) em $G$. Como $\delta(G) \geqslant k-1$, em $G$ existem dois vértices adjacentes a $v$ (respectivamente $u$ ) que não foram usados no empacotamento de $T_{k}^{\prime}$ e são diferentes de $v$ e $u$. Logo, existem vértices $w_{1}$ e $w_{2}$ em $G$ tais que $w_{1}$ é adjacente a $v, w_{2}$ é adjacente a $u, w_{1}$ e $w_{2}$ não foram usados no empacotamento de $T_{k}^{\prime}$, e $w_{1} \neq y^{\prime}$ e $w_{2} \neq z^{\prime}$ ou $w_{1}=y^{\prime}$ e $w_{2}=z^{\prime}$ em $G$.

Agora mostramos como estender o empacotamento de $T_{k}^{\prime}$ para obter um de $T_{k}$ em $G$. Para isso, mapeamos os centros de $S_{1}$ e $S_{2}$ nos vértices $v$ e $u$, respectivamente. Usando as arestas $y v, v w_{1}, z u$ e $u w_{2}$, obtemos uma empacotamento de $T_{k}$ em $G$. Para obter um empacotamento de $T_{k-1}$ em $G$, pela escolha de $w_{1}$ e $w_{2}$, existem duas arestas em $G$ com um extremo em vértices distintos de $C_{1} \cup C_{2}$, e o outro extremo nos vértices $y^{\prime}$ e $z^{\prime}$. Claramente, podemos usar essas arestas para obter um empacotamento de $T_{k-1}$ em $G$. Finalmente, note que existem $k-4$ arestas incidentes a $v$ que ainda podemos usar no empacotamento. Claramente, podemos empacotar a estrela $T_{k-3}$ mapeando o seu centro no vértice $v$. Por um argumento similar, obtemos um empacotamento da estrela $T_{k-4}$ mapeando o seu centro no vértice $u$.

Caso 2.2: $T_{k}$ é uma aranha.

Este caso é dividido em vários subcasos dependendo da estrutura das árvore $T_{k-1}$ e $T_{k-2}$. Em alguns desses subcasos, descrevemos em linhas gerais a ideia da prova, porque muitas das ideias são similares aos casos já vistos. Primeiramente, notamos que se $T_{k}$ é uma aranha e $k \geqslant 7$, existem três vértices distintos, digamos $x_{1}, x_{2}, x_{3}$ tais que cada $x_{i}$ é adjacente a pelo menos uma folha de $T_{k}$. Além disso, no resto da prova denotamos por $T_{k}^{\prime}$ a árvore que resulta após retirar uma folha adjacente a cada $x_{i}$. Distinguimos os seguintes casos dependo da estrutura de $T_{k-1}$. 
Caso 2.2.1: $T_{k-1}$ tem uma estrela pendurada $S$ de ordem $s \geqslant 4$.

Seja $y^{\prime}$ o vizinho de $S$ em $T_{k-1}$. Sejam $z_{1}^{*}$ e $z_{2}^{*}$ vértices distintos de $T_{k-2}$ tais que existe pelo menos uma folha adjacente a cada um deles. Seja $T_{k-1}^{\prime}=T_{k-1}-S$ e seja $T_{k-2}^{\prime}$ a árvore que resulta após retirar de $T_{k-2}$ uma folha adjacente a $z_{1}^{*}$ e outra adjacente a $z_{2}^{*}$. Pela hipótese de indução, podemos empacotar a sequência $T_{2}, \ldots, T_{k-1}^{\prime}, \ldots, T_{k-2}^{\prime}, T_{k}^{\prime}$ em $G_{k-3}$. Agora, mostramos como estender o empacotamento de $T_{k-1}^{\prime}$ para obter um empacotamento de $T_{k-1}$ em $G$. Seja $v \in C_{1}$ um vértice adjacente a $y^{\prime}$ em $G$. Como $g_{G}(v) \geqslant k-1$, existem $s$ vértices, digamos $t_{1}, \ldots, t_{s}$, adjacentes a $v$ tais que $t_{i}$ não foi usado no empacotamento de $T_{k-1}^{\prime}$, para $i=1, \ldots, s$. Se algum $t_{i}$ é igual a $x_{1}, x_{2}, x_{3}$, suponha que $x_{3}=t_{s}$, caso contrário, suponha sem perda de generalidade que $y^{\prime} \neq x_{3}$. Para estender o empacotamento de $T_{k-1}^{\prime}$, mapeamos o centro de $S$ no vértice $v$. Usando as arestas $y^{\prime} v, v t_{1}, \ldots, v t_{s-1}$ obtemos um empacotamento de $T_{k-1}^{\prime}$ em $G$.

Agora mostramos como estender os empacotamentos de $T_{k}^{\prime}$ e $T_{k-2}^{\prime}$ para obter empacotamentos de $T_{k}$ e $T_{k-2}$, respectivamente. Seja $u \in C_{2}$ (respectivamente, $w \in C_{3}$ ) um vértice adjacente a $x_{1}$ (respectivamente, $x_{2}$ ) em $G$. Notamos que, pela escolha de $t_{s}$, existe uma aresta $x_{3} v^{\prime}$ em $G$ tal que $v^{\prime} \in C_{1}$ (possivelmente $v^{\prime}=v$ ). Então, podemos obter um empacotamento de $T_{k}$ em $G$ usando as arestas $x_{1} u, x_{2} w$ e $x_{3} v^{\prime}$. De forma similar, podemos obter um empacotamento de $T_{k-2}$ usando duas arestas com um extremo em vértices distintos de $C_{2} \cup C_{3}$ e o outro extremo nos vértices $z_{1}^{*}$ e $z_{2}^{*}$.

Finalmente, notamos que $v$ tem pelo menos $k-r-2$ arestas livres após os passos anteriores. Claramente, podemos empacotar a estrela $T_{k-r-1}$ mapeando seu centro no vértice $v$. Por argumentos similares, podemos empacotar as estrelas $T_{k-3}$ e $T_{k-4}$ mapeando seus centros nos vértices $u$ e $w$.

Caso 2.2.2: $T_{k-1}$ tem uma estrela pendurada $S$ de ordem 3 .

Seja $y^{\prime}$ o vizinho de $S$ em $T_{k-1}$. Este caso é subdividido em dois subcasos dependendo da estrutura da árvore $T_{k-2}$. Nos dois subcasos seguintes considere a árvore $T_{k-1}^{\prime}=T_{k-1}-S$.

Caso 2.2.2.1: $T_{k-2}$ tem uma estrela pendurada $S^{\prime}$ de ordem $s^{\prime} \geqslant 3$.

Seja $y^{*}$ o vizinho de $S^{\prime}$ em $T_{k-2}$. Considere a árvore $T_{k-2}^{\prime}=T_{k-2}-S^{\prime}$. Pela hipótese de indução, podemos empacotar a sequência $T_{1}, \ldots, T_{k-2}^{\prime}, \ldots, T_{k-5}, T_{k-1}^{\prime}, T_{k}^{\prime}$ em $G_{k-3}$. Sem perda de generalidade, suponha que $x_{3} \neq y^{\prime}$ e $y^{*} \neq x_{2}$. Sejam $v \in C_{1}, u \in C_{2}$ e $w \in C_{3}$ vértices em $G$ tais que $v$ é adjacente a $y^{*}$ e $w$ é adjacente a $y^{\prime}$. De forma similar ao Caso 2.2.1, podemos mostrar que mapeando o centro de $S$ em $w$ e o centro de $S^{\prime}$ em $v$ obtemos um empacotamento de $T_{k-2}$ e $T_{k-1}$, respectivamente. Além disso, após o passo anterior, podemos garantir que existem três arestas em $G$, digamos $a, b, c$, tais que $a$ incide em $x_{3}$ e $C_{3}, b$ incide em $x_{2}$ e $C_{1}$ e $c$ incide em $x_{1}$ e $C_{2}$. Claramente, podemos usar essas arestas para obter um empacotamento de $T_{k}$ em $G$. Finalmente, pode-se mostrar que mapeando os centros das estrelas $T_{k-s^{\prime}-2}, T_{k-4}$ e $T_{k-3}$ nos vértices $v, u$ e $w$ completamos o empacotamento da sequência.

Caso 2.2.2.2: Toda estrela pendurada de $T_{k-2}$ tem ordem 2 .

Seja $S^{\prime}$ uma estrela pendurada de $T_{k-2}$. Seja $y^{*}$ o vizinho de $S^{\prime}$. Como $k \geqslant 7$, existe em $T_{k-2}$ um vértice $z^{*}$ tal que $z^{*} \neq y^{*}$ e $z^{*}$ é adjacente a pelo menos uma folha de $T_{k-2}-S^{\prime}$. Considere a árvore $T_{k-2}^{\prime}$ que resulta após retirar os vértices de $S^{\prime}$ e uma folha adjacente a $z^{*}$. Pela hipótese de indução, podemos empacotar a sequência $T_{2}, \ldots, T_{k-6}, T_{k-2}^{\prime}, T_{k-1}^{\prime}, T_{k}^{\prime}$ em $G$. Sem perda de generalidade, suponha que $x_{3} \neq y^{\prime}, x_{2} \neq y^{*}$ e $x_{1} \neq z^{*}$ em $G$.

Agora, mostramos como estender o empacotamento de $T_{k-1}^{\prime}$ para obter um empacotamento 
de $T_{k-1}$. Seja $w \in C_{3}$ um vértice adjacentes a $y^{\prime}$ em $G$. Note que, em $w$, incidem arestas $a^{\prime}$ e $b^{\prime}$ tais que $a^{\prime}$ incide em $C_{1}$ e $b^{\prime}$ incide em $C_{2}$. Claramente, mapeando o centro de $S$ em $w$ e usando as arestas $y^{\prime} w, a^{\prime}$ e $b^{\prime}$ obtemos um empacotamento de $T_{k-1}$ em $G$.

A seguir, mostramos como estender o empacotamento de $T_{k-2}^{\prime}$ para obter um empacotamento de $T_{k-2}$ em $G$. Sejam $v \in C_{1}$ e $u \in C_{2}$ tais que $v$ é adjacente a $y^{*}$ e $u$ é adjacente a $z^{*}$. Note que $v$ tem $k-3$ vizinhos em $G$ que são diferentes de $u$ e $w$. Além disso, pelo menos dois desses vizinhos, digamos $t_{1}$ e $t_{2}$, não foram usados no empacotamento de $T_{k-2}^{\prime}$ em $G$. Sem perda de generalidade suponha que $x_{2} \neq t_{1}$ em $G$. Então, mapeando o centro de $S^{\prime}$ em $v$ e usando as arestas $v y^{*}, v t_{1}$ e $z^{*} u$ obtemos um empacotamento de $T_{k-2}$ em $G$. Após o passo anterior, pode-se garantir que existem três arestas em $G$, digamos $a, b, c$, tais que $a$ incide em $x_{3}$ e $C_{3}, b$ incide em $x_{2}$ e $C_{1}$ e $c$ incide em $x_{1}$ e $C_{2}$. Claramente, podemos usar essas arestas para obter um empacotamento de $T_{k}$ em $G$. Finalmente, pode-se mostrar que mapeando os centros das estrelas $T_{k-5}, T_{k-4}$ e $T_{k-3}$ nos vértices $v, u$ e $w$ completamos o empacotamento da sequência $T_{1}, \ldots, T_{k}$.

Caso 2.2.3: Toda estrela pendurada de $T_{k-1}$ tem ordem 2 .

Da mesma forma que no Caso 2, dividimos este caso em dois subcasos, dependendo se $T_{k-1}$ é uma aranha ou não.

Caso 2.2.3.1: $T_{k-1}$ não é uma aranha.

Sejam $S$ e $R$ estrelas penduradas de $T_{k-1}$ tais que seus centros não estão pendurados no mesmo vértice. Sejam $y^{\prime}$ e $z^{\prime}$ os vizinhos de $S$ e $R$, respectivamente. Considere a árvore $T_{k-1}^{\prime}$ que resulta após retirar os vértices de $S$ e $R$ de $T_{k-1}$. Sejam $y^{*}$ e $z^{*}$ vértices distintos de $T_{k-2}$ tais que $y^{*}$ e $z^{*}$ são adjacentes a pelo menos uma folha de $T_{k-2}$. Considere a árvore $T_{k-2}^{\prime}$ que resulta após retirar duas folhas, uma adjacente a $y^{*}$ e outra adjacente a $z^{*}$, de $T_{k-2}$. Pela hipótese de indução, podemos empacotar a sequência $T_{2}, \ldots, T_{k-6}, T_{k-1}^{\prime}, T_{k-2}^{\prime}, T_{k}^{\prime}$ em $G_{k-3}$.

Agora, descrevemos como estender o empacotamento da árvore $T_{k-1}^{\prime}$. Sejam $v \in C_{1}$ um vértice adjacente a $y^{\prime}$ e $u \in C_{2}$ um vértice adjacente a $z^{\prime}$. Para obter um empacotamento de $T_{k-1}$ mapeamos os centros de $S$ e $R$ nos vértices $v$ e $u$, respectivamente. A seguir, descrevemos como estender o empacotamento das árvores $T_{k}^{\prime}$ e $T_{k-2}^{\prime}$. Seja $w \in C_{3}$ um vértice adjacente a $x_{3}$. Para obter um empacotamento da árvore $T_{k}$ em $G$, usamos a aresta $x_{3} w$ e duas arestas que têm um extremo em $C_{1} \cup C_{2}$ e o outro extremo em $x_{1}$ e $x_{2}$. Pode-se mostrar que, após o passo anterior, sempre existem pelo menos duas arestas livres com um extremo em $C_{1} \cup C_{2} \cup C_{3}$ e o outro em $y^{*}$ e $z^{*}$. Claramente, usando essas arestas podemos obter um empacotamento de $T_{k-2}$ em $G$. Para completar o empacotamento da sequência, mapeamos os centros das estrelas $T_{k-5}, T_{k-4}$ e $T_{k-3}$ nos vértices $v, u$ e $w$, respectivamente.

Caso 2.2.3.2: $T_{k-1}$ é uma aranha.

Pelo mesmo argumento usado no Caso 2.2, temos que existem três vértices distintos em $T_{k-1}$, digamos $x_{1}^{\prime}, x_{2}^{\prime}$ e $x_{3}^{\prime}$, tais que cada $x_{i}^{\prime}$ é adjacente a pelo menos uma folha de $T_{k-1}$. No resto da prova, considere a árvore $T_{k-1}^{\prime}$ que resulta após retirar de $T_{k-1}$ uma folha adjacente a $x_{i}^{\prime}$, para $i=1,2,3$.

Caso 2.2.3.2.1: $T_{k-2}$ tem uma estrela pendurada $S$ de ordem $s \geqslant 3$.

Seja $y^{*}$ o vizinho de $S$ em $T_{k-2}^{\prime}$. Considere a árvore $T_{k-2}^{\prime}=T_{k-2}-S$. Pela hipótese de indução, podemos empacotar a sequência $T_{1}, \ldots, T_{k-s-2}^{\prime}, \ldots, T_{k-1}^{\prime}, T_{k}^{\prime}$ em $G_{k-3}$. Sem perda de generalidade suponha que, em $G$, os vértices $x_{3}, y^{*}$ e $x_{2}^{\prime}$ são distintos. Agora, vamos mostrar como estender a árvore $T_{k-2}^{\prime}$. Seja $v \in C_{1}$ um vizinho de $y^{*}$ em $G$. Note que existem $s+1$ vértices adjacentes a $v$, 
digamos $t_{1}, \ldots t_{s+1}$, tais que $t_{j}$ não foi usado no empacotamento de $T_{k-2}^{\prime}$, para $j=1, \ldots, s+1$. Se algum $x_{i}=t_{j}$ em $G$, suponha que $x_{3}=t_{s+1}$. Além disso, se $t_{s+1}=x_{j}^{\prime}$ para algum $j$, suponha que $x_{3}^{\prime}=t_{s+1}$. Por último, se temos outra coincidência entre $x_{1}^{\prime}, x_{2}^{\prime}$ e $t_{1}, \ldots, t_{s}$, suponha que $x_{2}^{\prime}=t_{s}$.

A seguir, mostramos como estender um empacotamento de $T_{k-2}^{\prime}$ para obter a árvore $T_{k-2}$. Note que mapeando o centro de $S$ no vértice $v$ e usando as arestas $y^{*} v, v t_{1}, \ldots, v t_{s-1}$ obtemos um empacotamento de $T_{k-2}$ em $G$. Agora, mostramos como estender o empacotamento de $T_{k}^{\prime}$ para obter $T_{k}$. Sejam $u \in C_{2}$ e $w \in C_{3}$ vértices adjacentes a $x_{1}$ e $x_{2}$, respectivamente. Note que podemos usar as arestas $x_{1} u, x_{2} w$ e $x_{3} v$ para obter um empacotamento de $T_{k}$. Note que, após o passo anterior, podemos usar a aresta $x_{2}^{\prime} v$ e as arestas $\left\{x_{1}^{\prime} u, x_{3}^{\prime} w\right\}$ ou $\left\{x_{1}^{\prime} w, x_{3}^{\prime} u\right\}$ para obter um empacotamento de $T_{k-1}$. Finalmente, podemos empacotar as estrelas $T_{k-s-2}, T_{k-4}$ e $T_{k-3}$ mapeando os seus centros nos vértices $v, u$ e $w$, respectivamente.

Caso 2.2.3.2.2: Toda estrela pendurada de $T_{k-2}$ tem ordem 2 .

Sejam $S$ uma estrela pendurada de $T_{k-2}$ e $y^{*}$ o seu vizinho. Seja $z^{*}$ um vértice de $T_{k-2}-S$ tal que $z^{*} \neq y^{*}$ e existe uma folha adjacente a $z^{*}$ (esse vértice existe já que $k \geqslant 7$ ). Considere a árvore $T_{k-2}^{\prime}$ que resulta após retirar de $T_{k-2}$ os vértice de $S$ e uma folha adjacente a $z^{*}$. Pela hipótese de indução, podemos empacotar a sequência $T_{1}, \ldots, T_{k-2}^{\prime}, T_{k-1}^{\prime}, T_{k}^{\prime}$ em $G_{k-3}$. Agora, vamos mostrar como estender o empacotamento de $T_{k-2}^{\prime}$ para obter um empacotamento de $T_{k-2}$. Sem perda de generalidade suponha que $x_{1}^{\prime} \neq z^{*}$. Seja $v \in C_{1}$ (respectivamente, $u \in C_{2}$ ) um vértice adjacente a $z^{*}$ (respectivamente, $y^{\prime}$ ) em $G$. Note que, existem três vértices, digamos $t_{1}, t_{2}$ e $t_{3}$, tais que $t_{i} \neq v, t_{i}$ é adjacente a $u$ e $t_{i}$ não é usado no empacotamento de $T_{k-2}^{\prime}$, para $i=1,2,3$. Se algum $x_{i}=z^{*}$ ou $x_{j}^{\prime}=z^{*}$, suponha que $z^{*}=x_{1}$ ou $z^{*}=x_{2}^{\prime}$ (ou ambos). Além disso, podemos supor que $x_{1}, x_{1}^{\prime}$ e $t_{1}$ são distintos. Para estender a árvore $T_{k-2}^{\prime}$ mapeamos o centro de $S$ no vértice $u$, e usamos as arestas $z^{*} v, y^{*} u$ e $u t_{1}$ para obter um empacotamento de $T_{k-2}$ em $G$. Após o passo anterior, pode-se mostrar que sempre podemos estender as árvores $T_{k}^{\prime}$ e $T_{k-1}^{\prime}$ usando, em cada caso, três arestas incidentes em classes distintas de $C_{1}, C_{2}$ e $C_{3}$. Finalmente, como nos casos anteriores podemos mapear os centros das estrelas $T_{k-3}, T_{k-4}$ e $T_{k-5}$ nos vértices $v, u$ e $w \in C_{3}$, respectivamente. Com isso, fica completa a prova do teorema. 


\section{Capítulo 5}

\section{Considerações finais}

Apresentamos nos capítulos anteriores os resultados que consideramos mais importantes a respeito da conjectura de Gyárfás \& Lehel. Dentre esses resultados, vimos a técnica usada por Bollobás, muito interessante e relevante, pois ajudou a obter outros resultados positivos sobre variantes da conjectura original. Vimos porém, que essa técnica dificilmente ajudará a encontrar uma resposta positiva para a conjectura, conforme discutimos no Capítulo 3. Outros resultados que apresentamos, essencialmente mostram como estender um empacotamento parcial da sequência de árvores para encontrar um empacotamento de toda a sequência. Com essa técnica, respostas positivas para a conjectura foram obtidas somente restringindo-se as classes das árvores da sequência. Além disso, vimos que tais técnicas são específicas para as classes de árvores em questão, e não fornecem um caminho claro para atacar a conjectura de Gyárfás \& Lehel em sua forma geral.

Considerando os resultados obtidos até o presente, não resta dúvida de que o problema em foco é difícil e que, talvez apenas usando outro enfoque, seja possível obter uma resposta definitiva para a conjectura. Nessa direção, tentar encontrar uma equivalência entre a conjectura de Gyárfás \& Lehel e um outro problema talvez possa fornecer um caminho. Isso porém, parece ser tão difícil quanto resolver a própria conjectura. 


\section{Referências Bibliográficas}

[1] B. Bollobás. Some remarks on packing trees. Discrete Math., 46(2):203-204, 1983. 1, 7, 23

[2] B. Bollobás and A. Thomason. Hereditary and monotone properties of graphs. In Ronald Graham and Jaroslav Nešetřil, editors, The Mathematics of Paul Erdös II, volume 14 of Algorithms and Combinatorics, pages 70-78. Springer Berlin Heidelberg, 1997. 27

[3] J. A. Bondy and U. S. R. Murty. Graph theory, volume 244 of Graduate Texts in Mathematics. Springer, New York, 2008. 3

[4] Y. Caro and Y. Roditty. A note on packing trees into complete bipartite graphs and on Fishburn's conjecture. Discrete Math., 82(3):323-326, 1990. 2, 33

[5] R. Diestel. Graph theory, volume 173 of Graduate Texts in Mathematics. Springer-Verlag, Berlin, third edition, 2005. 3

[6] E. Dobson. Packing almost stars into the complete graph. Journal of Graph Theory, 25(2):169172, 1997. 1, 26

[7] E. Dobson. Packing trees into the complete graph. Combin. Probab. Comput., 11(3):263-272, 2002. 28

[8] E. Dobson. Packing trees of bounded diameter into the complete graph. Australas. J. Combin., 37:89-100, 2007. 28

[9] P. Erdôs. Extremal problems in graph theory. In Theory of Graphs and its Applications (Proc. Sympos. Smolenice, 1963), pages 29-36. Publ. House Czechoslovak Acad. Sci., Prague, 1964. 25

[10] P. C. Fishburn. Balanced integer arrays: A matrix packing theorem. Journal of Combinatorial Theory, Series A, 34(1):98 - 101, 1983. 2, 22, 29, 30

[11] P. C. Fishburn. Packing graphs with odd and even trees. Journal of Graph Theory, 7(3):369383, 1983. 1, 2, 17, 26

[12] D. Gerbner, B. Keszegh, and C. Palmer. Generalizations of the tree packing conjecture. Discuss. Math. Graph Theory, 32(3):569-582, 2012. 1, 2, 31, 39

[13] A. Gyárfás and J. Lehel. Packing trees of different order into $K_{n}$. In Combinatorics (Proc. Fifth Hungarian Colloq., Keszthely, 1976), Vol. I, volume 18 of Colloq. Math. Soc. János Bolyai, pages 463-469. North-Holland, Amsterdam, 1978. 1, 7, 8, 11

[14] A. M. Hobbs, B. A. Bourgeois, and J. Kasiraj. Packing trees in complete graphs. Discrete Math., 67(1):27-42, 1987. 2, 9, 10, 26, 29, 31

[15] S. Hollingsworth. Packing trees into complete bipartite graphs. Discrete Math., 313(8):945-948, 2013. 31,36

[16] H. J. Straight. Packing trees of different size into the complete graph. Annals of the New York Academy of Sciences, 328(1):190-192, 1979. 2 
[17] R. Yuster. On packing trees into complete bipartite graphs. Discrete Math., 163(1-3):325-327, 1997. 2,34

[18] S. Zaks and C. L. Liu. Decomposition of graphs into trees. In Proceedings of the Eighth Southeastern Conference on Combinatorics, Graph Theory and Computing (Louisiana State Univ., Baton Rouge, La., 1977), pages 643-654. Congressus Numerantium, No. XIX, Winnipeg, Man., 1977. Utilitas Math. 2, 11, 15, 17, 32 